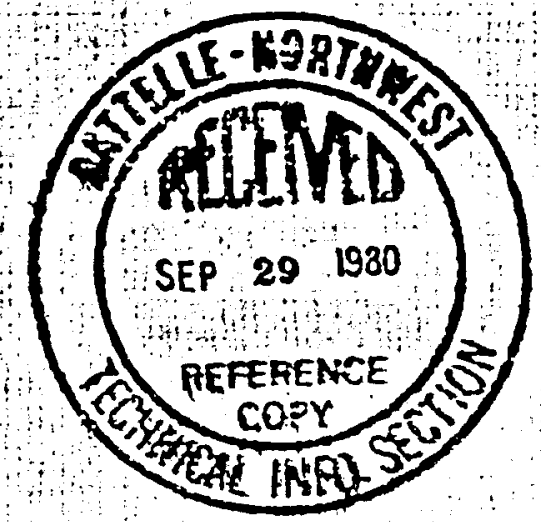

Peopit

MAR 271991

\title{
RUPTURE OF PLUTONIUM OXIDE STORAGE CONTAINER, MARCH 13, 1979
}

\section{Wtoth MAY 29, 1979}
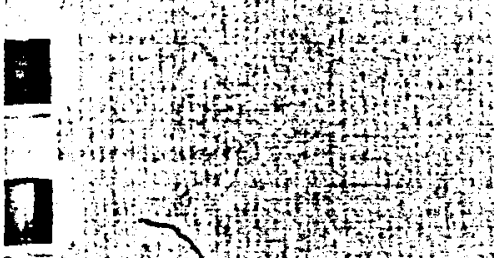

.

Wat

$3+4+4+4$

thetsing

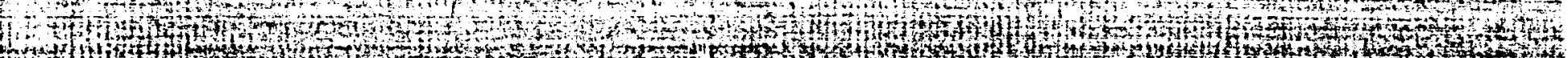

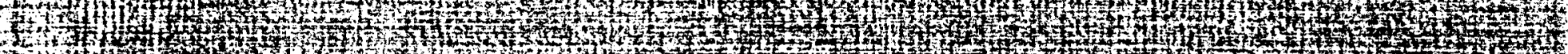

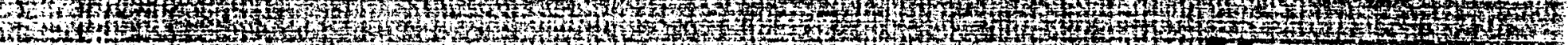

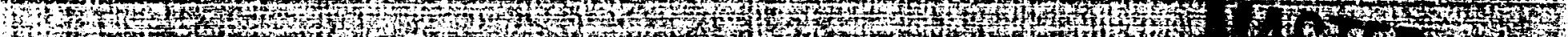
Hif

H.

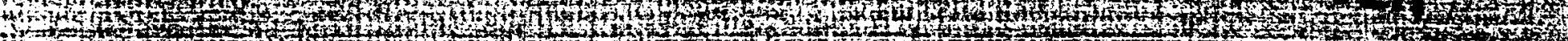

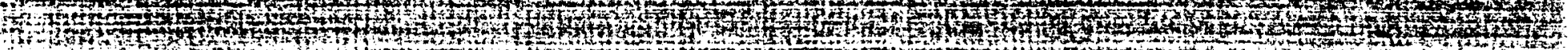

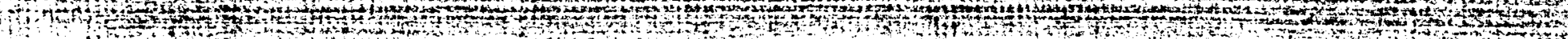

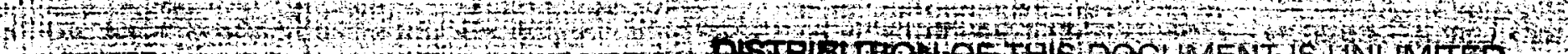

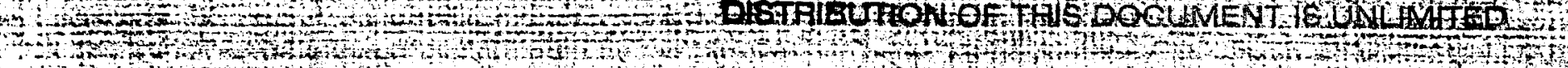
and 
MAY 29, 1979

\section{DISCLAIMER}

This report was prepared as an account of work sponsored by an agency of the United States Government. Neither the United States Government nor any agency thereof, nor any of their employees, makes any warranty, express or implied, or assumes any legal liability or responsibility for the accuracy, completeness, or usefulness of any information, apparatus, product, or process disclosed, or represents that its use would not infringe privately owned rights. Reference herein to any specific commercial product, process, or service by trade name, trademark, manufacturer, or otherwise does not necessarily constitute or imply its endorsement, recommendation, or favoring by the United States Government or any agency thereof. The views and opinions of authors expressed herein do not necessarily state or reflect those of the United States Government or any agency thereof. 


\section{DISCLAIMER}

This report was prepared as an account of work sponsored by an agency of the United States Government. Neither the United States Government nor any agency Thereof, nor any of their employees, makes any warranty, express or implied, or assumes any legal liability or responsibility for the accuracy, completeness, or usefulness of any information, apparatus, product, or process disclosed, or represents that its use would not infringe privately owned rights. Reference herein to any specific commercial product, process, or service by trade name, trademark, manufacturer, or otherwise does not necessarily constitute or imply its endorsement, recommendation, or favoring by the United States Government or any agency thereof. The views and opinions of authors expressed herein do not necessarily state or reflect those of the United States Government or any agency thereof. 


\section{DISCLAIMER}

Portions of this document may be illegible in electronic image products. Images are produced from the best available original document. 
1.0 SCOPE

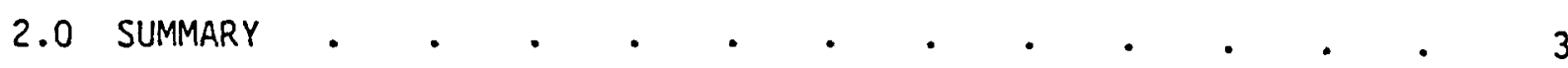

3.0 FACTS $. \quad . \quad . \quad . \quad . \quad . \quad . \quad . \quad . \quad . \quad . \quad .77$

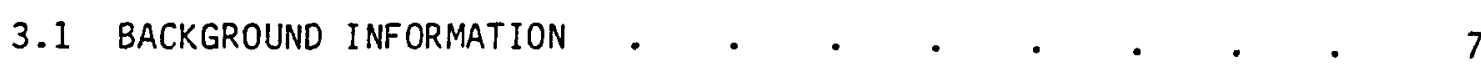

3.2 CHRONOLOGICAL ACCOUNT OF EVENTS . • . . . . . . 13

3.3 NUCLEAR HAZARDS AND SAFETY CONTROLS . . . . . . 19

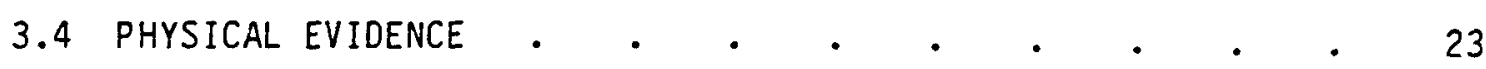

3.5 TECHNICAL DATA ACCUMULATED.$\quad$. . . . . . . . 32

3.6 DESCRIPTION OF LOSS DUE TO OCCURRENCE . . . . . . . 33

3.7 RELATED EVENTS • • • • • • • • • • • • . . 35

4.0 ANALYSIS . . . . . . . . . . . . . . . . 37

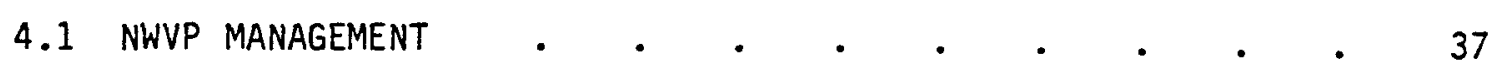

4.2 SPECIAL NUCLEAR MATERIALS STORAGE
FACILITY $-303-C$ BUILDING...
.

4.3 CALCINING OPERATION • . . . . . . . . . . . . 41

4.4 PACKAGING AND TRANSFER METHODS . • . . . . . . 45

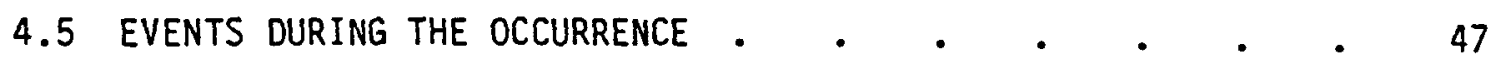

4.6 EVENTS AFTER THE OCCURRENCE $. \quad . \quad$. . . . . . . . . 48

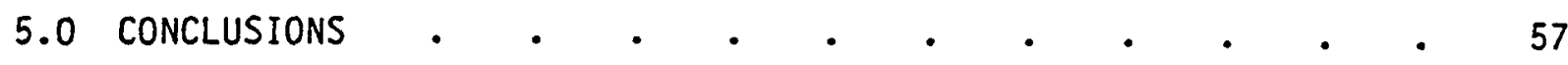

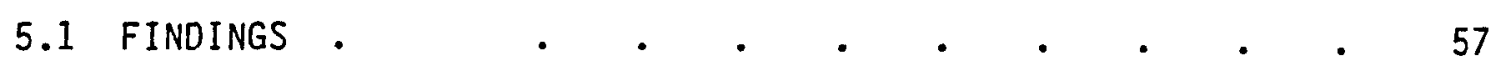

5.2 PROBABLE CAUSES AND CONTRIBUTING FACTORS $. \quad . \quad . \quad . \quad 59$

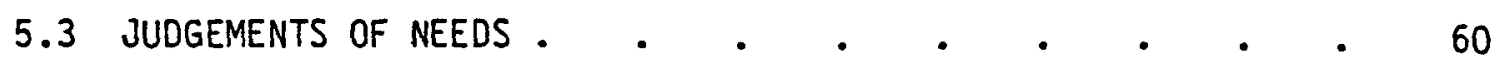

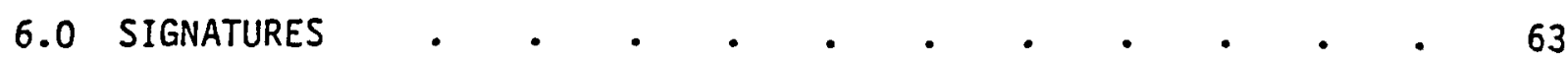

7.0 BOARD AUTHORITY $. . . \quad . \quad . \quad . \quad . \quad . \quad . \quad . \quad . \quad .65$

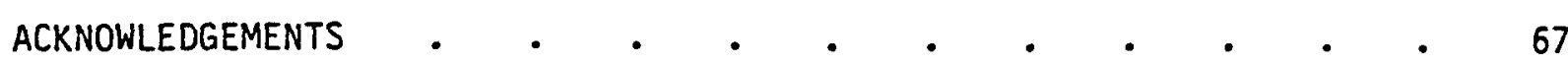


FIGURES

1. Location of the Hanford Site Within Washington State . . . 2

2. Summary of Events and Causal Factors Chart - Rupture of Plutonium Oxide Storage Container . . . . . . . 4

3. Management Structure of the Nuclear Waste Vitrification
Project

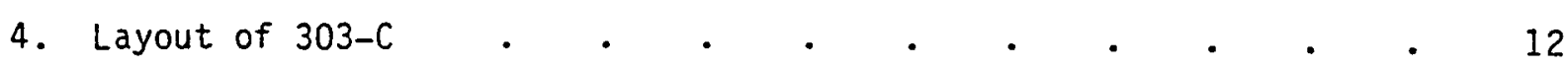

5. Organizational Responsibility for Operations in 303-C . . . 13

6. Plutonium Oxide Storage Containers . . . . . . . . 15

7. Placement of Containers Inside $2 R$ Transfer Container . . $\quad 15$

8. Placement of $2 R$ Container Inside 5791 Transfer Container . .

9. Layout of 303-C Including Positions of Personnel

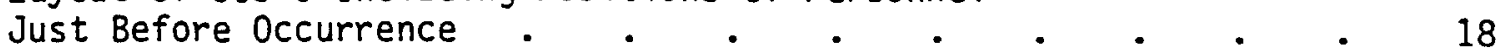

10. Physical Evidence Examined in Room 515 .

11. Physical Evidence Examined in Room $604^{\circ}$. $\quad . \quad$. . . . 29

12. Events and Causal Factors Chart - Rupture of Plutonium Storage Container . • . • . • . . 51

13. Personnel Protection Events and Conditions . . . . . 53

14. Environmental Protection Events and Conditions . . . . 54

15. Evidence Recovery and Protection Events

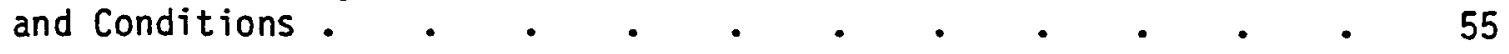

EXHIBITS

1. Memo Appointing PNL's Class C Investigating Committee • • . 71

2. Letter Approving 303-C Building as P7utonium Storage Facility 
3. Pertinent Portions of the Run Plan for Calcination of

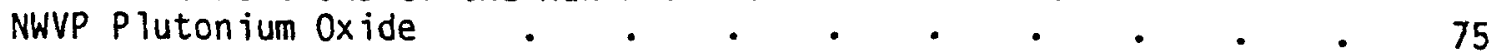

4. Memo, "Tests Related to Rupture of $\mathrm{PuO}_{2}$ Storage Can" . . . 81

5. Memo, "Background Information on Studies Related to
Storing and Shipping PuO 2 Associated with the NwVP"

6. Memo, "Laboratory Studies Related to 303-C Incident" . . . 85

7. Memo, "Nitrogen Content of 6B Sample" . . . . . . . 89

8. Contamination of Personnel as a Result of Occurrence . . . 91

9. Release to the Environment as a Result of Occurrence . . . 99

10. Report on Property Damage or Loss . . . . . . . 101

11. Correspondence Regarding NWVP Items Identified for
Corrective Action . . . .

12. Safe Operating Procedure for NWVP Calcining Operation . . . 105

13. Safe Operating Procedure for Plutonium Oxide Transfer
from the 324 Building to the 303-C Building. . . . 111

14. Memos, "303-C Dose Calculations" • • • • • . . . 113

15. Memo, "Surmary of Air Sample Data" • • • • • • . . 117 


\subsection{SCOPE}

On March 13, 1979, a plutonium oxide storage can ruptured in the 303-C storage facility, which is in the 300 Area of the Hanford Site, Washington (Figure 1). The facility is operated by the Pacific Northwest Laboratory (PNL); three PNL staff members were performing the storage operation. No injuries to these staff members resulted from the occurrence.

A Class C Investigation Committee was appointed on March 14, 1979, by the Director, PNL (Exhibit 1). Subsequently, when the loss estimates became available, the Manager, Department of Energy-Richland Operations Office (DOE-RL), appointed a Class $B$ Investigation Committee in accordance with DOE Manual Chapter 0502. (See Section 7.0, "Board Authority.")

As requested by DOE-RL, the Cormittee investigated technical elements of the causal sequence and management systems that should have or could have prevented the occurrence. For guidance in preparing this report the committee used DOE Manual Chapter 0502 and the Accident Investigation Manual (ERDA 76-20).

The investigation included:

- review of the use of the 303-C facilities and the transfer containers

- interviews with the involved personnel and their managers

- analysis of technical studies related to involved materials and procedures

- review of safe operating procedures, radiation work procedures, and transfer requirements applicable to the occurrence

- use of the Management Oversight and Risk Tree (MORT) and the Events and Causal Factors Charting methods. 


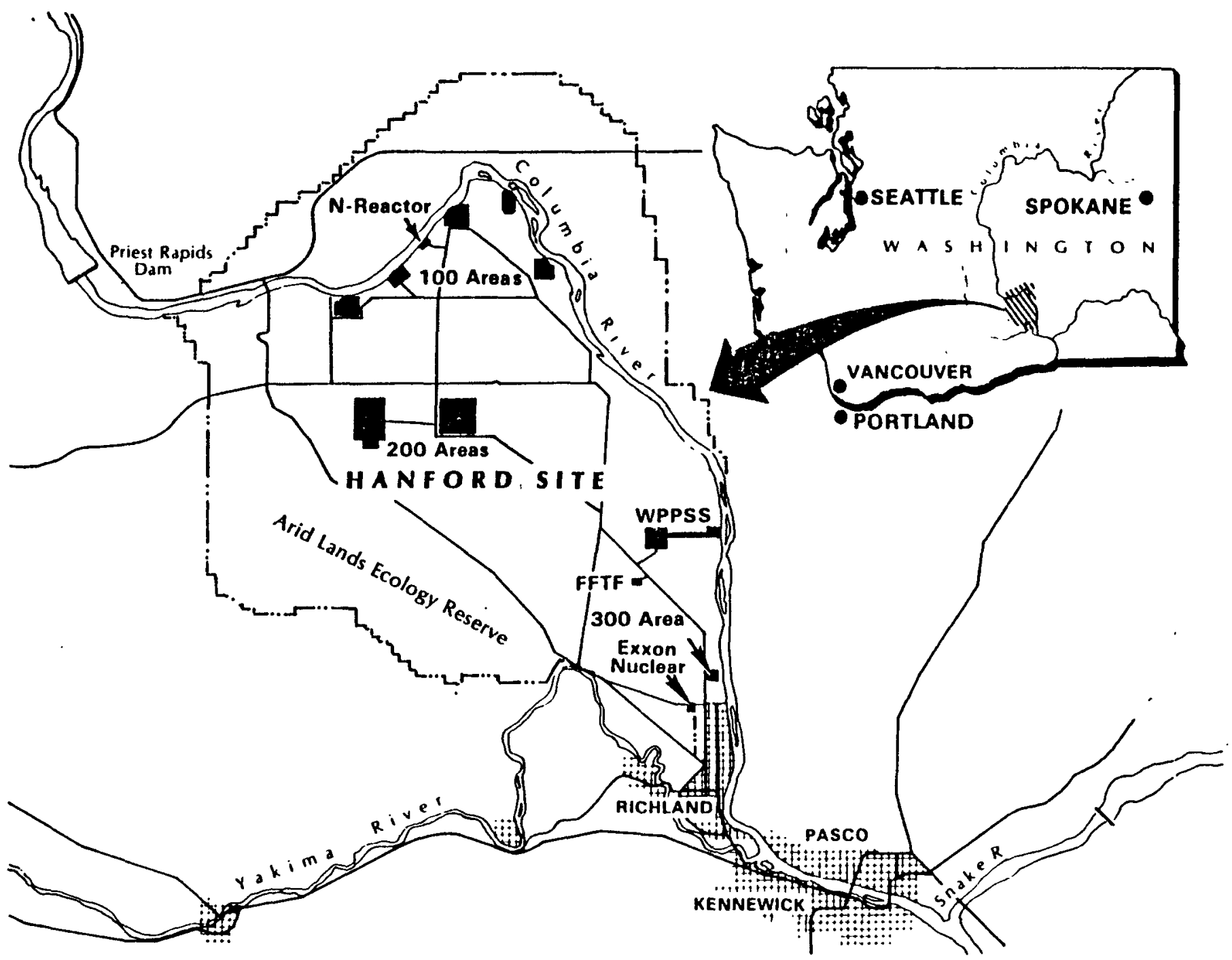

FIGURE 1. Location of the Hanford Site Within Washington State 


\subsection{SUMMARY}

On March 13, 1979 at approximately 9:15 a.m., plutonium oxide storage container $6 \mathrm{~A}$ ruptured, releasing a $\mathrm{PuO}_{2}^{(a)}$ aerosol within the 303-C storage facility. The rupture occurred at the start of the transfer of container $6 \mathrm{~A}$ from a 5791 shipping container to the storage tubes in 303-C. Three PNL employees who were performing the transfer immediately evacuated the building, escaping with minor external radioactive contamination and no significant exposure or internal deposition.

Plant emergency personnel responded promptly and efficiently. The facility was sealed to prevent any significant release to the environment. It is estimated that between 1.2 and 1.3 millicuries of material were released to the atmosphere. Measurements and calculations demonstrated that no employee or member of the general public received any exposure or internal deposition exceeding applicable radiation protection standards.

The events and conditions leading up to this accident are summarized in Figure 2. In the planning stages of the Nuclear Waste Vitrification Project (NWVP) there were inadequate specifications and procedures for the processing, transfer, and storage of the plutonium oxide by-product. Transfers were conducted without incident until the transfer of blend 6 . 8 iend 6 was made of material that had been exposed at 29,500 megawatt days per metric ton of uranium (MWd/tU). All previously processed blends had been made of lower exposure material $(20,500 \mathrm{MWd} / \mathrm{tU})$. Because of its higher exposure, the blend 6 material had a 50\% higher heat output than previously processed material. No heat transfer analysis was performed for the fully loaded transfer container. In addition, this container was allowed to sit for about 12 hours before delivery to $303-c$. The resultant heat buildup in the storage

(a) While the formula $\mathrm{PuO}_{2}$ infers an exact relationship between plutonium and oxygen, the formula is used as a symbolic representation of plutonium oxide. 


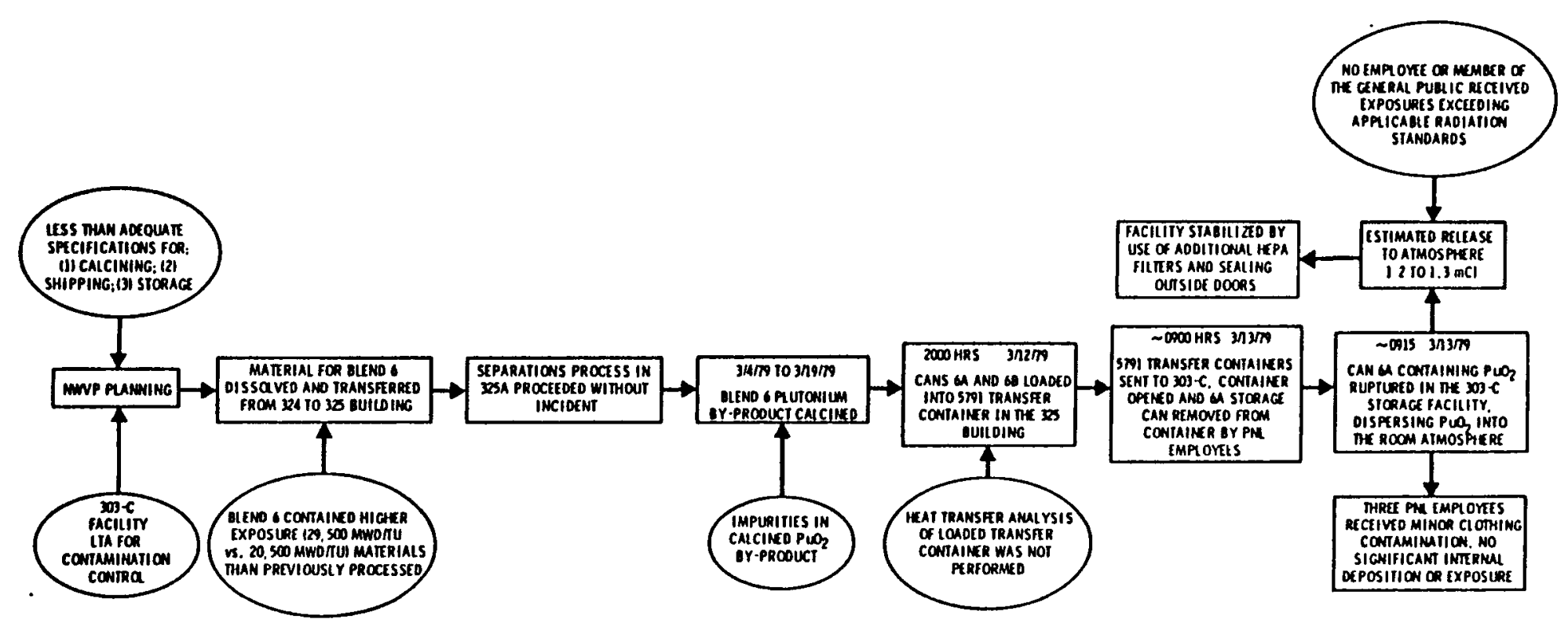

FIGURE 2. Summary of Events and Causal Factors Chart - Rupture of Plutonium 0xide Storage Container 
can, along with decomposition products and water in the plutonium oxide, led to the pressurization and the subsequent rupture of can $6 A$ upon its removal from the shipping container.

On Aprif 5, 1979 the Manager, DOE-RL, appointed the Investigation Committee that conducted this investigation. 



\subsection{FACTS}

This section includes: background information pertinent to the occurrence; a chronological account of events; a characterization of loss due to the occurrence; a description of physical evidence associated with the occurrence; information regarding physical hazards and a review of safety controls associated with the 303-C facility; a sumary of technical data accumulated during the investigation; and a discussion of related events that were not in the causal sequence of the occurrence.

\subsection{BACKGROUND INFORMATION}

Because the plutonium oxide released in 303-C was produced as a by-product during the Nuclear Waste Vitrification Project (NWVP), NWVP planning and operations are discussed below. Also included in this section is background information related to the location, layout, and use of the 303-C facility.

Nuclear Waste Vitrification Project

Management control and configuration control of the NWVP were investigated by the Cormittee. A brief summary of the project's objectives, operations, and management system follows.

\section{Objectives}

The objective of the NWVP was to demonstrate the solidification (vitrification) and packaging of actual (light water reactor fuel) high-level liquid waste, as a silicate glass, into two canisters. It is important that the principal emphasis of this activity was on the treatment and solidification of the high-level liquid waste (HLLW) stream. This is an inversion of the usual emphasis in operations of this type; the emphasis is usually placed on the recovery of the plutonium and uranium, rather than on the disposition of the waste stream. The activities to achieve the NWVP objectives consisted of two tasks of the ongoing Commercial High-Level Waste Fixation Program at the Pacific Northwest Laboratory (PNL): 
- Task 5 - Radioactive Demonstration

- Task 6 - Commercial Nuclear Waste Preparation. Operations

Because the sole purpose of the waste preparation task was to produce actual HLLW, the processing approach was the same as that planned for commercial fuel reprocessing plants through the first solvent extraction cycle (necessary to produce the HLLW). Downstream processing was atypical and was designed only to provide for the appropriate disposition of the uranium, plutonium and the residual fission products. Downstream processing included separation of the plutonium from the uranium by ion exchange and calcinatinn of the plutonium to the oxide. The uranium solution, along with the other liquid waste, was shipped to the 200 Area Waste Management Contractor for storage in the 200 Area Waste Facilities. Conversion of the plutonium to an oxide was intended to provide for safety of transport and storage.

\section{Management Systems}

The NWV Project Management Plan established the responsibilities and authorities for all participants, the organizational structure, and the project management control system. Technical control was achieved through a series of baseline technical documents, which were reviewed and formally approved by the various project participants. Safety and security controls on the NWVP included:

- a document titled ("Feasibility Assessment - Nuclear Waste Demonstration Project - Task 6 - Commercial Nuclear Waste Preparation," July 1, 1976, which identified Safety and Security as a major task, with subtasks for Environmental Assessment, Revision or Supplement to Building Safety Analysis Reports, Transfer Cask Safety Analyses, Criticality Control, Operational Safety, and Physical Security

- review of operational safety by the Battelle Safety Review Council and others in the nuclear industry

- development of safe operating procedures for all operations. 
The Conceptual Design Report ${ }^{(a)}$ was submitted to the Energy Research and Development Administration - Richland Operations Office ${ }^{(b)}$ (ERDA-RL) for approval in 1976; it included NWVP scope, functional criteria, total estimated cost, overall schedule, and management plan. (See Figure 3 for the management structure of the NWVP. Note that the management structure for the project changed in January 1977; both structures are shown in Figure 3.)

The Conceptual Design Report specifies that the plutonium by-product will be in the form of plutonium oxide powder suitable for storage in the 200 Area or for potential use in fabrication of mixed-oxide fuel elements. There is no written record of an approved American Society of Testing Materials (ASTM) or Reactor Development Technology (RDT) technical specification being imposed on the by-product. Instead, a by-product specification was established that related primarily to safe storage. This specification defined temperature of calcining, moisture content, and volatility content of the plutonium oxide by-product.

\section{3-C Facility}

The 303-C Building, which was approved as a permanent plutonium storage facility (Exhibit 2), is located in the 300 Area of the Hanford Site. Features of 303-C include:

- $25 \mathrm{ft} \times 56 \mathrm{ft}$ dimensions

- one-story, concrete-block construction

- a 6-ft-wide door on the north end and a 3-ft-wide emergency exit on the south end

- an array of storage tubes, with sealed covers, embedded in the wall

- fire-resistant steel file cabinets.

- a ventilation system [two high-efficiency particulate air (HEPA) filters, blower and related ductsl placed entirely inside the building.

(a) Conceptual Design Report, Commercial Nuclear Waste Vitrification, December 1976. Pacific Northwest Laboratory, Richland, WA 99352 p. 8, p. 58 and p. 137 .

(b) In 1976, the Energy Research and Development Administration became part of the Department of Energy. 

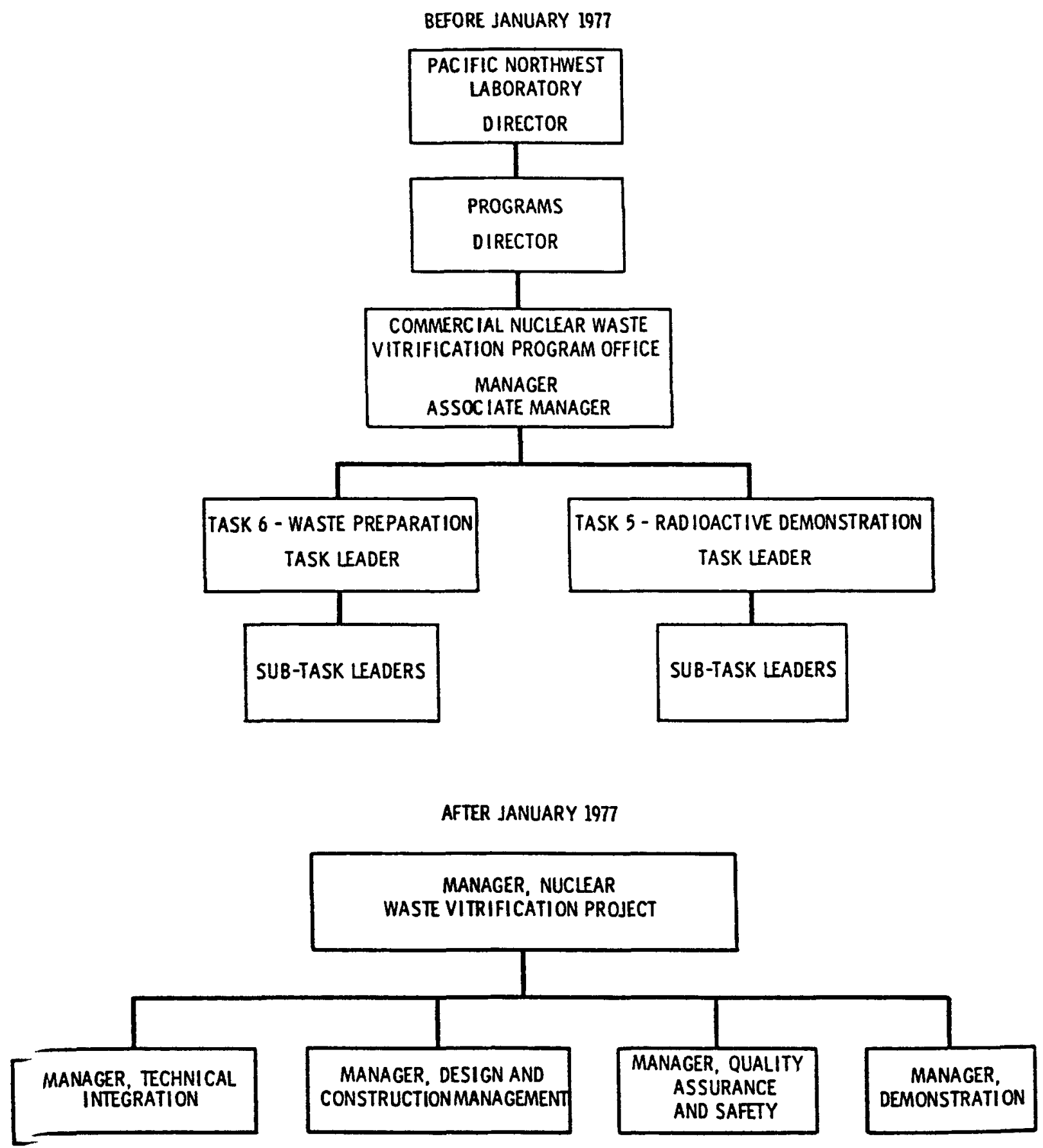

FIGURE 3. Management Structure of the Nuclear Waste Vitrification Project 
No controlled environment facility (e.g., hood or down-draft room) is provided in the building. See Figure 4 for a layout drawing of the building.

There are 218 storage tubes in the concrete array with three sizes of pipes provided: 4-in. diameter, 8-in. diameter, and 8-in square. Each storage tube has a steel door with a rubber gasket that provides some degree of sealing the material into the tube. The bulk of the nuclear materials stored in the facility are stored in the concrete array, and no plutonium is allowed to be stored within 303-C except in the concrete storage array or in DOT-approved shipping containers. There are no provisions for handling powders or solutions of special nuclear materials outside primary containers, i.e., tape-sealed or mechanically sealed cans for powders and DOT-approved shipping containers for liquids. Thus the following restrictions are imposed by the Nuclear Safety Limits:

- Plutonium or plutonium-bearing materials shall be stored either in the concrete embedded tube array or in DOT-approved shipping containers, loaded in accordance with DOE specifications. In addition to storage in the tube array or DOT shipping containers, nonplutonium fissile material can be stored in the metal fire-resistant file cabinets. Storage of plutonium in the file cabinets is prohibited.

- All plutonium, other than that in clad fuel elements or held in DOT-approved shipping containers, shall be packed one of the following ways: 1) in a plastic bag inside two tape-sealed metal cans or in a single mechanically sealed can, 2) in sealed transfer containers, or 3 ) in other transfer containers sealed in heavy plastic bag.

- Access doors to $303-C$ shall be closed whenever any fissionable material is removed from its transfer container. Two people are required to be present for handling of fissionable material outside of transfer containers.

- Transfer of powders and solutions between primary containers (tape-sealed cans for powders and DOT-approved shipping containers for liquids) is prohibited. 


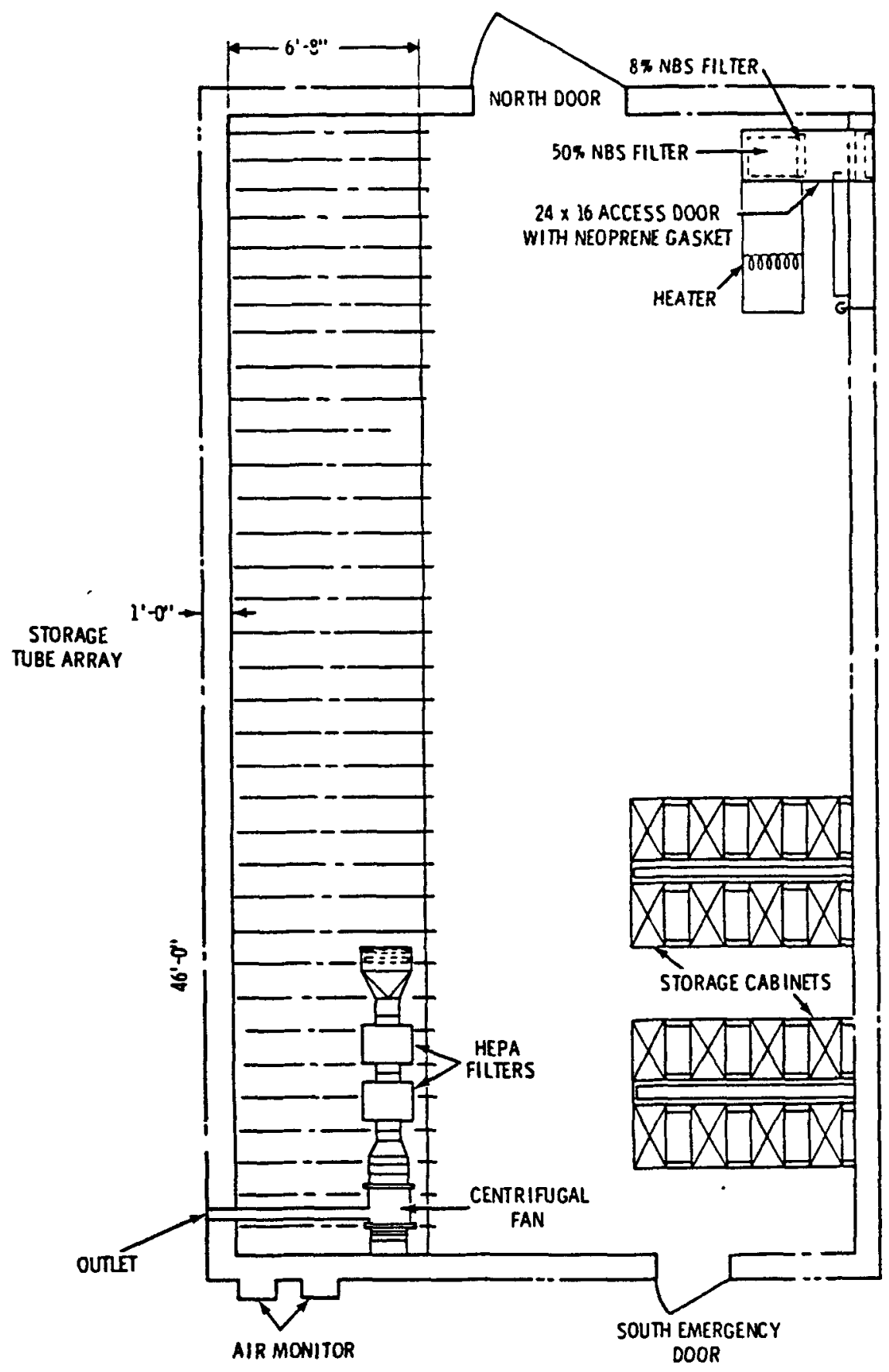

FIGURE 4. Layout of 303-C

$-$ 
The operations in the 303-C Building are the responsibility of the Manager, Safety and Nuclear Materials Management (Figure 5). Building operations include: loading and unloading delivery vehicles, moving material within the facility, and loading and unloading transfer containers. See Section 3.3 for a discussion of safety controls that regulate 303-C Building operations.

\subsection{CHRONOLOGICAL ACCOUNT OF EVENTS}

Processing of NWVP plutonium oxides was begun on 12/21/78. Biends 2 through 5 contained material exposed at 20,500 megawatt days per metric ton of uranium (MWd/tU); blends 6 through 8 contained material exposed at 29,500 MWd/tu. The table on the following page shows the dates the blends were calcined, canned, drummed and shipped to 303-C.

Between the calcining of blends 4 and 5 , the calciner was shut down for nuclear material inventory. The personnel performing the inventory discovered a ceramic coating on the floor of the calciner screw trough, and dry ice and nitric acid were used to remove the coating. The thermocouples in the calciner were subsequently recalibrated and two of the thermocouples were

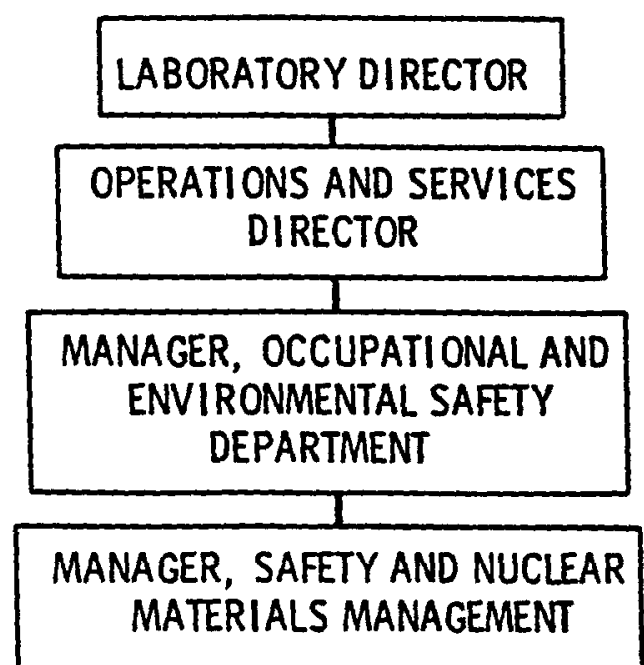

FIGURE 5. Organizational Responsibility for Operations in 303-C 


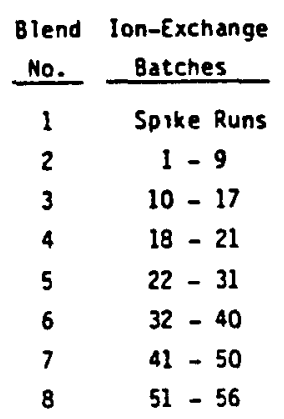

\begin{tabular}{cc}
\multicolumn{2}{c}{ Last Calcine } \\
\cline { 1 - 1 } Date & Time (d) \\
\hline $12 / 24 / 78$ & $11: 30$ \\
$01 / 27 / 79$ & $17: 45$ \\
$02 / 06 / 79$ & $13: 15$ \\
$02 / 11 / 79$ & $05: 25$ \\
$03 / 04 / 79$ & $11: 30$ \\
$03 / 09 / 79$ & $17: 50$ \\
$03 / 24 / 79$ & $03: 00$ \\
$03 / 28 / 79$ & $03: 30$
\end{tabular}

\begin{tabular}{cc}
\multicolumn{2}{c}{ Drummed } \\
\hline Date & Time(a) \\
\cline { 1 - 1 } $01 / 15 / 79$ & MA \\
$01 / 29 / 79$ & $15: 30$ \\
$02 / 07 / 79$ & $23: 30$ \\
$02 / 14 / 79$ & $04: 00$ \\
$03 / 07 / 79$ & $10: 00$ \\
$03 / 12 / 79$ & $22: 00$ \\
\multicolumn{2}{c}{ Not drumed } \\
Not drummed
\end{tabular}

\begin{tabular}{l} 
Date Trans. \\
To $303-C$ \\
\hline $01 / 16 / 79$ \\
$01 / 30 / 79$ \\
$02 / 08 / 79$ \\
$02 / 14 / 79$ \\
$03 / 08 / 79$ \\
$03 / 13 / 79$ \\
Not sent \\
Not sent
\end{tabular}

NA - not avallable.

(a) These are approximate tumes.

replaced along with two heating elements. The controlling thermocouple temperature was reset at $450^{\circ} \mathrm{C}$, in compliance with the run plan (Exhibit 3). (a) (See Section 4.3, page 44, for analys is of the significance of these facts.)

As shown in the table (above), calcining of blend 6 was done from 03/04/79 to 03/09/79. Between calcining and blending, blend 6 was kept in cans with slip-fit lids in a glove box for 3 to 8 days. After it was blended, the material was weighed for accountability and a sample was sent to the Hanford Engineering Development Laboratory (HEDL) for analysis. Normal operating procedures were followed.

On $03 / 12 / 79$, during the 8 a.m. to 4 p.m. shift, blend 6 was loaded into two cans (6A and $6 \mathrm{~B})$. The cans were then tape sealed, sealed in plastic, wrapped in aluminum foil and placed in a metal can that was mechanically (crimp) sealed (Figure 6 ). Can $6 \mathrm{~A}$ was packaged without incident. However, contamination was found on $\mathrm{Can} 6 \mathrm{~B}$; therefore, can $6 \mathrm{~B}$ was sealed back into the glove box. Investigation showed the plastic bag to have been cut during the sealing of the outer metal can. Can $6 B$ was sealed out a second time on the following shift.

In preparation for shipping from the 325 Building to 303-C, the mechanically sealed cans were wrapped in heavy aluminum foil and secured inside the DOT-approved $2 R$ shipping container (Figure 7 ). (Note: Results of the HEDL analysis were not known at this time. Operating procedures did not require

(a) Run Plans, Waste Preparation Task, 325-A Building, October 1978. 


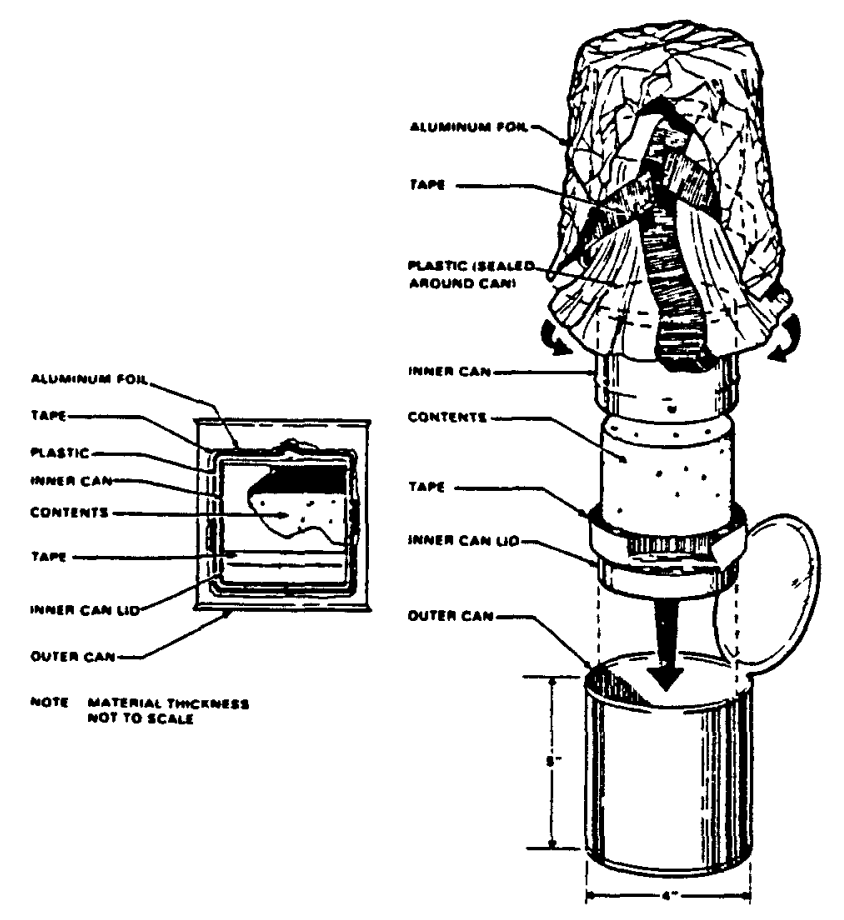

FIGURE 6. Plutonium Oxide Storage Containers

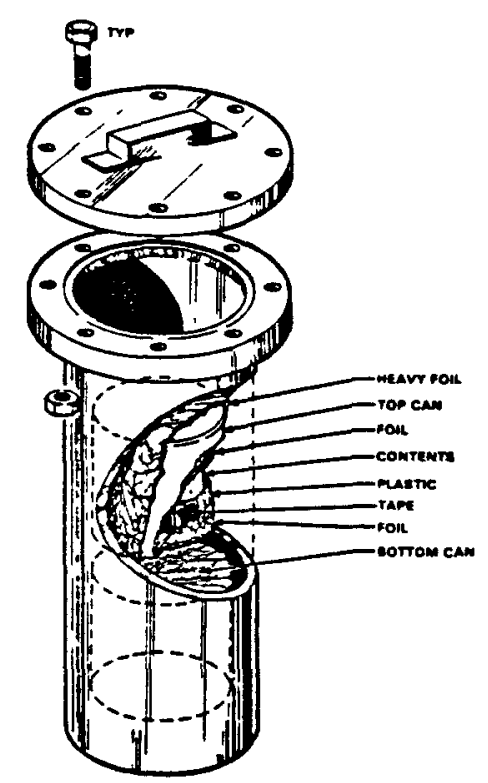

FIGURE 7. Placement of Containers Inside $2 R$ Shipping Container 
receiving analysis results before packaging and shipping.) At approximately 2200 hours on $03 / 12 / 79$, the $2 R$ container (surrounded by firedike packing material) was placed inside a DOT-approved 5791 shipping drum (Figure 8). The 5791 container was held in Room 604, 325 Building, for approximately 12 hours.

On the morning of $03 / 13 / 79$, the drum was loaded onto a truck, transferred to 303-C, and unloaded without incident. A senior specialist, a specialist, and a radiation monitor were at $303-C$ to remove the cans from the transfer container and transfer them into the storage tubes (see Figure 4). The radiation monitor surveyed the outside of the 5791 container; the reading showed no detectabie contamination.

When the specialist opened the 5791 container, the radiation monitor took another reading, which showed no detectable contamination on the inside of the drum or on the packing material. The specialists then removed the packing material and the radiation monitor surveyed the outside of the $2 R$ container.

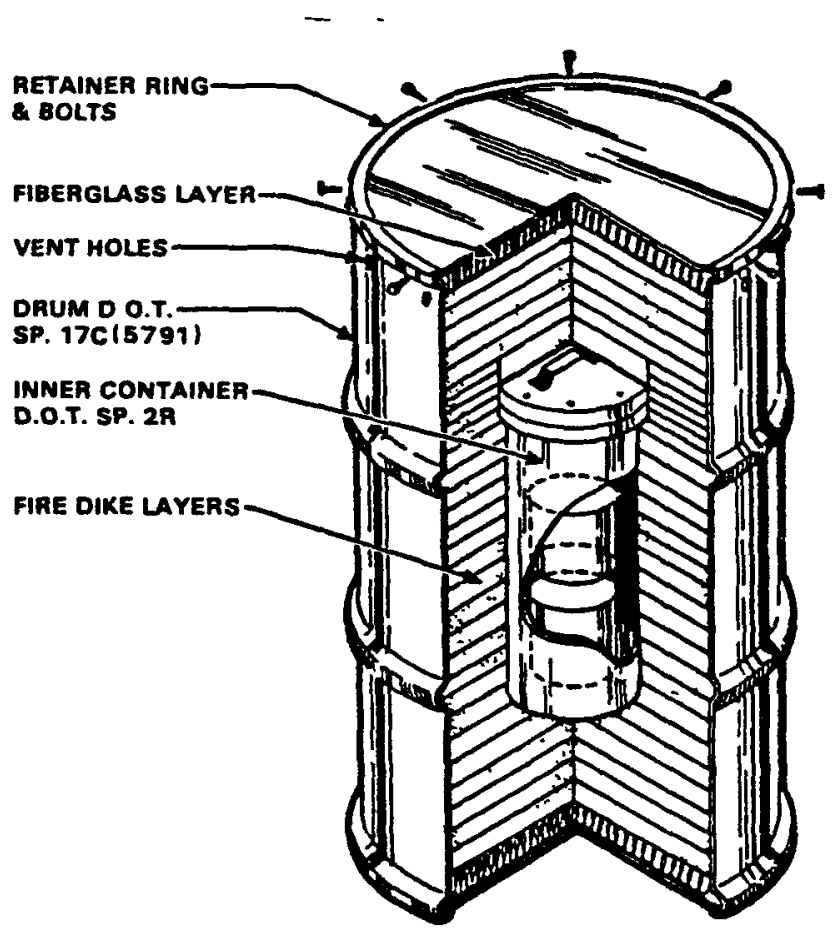

FIGURE 8. Placement of $2 R$ Container Inside 5791 Shipping Container 
It was free of contamination. The radiation monitor reported that the radiation level was approximately 8 millirads/hour at 1 foot.

The specialists lifted the $2 R$ container out of the 5791 so that the $2 R$ 's bolted lid could be removed. When the specialists removed the lid, they noticed that one of the 0 -rings was broken. No contamination was detected by the radiation monitor.

As the specialists began to peel back the foil around the top, mechanically sealed can, they noticed that under the foil the can was bulged. (Bulged cans had been observed during previous NWVP transfer/storage operations, and NWVP personnel had stated that bulging was caused by excess packing materials.) During the unwrapping of the foil, the radiation monitor was taking a radiation dose-rate measurement. The indicator went off the first scale (0 to $5 \mathrm{millirads/hour),} \mathrm{so} \mathrm{the} \mathrm{monitor} \mathrm{started} \mathrm{to} \mathrm{change} \mathrm{scales} \mathrm{(0} \mathrm{to} 50$ millirads/hour) and rezero the instrument.

As the specialist held the top $c$ an, the senior specialist continued to peel back the foil. At that point, all three men heard a sound "like escaping air." The specialist and senior specialist saw a brownish-yellow cloud coming from the can. The monitor noticed the cloud when he looked up from rezeroing his instrument.

As shown in Figure 9, the radiation monitor and the senior specialist were positioned between the can and the north door; the specialist was between the can and the south emergency door. When he saw the cloud, the specialist released the can he was holding and ran from the cloud to the south door, while the senior specialist and radiation monitor turned and ran to the north door. The radiation monitor stopped only long enough to make sure that the specialist had gotten out the south door.

Outside the north door, the radiation monitor surveyed the senior specialist and found no contamination. They went to the west side of the building, where they met and surveyed the specialist. Greater than 100,000 disintegrations/minute $(\mathrm{d} / \mathrm{m})$ per 100 square centimeters $\left(\mathrm{cm}^{2}\right)$ were found on the left side of the specialist's lab coat. 


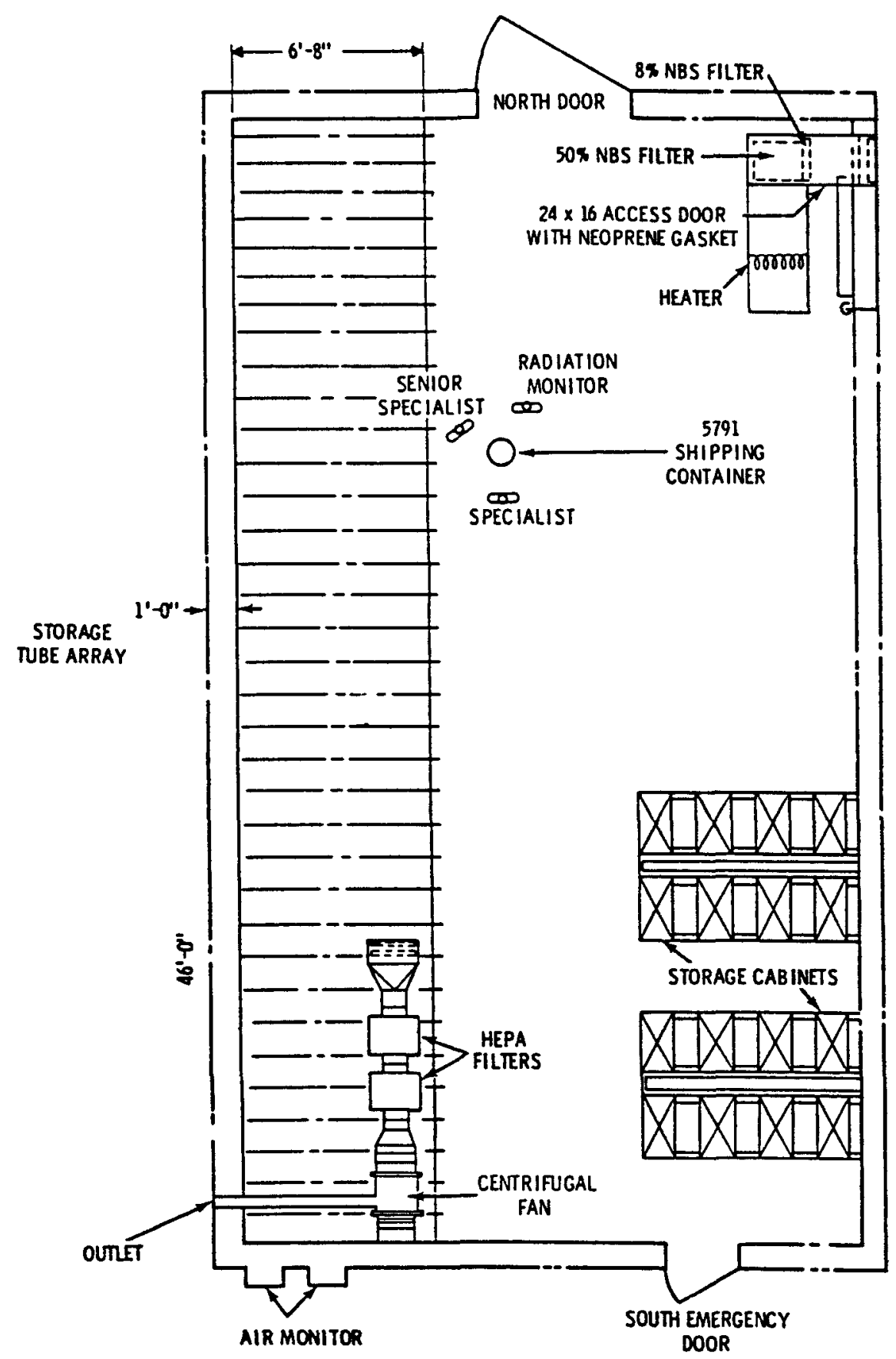

FIGURE 9. Layout of 303-C Including Positions of Personnel Just Before Occurence 
The radiation monitor surveyed his own hands and shoes, found them to be free of contamination, and then went to get gloves from a box outside the building. However, the gloves inside the box were wet, moldy and unusable. The radiation monitor then went to his truck to get gloves, tape and a lab coat. The specialist put on the clean lab coat over the contaminated coat in order to prevent further contamination spread. The radiation monitor subsequently called for additional monitoring help, which arrived promptly. At that time the radiation monitor was found to have hand contamination of up to $2500 \mathrm{~d} / \mathrm{m}$ per $100 \mathrm{~cm}^{2}$.

The involved personnel were taken to a decontamination facility in the 325 Building and were successfully decontaminated. Whole-body counting and bioassay indicated that no detectable internal deposition resulted. See Section 3.6 for additional information.

An estimated 1.2 to 1.3 millicuries of alpha-emitting transuranics escaped to the atmosphere as determined by direct measurement. See Section 3.6 for additional information regarding environmental releases.

Minor amounts of contamination, up to $5000 \mathrm{~d} / \mathrm{m}$ per $100 \mathrm{~cm}^{2}$, were tracked in the immediate vicinity outside the facility. All contamination was removed shortly after it was detected.

Stabilization of the conditions at the 303-C facility was assured by sealing the doors with tape, covering the intake of the ventilation system, and placing an additional HEPA filter over the exhaust ventilation port.

\subsection{NUCLEAR HAZARDS AND SAFETY CONTROLS}

Potential nuclear hazards associated with materials in the 303-C storage facility include nuclear criticality, personnel radiation exposure and radiological contamination. Administrative controls and engineered safety features are applied to the 303-C facility and its operation to reduce the probability and consequences of such occurrences to an acceptable level. 
Administrative Controls

Administrative controls are prescribed for operations within PNL to: 1) ensure a high degree of safety to the public, employees, and equipment and property, and 2) meet applicable DOE regulations and requirements. These administrative controls are formulated in accordance with the following PNL Management Guides and related PNL manuals:

PNL Management Guides

5.4 Quality Assurance

9.9 Facility Management

12.1 Industriai Health and Safety

12.3 Nuclear Safety

12.4 Radiation Protection

12.6 Emergencies

12.8 Reporting Occurrences

12.9 Waste Management

12.10 Nuclear Materials Management and Safeguards

12.12 Packaging and Transportation of Radioactive Material
Related PNL Manuals

MA-65

MA-93

MA-43

MA-25

$M A-3$ and -6

MA-11

None

MA-8

$M A-5$

MA-81

For PNL nuclear facilities(a) where approved safety analys is reports (SAR) are required, safety requirements are defined in the form of operations safety requirements (OSR) and/or nuclear safety limits (NSL). These requirements and limits are based upon and justified by the safety analys is presented in the SAR and are part of the SAR for a facility. These limits are binding for the facility and its operations and can only be changed by revising, with subsequent approval, the applicable SAR. The OSRs and/or NSLs are implemented

(a) A PNL nuclear facility is primarily a facility containing more than $45 \%$ of a minimum critical mass of fissionable material. 
as appropriate at the operations level by safe operating procedures (SOP), job hazard breakdowns (JHB), radiation work procedures (RWP), and criticality safety specification (CSS).

The NSLs for the 303-C Building are given in the SAR for the facility. (a) Operation of the facility is conducted within these limits and other commitments made in the SAR. Operations safety requirements are a relatively recent DOE requirement and summarize in one place (a chapter of or a supplement to the SAR) commitments stated in the SAR, including the NSLS. A first draft of the OSRS has been prepared as a supplement to the 303-C Building SAR. These have yet to be submitted to DOE-RL for its review and approval. Although this draft $O S R$ is not currently in force at the 303-C facility, the operation of the 303-C Building is in compliance with the SAR and thus complies with the draft OSRs.

An SOP provides instructions for the conduct of an orderly and safe operation. These procedures include steps to be taken under both routine and unusual conditions. The SOP for transfer of plutonium oxide from the 325 Building to the 303-C Building is number 325-10-2.

An RWP is prepared for all operations involving radioactive materials. These procedures provide a summary of the requirements for working with radioactive materials. The RWP for the operations in $303-C$ is number $303-C-1$ Rev 6.

The CSSs are developed for all operations involving fissionable materials in PNL nuclear facilities and provide limits for the safe handling, processing and storing of the fissionable materials. Preparation, review and approval of the CSS by the operating group, a nuclear safety engineer, and a criticality safety specialist assures adequate consideration of technical details, engi-

(a) Richey, C. R., H. L. Henry, and L. C. Davenport. Safety Analys is Report, 303-C Building, Special Nuclear Materials Storage FaciTity. BNWL-B-32I, Battelle, Pacific Northwest Laboratories, Richland, WA 99352, May 1974. 
neered safeguards, administrative controls and operations applications. Conformance to an approved CSS by the operating group assures compliance with facility NSLs.

A program of labeling and posting is conducted to identify fissionable material properly, to identify the fissionable material limit for each work location, storage area, and process area, and to record and control inventories of fissionable material. Posting and labeling conform to requirements specified in BNWL-MA-25, Criticality Safety Procedures.

A JHB is an analysis of the hazards encountered in a particular job, accompanied by the means of eliminating or controlling the hazards through use of safe practices and protective devices. The JHB lends itself especially well to tasks that are repetitive or routine such as materials handling, maintenance, machine tool operation, operation of laboratory apparatus, and research and analytical processes.

Emergency procedures for the facility deal primarily with criticality, fire, and area evacuation and do not cover a contamination incident within the building. However, a separate procedure deals with response to the alarm on the alpha air monitoring unit (Radeco alarm).

\section{Engineered Safety Features}

Engineered safety features include a ventilation system for contamination control; a fixed-spacing concrete storage array and fire-resistant, steel file cabinets; a continuous air monitor system, a products-of-combustion fire alarm system; a criticality alarm system; and emergency power for the ventilation, air monitor, and alarm systems.

The building is equipped with a once-through ventilation system maintaining a negative building pressure with respect to ambient atmosphere. The intake is filtered by roughing and medium-efficiency filters; the outlet is filtered by a roughing and two HEPA filters placed in series. The HEPA filters, blower, and corresponding exhaust ducts are housed completely within the 303-C Building with an exhaust port on the west wall, near the south end of the facility (Figure 4). To evaluate emissions from the facility, continuous 
samples of the air from the exhaust side of the HEPA filters pass through a filter pad, which is analyzed for radioactivity monthly, or more frequently. A continuous air monitor is provided to evaluate the inside air prior to building entry by personnel. Emergency power is provided as backup for the ventilation system and the continuous air monitors. Other engineered safety features are a products-of-combustion fire alarm system and a criticality alarm system with emergency power backup. Portable radiation survey instruments are available for personnel to use before they exit the facility.

\subsection{PHYSICAL EVIDENCE}

On March 27, the $6 \mathrm{~A}$ and $6 \mathrm{~B}$ containers of plutonium oxide were recovered from the 303-C Building and shipped to the 325 Building for examination. The two containers were inside the $2 R$ container that had been bagged in plastic and placed inside a metal drum. The $2 R$ container was warm-to-touch when it arrived at the 325 Building.

Examination of Can $6 \mathrm{~A}$ in Room 515

Following storage overnight in Room 603 , the $2 R$ container was loaded into a glove box in Room 515. Photograph A (Figure 10) shows the as-received condition of the foil wrap on can $6 A$ inside the $2 R$ container (with the $2 R$ lid removed). The only visible evidence of plutonium oxide on the outer surface of the foil was a small amount in an area near the center of the foil on an exposed underside. The presence of plutonium oxide was confirmed when the foil in this area was peeled back. Because the foil was wrapped completely around the can, it was necessary to remove the foil and can together from the $2 R$ container. The foil was warm to the touch.

Photograph B, Figure 10, shows the can resting partially in the foil with the site of the rupture exposed. The top of the can had noticeable deposits of plutonium oxide with an appreciable quantity of plutonium oxide powder inside the foil. The sides of the can were relatively clean and bright. Upon removal of the foil, the bottom of the can was found to be bulged. 
$$
\text { . }
$$ 


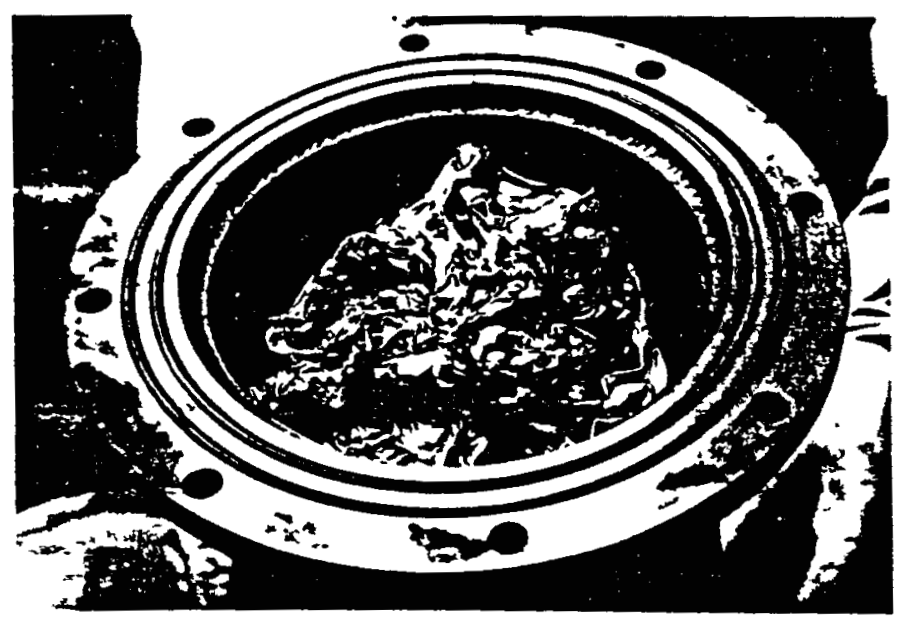

PHOTOGRAPH A. FOIL WRAP ON CAN 6A INSIDE 2R CONTAINER

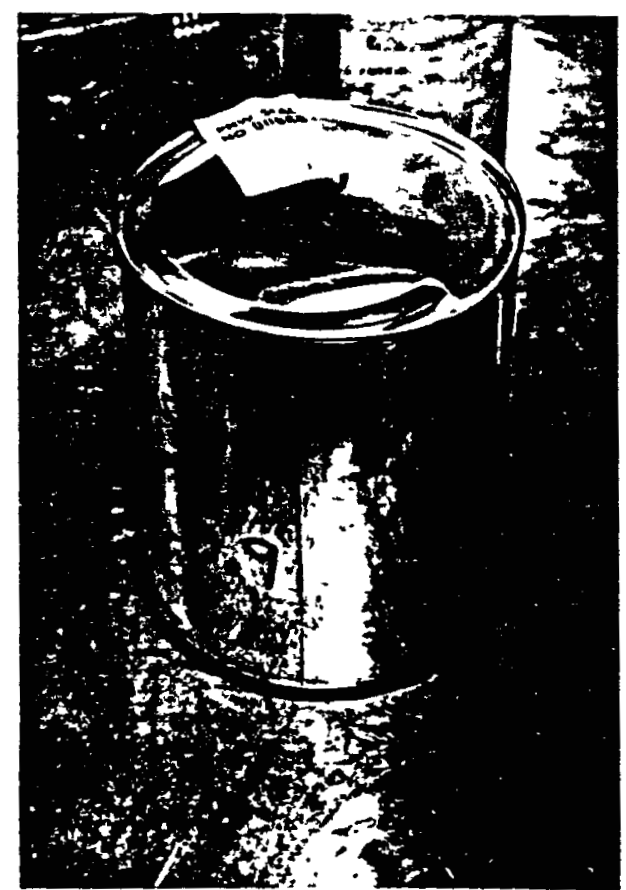

PHOTOGRAPH C. CAN 6B BEFORE IT WAS OPENED

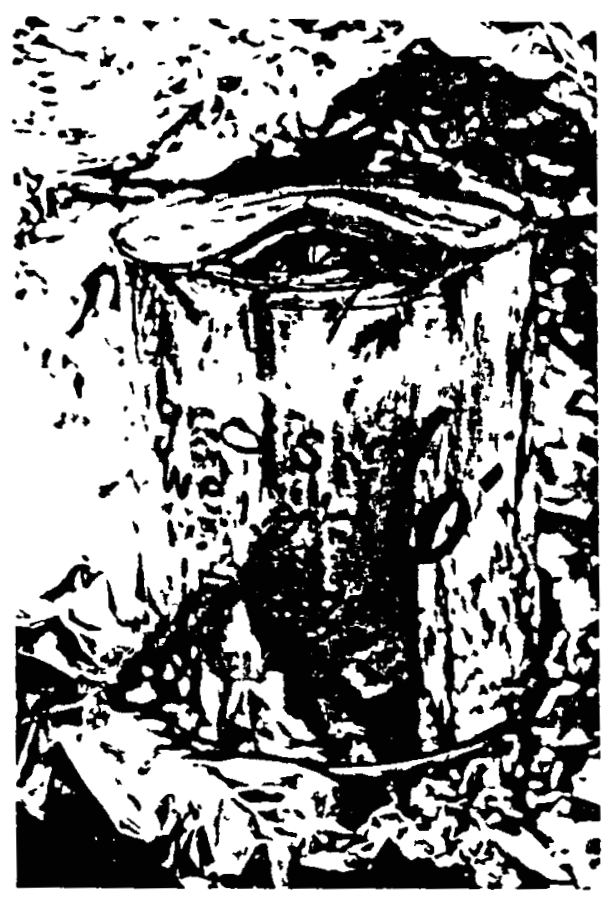

PHOTOGRAPH B. CAN 6A WITH SITE OF RUPTURE EXPOSED

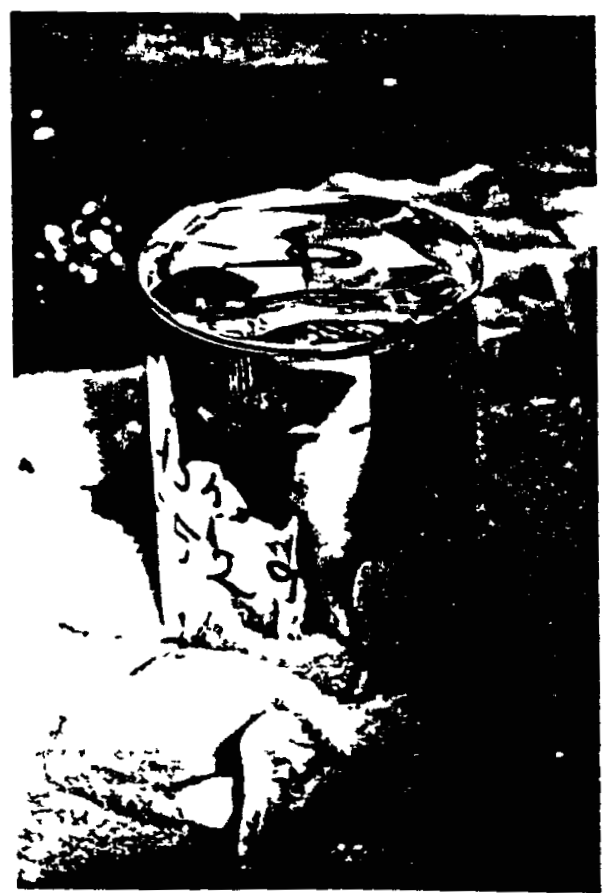

PHOTOGRAPH D. CAN $6 B$ AS IT WAS OPENED

FIGURE 10. PHYSICAL EVIOENCE EXAMINED IN ROOM 515 
$$
\text { . }
$$ 
Examination of Can 6B in Room 515

Can $6 \mathrm{~B}$ was removed from the $2 R$ container and examined. There was no visual evidence of plutonium oxide deposition on the can after removal of the foil. The can was warm and was bulged at the lop. Three locations in the lid of the can had visible crimps or deformations. However, close examination showed no signs of the can having been vented. As shown by Photograph $C$, Figure 10, there was a major crimp in the lid at about $50^{\prime} c l o c k$, a second crimp at about $90^{\prime}$ clock and a crimp under the seal at about 11 o'clock.

Can 68 was placed on a wet towel for venting. A can opener was placed on top of the can, and the can was covered with another wet towel. The can was then punctured with the can opener. The only sound was that of the can opener going through the metal; no escaping gas was evident. A section of the can top, roughly corresponding to positions from 3 to $5 \mathrm{o}^{\prime} \mathrm{clock}$ in Photograph $\mathrm{C}$, was then opened. As soon as the can was partially opened, the lid began to bulge up, indicating pressure inside the bag within the can. This cut could not be continued due to the crimp in the top at about the 5 o'clock position. A second cut was begun at about the 6 o'clock position. The can lid continued to bulge, and when the opening was sufficiently large, the plastic bag began to balloon out the opening (Photograph D, Figure 10). The cutting was stopped, and gentle pressure was applied by hand to the can top to restrain the bag. A wet towel was placed over the can and a pair of scissors placed under the towel was used to puncture the bag. A sound of escaping gas was evident but no fumes were visible (possibly because of the wet towel). When the investigators removed the towel, they noted that the bag had retreated from the opening and that the towel was discolored by plutonium oxide where it had been directly over the opening. The edge of the cut made by the can opener was not smooth as would be expected, but showed signs of tearing (possibly due to the pressure exerted upward on the lid by the expanding bag).

Because of the rather large amount of plutonium oxide observed in the foil around can $6 \mathrm{~A}$ and the desire to hold contamination of the glove box in Room 515 to a minimum, both cans were bagged out of the glove box and transferred to a glove box in Room 604 for further examination. 
Examination of Can $6 \mathrm{~A}$ in Room 604

The first can to be investigated in Room 604 was $6 \mathrm{~A}$ (the can that ruptured in 303-C Building). The bottom of the outer can was slightly bulged and this end was chosen for opening the can. The bottom was cut off with a can opener and pried up. Both the bottom lid and the exposed aluminum foil wrapped around the inner contents were shiny except for rust spots, which came from the implement used to pry up the lid (Figure 11, Photograph A). Shaking of the can could not dislodge the inner package.

The top of the can was cut with the can opener and the top was bent up. Mottled areas were observed on the underside of the top where the breach had occurred (Photograph B, Figure 11). As the inner package was held down with a small can, the outer can was slipped up from the inner package. Some discoloration was observed near the inside bottom of the can, especially near the seam in the can wall.

The inside package had been wrapped in aluminum foil. There was a gap in the foil where the can had ruptured; the foil looked like it had been slit open. A relatively large brown area (about 0.5 inch $\times 2$ inches) was apparent near the bottom where the plastic looked like it either had not been covered by the foil or had been pushed as ide when the package was crammed into the outer can. The location of the brown area did not line up with the discolored area observed on the inside of the outer can. A small brown area (about one-eighth inch in diameter) was located at a position of alignment with the discolored area on the inside wall of the outer can. The foil was pried up at the top of the can, exposing the plastic bag. The bag looked green-brown (various shades) and tended to rise up with the foil because some of the tape used on the bag adhered to the foil (Photograph C, Figure 11). Continued removal of the foil showed the bag to be very flexible and the tape to be "gummy." The bag was much darker near the bottom than at the top, with the line of dark color extending much higher in some places than in others (Photographs $D$ and $E$, Figure 11). Darker areas seemed to be located under areas where there was an extra fold of plastic. It was noted, however, that the 


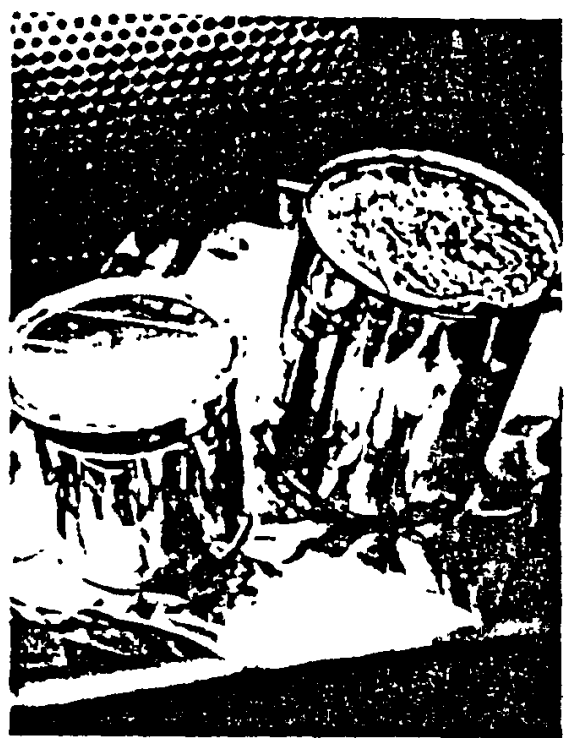

PHOTOGRAPH A. CAN GA AFTER BOTTOM LID WAS REMOVED

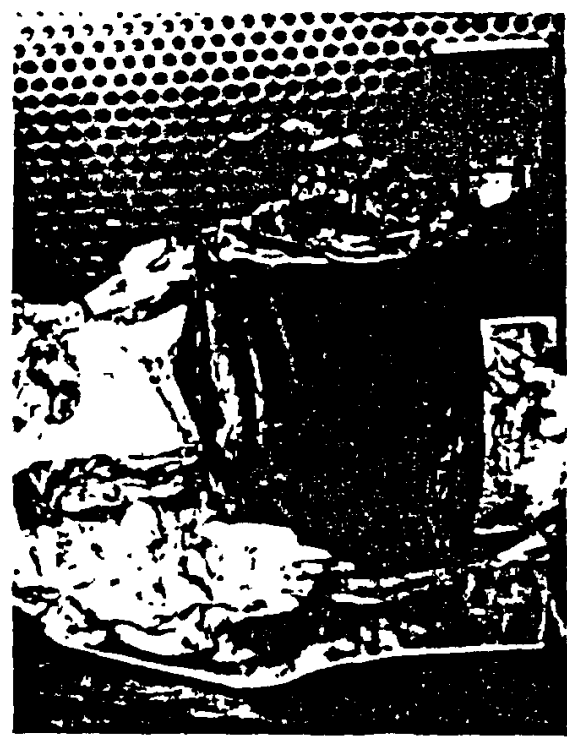

PHOTOGRAPH D. DISCOLORATION OF PLASTIC BAG INSIDE CAN GA

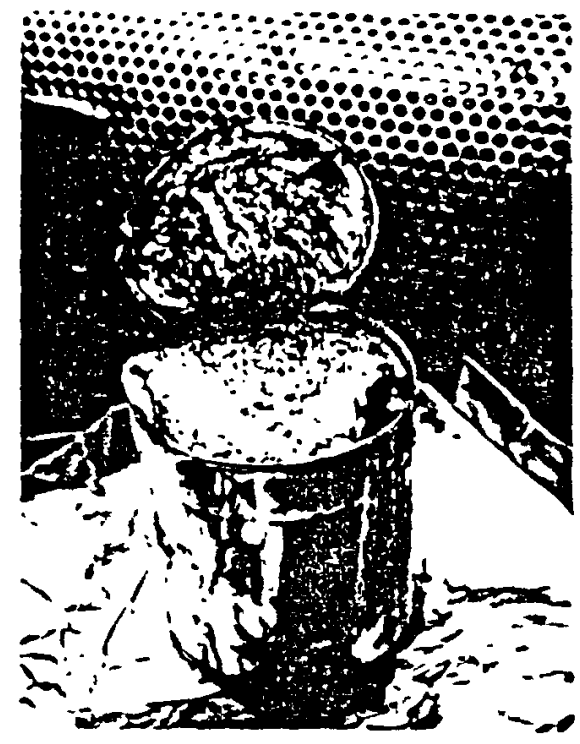

PHOTOGRAPH B. CAN GA AFTER TOP LID WAS PRIED UP

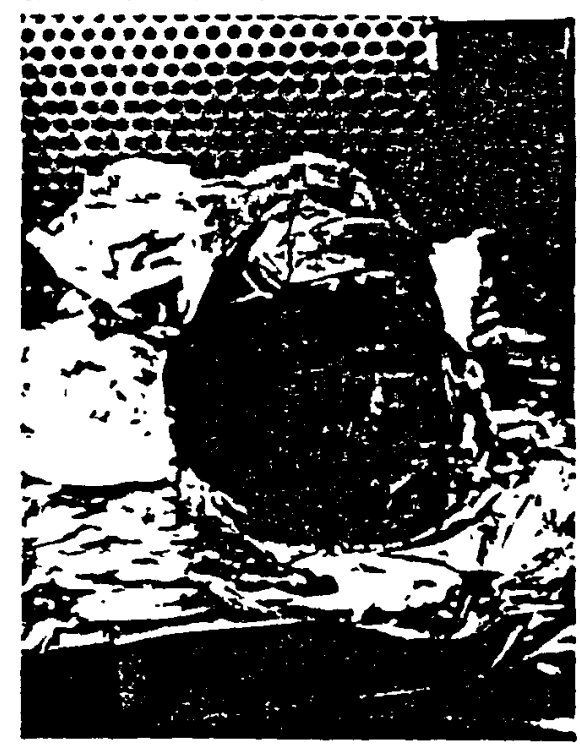

PHOTOGRAPHE. DISCOLORATION OF BOTTOM OF PLASTIC BAG INSIDE CAN $6 \mathrm{~A}$

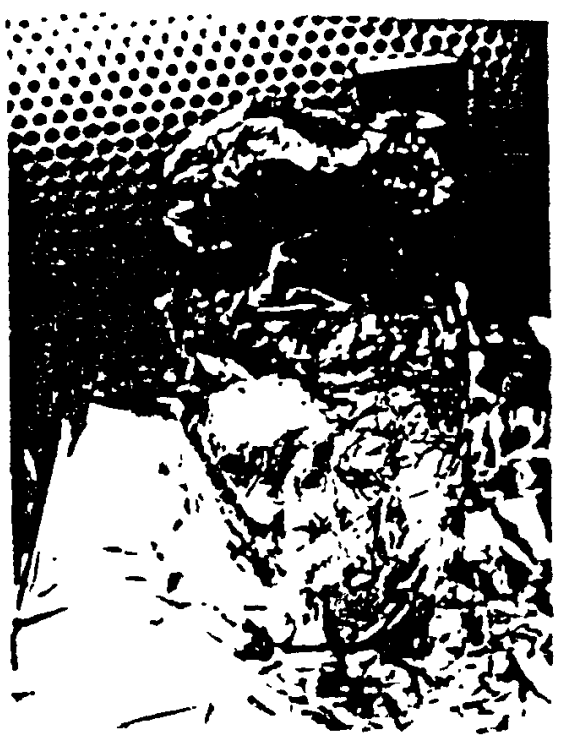

PHOTOGRAPH C. FOIL AND PLASTIC INSIDE CAN 6A

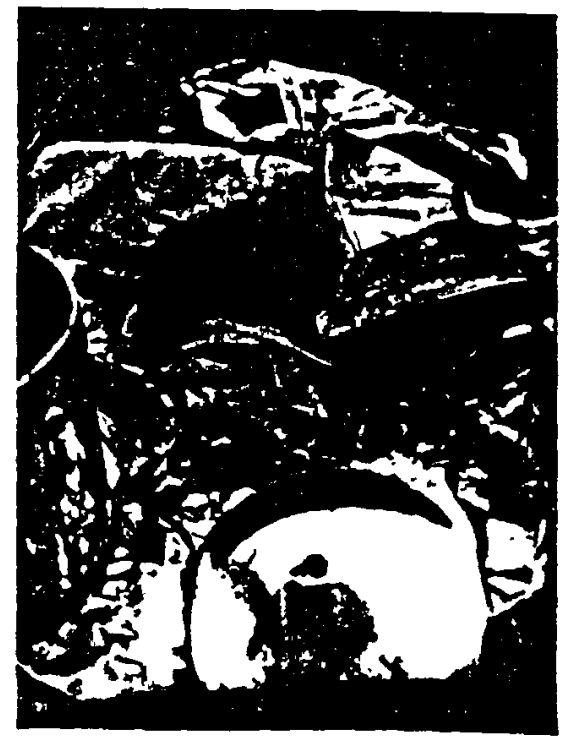

PHOTOGRAPH F. LUMPS IN CAN GA'S PLUTONIUM OXIDE

FIGURE 11. PHYSICAL EVIDENCE EXAMINED IN ROOM 604 
$$
\text { . }
$$ 
extra fold of plastic itself was not especially discolored. Inside the bag was a quantity of loose material; the lid and can were upside down.

The bag was cut with scissors to expose the inner can. Only one bag was present. The lid was resting "half-on" the can with the tape that held the lid in place split at the bottom of the lip of the lid (the inner can had been placed upside down inside the outer can). Examination of the 1id, following its removal, revealed some evidence of attack (discoloration other than that caused by adherent oxide). The special nuclear material seal on the can (and lid) did not appear to have been discolored.

The plutonium oxide outside the can, i.e., the loose material in the bag, contained some large lumps (up to 0.5 inch in the longest direction; Photograph F, Figure 11). These lumps were hard and difficult to break with tweezers. When the plutonium oxide was poured into a new can, many lumps were evident. The self-heating of the plutonium oxide was so severe that the technician needed to put the can down several times during the pouring because the can was too hot to hold. The interior of the can showed no obvious evidence of having been attacked. Neither the can nor the lid appeared to be deformed. No heat-induced discoloration was noted. Later re-examination of the ruptured can disclosed that the lid on the inner can contained scine rust spots along with a considerable amount of shiny metal. The powder poured out of the can looked like reasonably good plutonium dioxide.

Examination of $\mathrm{Can} 6 \mathrm{~B}$ in Room 604

Some observations made during opening the second can, 6B, were:

- The inner can was upside down in the outer can with oxide on the upper surface (which is really the bottom), and the lid was off the can.

- The tape was torn in some spots, but not split cleanly like the tape on can 6A. In some places the tape appeared to have been intact but had become unstuck from the can. The lid was loose on about 80 to $90 \Delta$ of the area; there was only one small area where the tape was still intact between the lid and can. Most of the tape was ruptured lengthwise, around the can at the level of the junction between the top of the can and the can itself. 
- A "worm track" of orange rust was apparent on the bottom of the lid. Some rust deposits were noted on top of the can where the oxide had flaked away (or possibly they were only rust deposits on the surface). The plutonium oxide powder appeared to be dry and free flowing with no evidence at the surface of any large lumps. Lumps were found when the plutonium oxide in the can was poured into a new can. These lumps were comparable in size and number to those observed in the can that ruptured.

- The tape on the plastic bag in which the inner can was bagged appeared to be slightly brittle and not strongly adherent to the plastic. It appeared to be regular masking tape rather than the green cloth tape used in can 6A. The heat seal on the plastic bag appeared to be in good condition.

\subsection{TECHNICAL DATA ACCUMULATED}

Laboratory studies of nonradioactive specimens were conducted to help the Committee understand the observations described in Section 3.4, "Physical Evidence." Plastic discoloration tests indicated a maximum plastic temperature in the ruptured $\mathrm{can}(6 \mathrm{~A})$ of 150 to $160^{\circ} \mathrm{C}$, and a minimum temperature of 120 to $130^{\circ} \mathrm{C}$. The maximum temperature in can $6 \mathrm{~B}$ was somewhat lower, and the temperature was apparently more uniform. Other tests, attempts to pressurize a simulated inner can, were not successful because the seams were not air tight (and some were not even liquid tight). Consequently, simulated total assemblies were prepared, one with moist sand in the inner can and one with an empty inner can. No pressure other than thermal expansion of the gas was observed in the assembly containing the empty inner can after three days at $140^{\circ} \mathrm{C}$, but the assembly containing water was badly bulged and buck led after only 45 minutes at $140^{\circ} \mathrm{C}$.

Temperatures were estimated for the containers inside the 5791 container and for the containers in 303-C storage. Heat transfer calculations indicated an equilibrium temperature of about $139^{\circ} \mathrm{C}$ at the outer can and $156^{\circ} \mathrm{C}$ at the inner can inside a 5791 shipping container, assuming a thermal conduc- 
tivity of 0.05 (Exhibit 4). After these calculations were made, the density of the insulation was measured to be 21 pounds per cubic foot, which corresponds to a thermal conductivity of 0.057 . The temperature would thus be a few degrees lower, but the uncertainties of the calculations did not warrant a repetition at the higher thermal conductivity value. Tests under 303-C storage conditions indicated temperatures corresponding to the inner can would be 129 to $144^{\circ} \mathrm{C}$ (Exhibit 5). Thus, the higher temperature is expected in the 5791 container.

Plastic composition was examined by infrared spectroscopy and found to be a polyvinyl chloride (PVC) with dioctyl phthalate stabilizer (Exhibit 6). Thermally degraded plastic contains more unsaturation than fresh plastic. Literature reports show decomposition to start about $100^{\circ} \mathrm{C}$, and to involve evolution of $\mathrm{HCl}$. However, Exhibit 6 states that the plastic decomposition products alone could not have generated enough pressure (at $130^{\circ}$ to $140^{\circ} \mathrm{C}$ ) to cause permanent deformation of the storage can.

The source of gas pressure inside the container was probably a combination of steam and decomposed $\mathrm{PuO}_{2}\left(\mathrm{NO}_{3}\right)_{2}$ (Exhibit 7). The nitrogen content of one sample was $3335 \mathrm{ppm}$ nitrogen, which would amount to $1.5 \%$ by weight if the nitrogen is present as nitrate. (See Section 4.3 for more detailed information.)

\subsection{DESCRIPTION OF LOSS DUE TO OCCURRENCE}

Personnel contamination and environmental consequences associated with the occurrence are described below. Also included in this section is an assessment of decontamination costs and property loss.

Personnel Involvement

No physical injury occurred to any of the individuals who were performing the storage operation in the 303-C Building when the can ruptured.

The specialist was contaminated on the hand, forearms, upper torso, back of the neck, and face. The maximum contamination level was up to $5000 \mathrm{~d} / \mathrm{m}$ per $100 \mathrm{~cm}^{2}$ on his arms. Other contamination levels ranged from $3000 \mathrm{~d} / \mathrm{m}$ per 
$100 \mathrm{~cm}^{2}$ on his hands to $500 \mathrm{~d} / \mathrm{m}$ per $100 \mathrm{~cm}^{2}$ on his face. The radiation monitor had hand contamination up to $2500 \mathrm{~d} / \mathrm{m}$ per $100 \mathrm{~cm}^{2}$. The senior specialist was subjected to no detectable personal contamination.

The specialist and the radiation monitor were taken to the 325 Building and were decontaminated to less-than-detectable levels. All three individuals were taken to the whole-body counter. (See Exhibit 8 for more detailed information.) No internal deposition was detected. Analyses of urine and fecal samples likewise indicated no internal deposition.

All three individuals had some of their personal clothing contaminated. The clothing was discarded as contaminated waste (Exhibit 8).

There was no indication of unusual external radiation exposure.

Environmental Consequences

An estimated 1.2 to 1.3 millicuries of alpha-emitting transuranics escaped through the gaseous exhaust. The release time was less than an hour, after which an additional HEPA filter was placed over the exhaust port. Air sample results from analyses of samples collected in surrounding facilities that span the time of release show air concentrations of some consequence in the nearest facility downwind. The maximum concentration averaged over one hour was $1.4 \times 10^{-10}$ microcuries per milliliter of alpha-emitting material (see Exhibit 9 for more detailed information). Refer to Section 4.6 for an analysis of environmental release of radioactive materials.

Decontamination Costs and Property Loss

The total estimated cost to decontaminate the 303-C Building and restore it to preoccurrence condition without improvements, disposal of all contaminated residues, or replacement of contaminated property is $\$ 238,000$ (Exhibit 10).

Property loss primarily results from items not considered cost effective to decontaminate, such as shipping containers, desks, chairs, and cabinets. Total cost of these items is $\$ 18,000$. 
Decontamination costs were estimated based on recent experience in decontaminating and restoring other plutonium-contaminated laboratory space. The total estimated cost of decontamination and disposing of all contaminated residues is $\$ 220,000$.

\subsection{RELATED EVENTS}

This section delineates related events that are not in the causal sequence of the occurrence. Related events are discussed because they reveal deficiencies in administration and operations. Analysis of these events is included in Section 4.0 .

Sampling and Analysis of NWVP Plutonium Oxide

After calcining, NWVP operations personnel routinely sent plutonium oxide samples to the Hanford Engineering Development Laboratory (HEDL) for analyses. These analyses were made for verification of packaging criteria and for nuclear materials accountability. The Committee's investigation of sampling and analysis procedures revealed the following:

- Lumps were present in the calcined plutonium oxide powder, but these lumps were not necessarily included in the samples sent to HEDL for analysis. Project procedures do not address any problem with lumps; no procedures specify that personnel should ensure representative sampling.

- The Hanford Engineering Development Laboratory performed the analyses of the material differently than specified in NWVP procedures. They measured the amount of moisture trapped from off-gassing at $400^{\circ} \mathrm{C}$ and reported this as " $\%$ water." The NWVP procedures specified heating the material to $200^{\circ} \mathrm{C}$ for two hours to obtain loss on ignition (LOI) results, and NWVP personnel misinterpreted the " $\%$ water" to be the requested LOI measurement.

- Operations personnel did not wait for analysis results before they packaged and transferred the material to 303-C. No procedures require receiving analysis results before transfer. 
Packaging and Transfer

Packaging and transfer procedures were also examined by the Committee. This study revealed that:

- The inner can (6A) was placed upside-down inside the outer (mechanically sealed) can before loading into the $2 R$ container. No procedures regulate this practice.

- No heat transfer analysis was performed for the loaded transfer container. The cognizant personnel assumed that the material would be transferred to 303-C and unloaded immediately after packaging, but a 12-hour interval occurred between packaging and unloading. No procedure limits the amount of time the material can be kept inside the transfer container. No specifications require heat transfer analysis for the loaded transfer container.
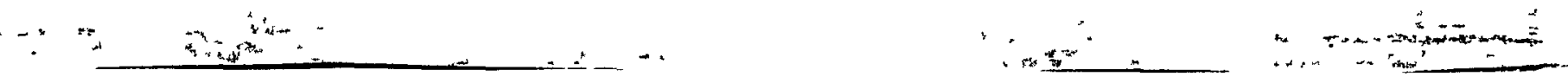


\subsection{ANALYSIS}

The Events and Causal Factors Chart (Figure 12) summarizes the factors discussed in this section. These factors involve: NWVP management, the 303-C Building, the calcining operation, packaging and transfer methods, events during the occurrence, and events after the occurrence.

\subsection{NWVP MANAGEMENT}

Organizational and management systems for the Nuclear Waste Vitrification Project were examined to determine whether certain management decisions or actions could have precluded the occurrence. See Section 3.1 for a description of NWVP management controls.

Disposition of NWVP Plutonium

Particularly relevant to this investigation are the activities and decisions concerning the processing, packaging and disposition of plutonium oxide. from the NWVP. Because many NWVP instrumentation and analytical requirements were contingent on the disposition of the plutonium, NWVP personnel sought agreement on this disposition in order to properly accommodate these requirements in the project. No written record of an approved technical specification consistent with the ASTM or RDT requirements was found. Instead, a by-product specification primarily related to safe storage was established. This specification defined only temperature of calcining, moisture content, and volatility content. However, the sustaining requirement throughout the project was to operate according to the Conceptual Design Report (see Section 3.1); namely, that the plutonium oxide by-product had to be in a form suitable for storage in the 200 Areas or for use in fabrication of mixed-oxide fuel elements.

Had the requirement been formally established to meet either the ASTM or RDT specifications for nuclear-grade plutonium oxide, additional process control requirements and analytical confirmation of by-product quality would 
have been necessary. The absence of technical specifications on by-product quality to meet the above specifications leads the Committee to believe that such requirements were not placed on the project.

The question is, then, whether applying the ASTM or RDT requirements to by-product quality would have precluded the occurrence in 303-C. There is insufficient technical information on the handling and packaging of plutonium from high-exposure LWR fuels to conclude that meeting these specifications would have prevented the occurrence.

NWVP Safety and Security

The importance of safety and security was recognized from the outset of the project. The feasibility assessment document ("Feasibility Assessment Nuclear Waste Demonstration Project - Task 6 - Commercial Nuclear Waste Preparation," July 1, 1976) identified Safety and Security as a major task, with subtasks for Environmental Assessment, Revision or Supplement to Building SAR's, Transfer Cask Safety Analyses, Criticality Control, Operational Safety; and Physical Security. All of these subtask elements were carried throughout the project. Operational safety was reviewed by the Battelle Safety Review Council, an Occupancy-Use Readiness Review team, the HEDL Safeguards Council, and a Senior Advisory Council from the nuclear industry established specifically for the project. Safe operating procedures were developed and approved for all operations. Some reviews were performed before the disposition of plutonium was finalized. It is at least possible (but far from certain) that the reviews would have identified a problem with plutonium transfer and storage if procedures had been defined at the time the reviews took place.

Additional reviews were conducted immediately prior to operations with plutonium, and many items were identified for corrective action (Exhibit 11). of particular concern to this investigation are items relating to calcining, packaging and storing nonstoichiometric oxide (which results in unstable components in the product). Item $F$ of Exhibit 11 cites items to be completed that were identified in a memo titled, "Room 604, 325A Building Readiness Review" (dated December' 7, 1978): "One item states, 'Procedures for safe 
handling of nonstoichiometric oxide must be in place before calcining of plutonium begins." Item $F$ also refers to Item $A$ of Exhibit 11, which cautions that, "The likelihood of obtaining nonstoichiometric oxide product from the calciner is very real. What provisions have been made for handling, further treatment, etc., if this occurs?" The memo described in Item F also states, "Procedures to satisfactorily determine the presence of nonstoichiometric oxide in sealed containers must be in place before calciner operation with plutonium feed."

So far as can be determined, no additional criteria or procedures were developed for the disposition of this item, indicating that NWVP accepted existing criteria and procedures as adequate. That is, NWVP personnel expected that plutonium oxide not within the run plan specification would be recalcined (Exhibit 3 ). Even if the concern over production of nonstoichiometric plutonium oxide had resulted in re-examination of the technical base of the run plan specification, it is unlikely that information would have been found to alter the run plan criteria.

\subsection{SPECIAL NUCLEAR MATERIALS STORAGE FACILITY - 303-C BUILDING}

There were several potential problems associated with use of the $303-C$ Building for receipt and storage of the NWVP plutonium oxide (see building description in Section 3.1). These problems were:

- lack of a controlled environment facility (e.g., hood, down-draft room) for unpackaging nuclear material received into the building.

- placement of the entire ventilation system, i.e., the two HEPA filters, blower and related ducts, inside the building

- current storage of blends 1-5 in the 303-C facility. (Two of these cans are known to be bulged.)

A controlled environment enclosure (a down-draft room) within the 303-C Building would have negated the seriousness of the plutonium oxide contamination resulting from this accident and releases to the environment would 
probably have been at a much lower level. In addition, the risk that employees were subjected to would have been significantly reduced.

Ventilation System Inside the Building

The design of the exhaust ventilation system for the 303-C facility is believed to be responsible for the release of radioactive material to the outside environment. All components of the system are housed inside the building where the airborne release occurred. Since the ventilation system is under a negative pressure differential relative to the room, any leakage into the ducts or blower unit beyond the second-stage HEPA filter escapes directiy to the outside environment. These ducts are normally not air tight. There are unsealed holes, such as ports for conducting tests and measurements, and there are penetrations for the blower shaft. Most of the released airborne contamination probably escaped by these routes.

Current Storage of NWVP Blends

Blends 1-5 are currently stored in the 303-C Building, including two cans of plutonium oxide received from NWVP that are known to be bulged. When the first bulged can was received, NWVP personnel were contacted. Their response was that the can was bulged during packaging-sealing operations because of the excess plastic wrap in the sealed cans. This information lead 303-C personnel to believe that other bulged cans received were bulged because of excess plastic and not because of overpressurization.

Blends 2-5 were packaged and transferred in the same manner as blend 6 , and some of these cans even had longer residence time in the transfer container than did blend 6 . Some of these cans may have ruptured or may rupture in the future. However, two factors tend to lessen the rupture potential for these cans:

1) The plutonium heat generation within these cans is about two-thirds that in blend 6 (j.e., the ${ }^{238} \mathrm{Pu}$ content of blend 6 is approximately twice that of blends 2-5). 
2) The cans are thought to be a good deal cooler in the 303-c concrete storage array than they were inside the thermally insulated container used to transfer the cans from the 325 Building to 303-C.

\subsection{CALCINING OPERATION}

Several factors associated with the NWVP calcining operation have been identified as probable contributors to the accident. These factors involve the:

- less-than-adequate technical information relating to the safe handling and storage of material from the calcining operation

- translation of the available technical information (relating to safety of the calcined material) into the safe operating procedures

- actual final temperature to which the material was heated and the uniformity of heating in the calciner (because temperature of calcining . determines the purity and water content of the material).

Technical Information

Primary contributing factors that led to the pressurization and resultant rupture of the can containing blend $6 \mathrm{~A}$ plutonium oxide were: the industry-wide scarcity and inadequacy of technical information related to calcining, packaging, and storing plutonium oxides from high-exposure power reactor fuel; the inadequacy of the technical information in the run plan for the NWVP calcining operation; and the less-than-adequate translation of available technical information into safe operating procedures intended to ensure the safe handling and storage of the plutonium oxides.

Industry-Wide Technical Information

Less-than-adequate technical information on high-exposure plutonium is a problem for both the nuclear industry as a whole and the NWVP project in particular. Minimal verified technical information on the composition and behavior of the high-exposure plutonium oxide by-product was available at the time blend 6 was processèd. Consequently, calculations and analyses involving this product were based on extrapolations of calculations for different (i.e., lower exposure) material. 
NWVP Run Plan

A technical run plan was developed for the calcining operation (Exhibit 3 ). This run plan specifies that the volatile components of the plutonium oxide should be reduced to "a nominal 1 to 1.5 wt\% loss of weight in two hours at $200^{\circ} \mathrm{C} . "$ The reference given in the run plan as the technical bas is for this requirement is "Measurements Involved in Shipping Plutonium oxide."(a) The specification given in this document states: "The weight percent of volatile components, measured by loss of weight in two hours at $200^{\circ} \mathrm{C}$ in dry ( $<5^{\circ} \mathrm{F}$ dew point) dynamic atmosphere, shall not exceed one percent." This statement is accompanied by the following comment: "It has been our experience that this requirement. can be met by calcination at $400^{\circ} \mathrm{C}$ if sulfate anions are absent." Although the controlling thermocouple in the NWVP calciner was set at $450^{\circ} \mathrm{C}$, the actual temperature obtained and the uniformity of heating of the material is unknown.

Post accident measurements, experiments, and calculations (Exhibits 4, 5 and 6) revealed a probable mechanism for container pressurization. The pastulated mechanism involves the production of a plutonium oxide product that was nonstoichiometric. The HEDL analysis of blend 6B revealed that this product contained about $1 / 2$ to $1 \%$ water and approximately $3300 \mathrm{ppm}$ of nitrogen. If the nitrogen was in the form of $\mathrm{PuO}_{2}\left(\mathrm{NO}_{3}\right)_{2}$, an intermediate compound believed to be formed during the thermal decomposition of plutonium nitrate at $190-280^{\circ} \mathrm{C}$ (as reported by G. H. Bryan, et al., in BNW-1941, p. 20), the reaction for decomposition to $\mathrm{PuO}_{2}$ follows the equation

$$
\mathrm{PuO}_{2}\left(\mathrm{NO}_{3}\right)_{2} \stackrel{\triangle}{\rightarrow} \mathrm{PuO}_{2}+2 \mathrm{NO}_{2}+\mathrm{O}_{2}
$$

The amount of gaseous products produced by heating the contents of $6 B$ to convert it all to plutonium oxide would exert a pressure of about 206 pounds per square inch absolute within the free volume of the outer can $(=900 \mathrm{ml})$. Similarly, for 1289 grams of plutonium oxide containing $0.43 \%$ water 10.31

(a) Byrne, J. T., et al., Measurements Involved in Shipping Plutonium Oxide. RFP-502, Dow Chemical Company, Rocky Flats Division, August 10, 1965, p. 13. 
moles), the water vapor pressure, upon heating, would exceed the estimated pressure of 60 pounds per square inch gage needed to rupture the can. This content of gaseous products and water is significantly less than the $1.5 \%$ of volatile components that is allowed for the by-product plutonium oxide as specified in Exhibit 3. Consequently, if the material was heated to high enough temperatures, either the water or nitrate could have furnished sufficient pressure to rupture the storage cans.

Heating of the plastic wrapping material and the tape revealed that insufficient decomposition products were formed from these sources to significantly affect the pressure inside the can. See Exhibit 6 .

Translation of Run Plan to Safe Operating Procedures

Another factor related to problems with technical information is that the technical information included in the run plan (Exhibit 3) was not faithfuliy translated into the safe operating procedure (Exhibit 12). Samples of the calcined oxide from the blending operation were routinely sent to HEDL for analysis. This analysis was to determine the loss on ignition (LOI) at $200^{\circ} \mathrm{C}$ for 2 hours and also at $950^{\circ} \mathrm{C}$. This latter measurement was needed for nuclear material accountability. Unknown to NWVP operations, HEDL made the analysis using a procedure HEDL had devised for other fuel materials. Instead of determining the LOI at $200^{\circ} \mathrm{C}$ for 2 hours, they measured the amount of moisture trapped from off-gassing at $400^{\circ} \mathrm{C}$ and reported this as " $\mathrm{W}$ water" along with the $950^{\circ} \mathrm{C}$ LOI value. The NWVP personnel interpreted the " $\%$ water" to be the requested LOI at $200^{\circ} \mathrm{C}$ for 2 hours. The " $\mathrm{z}$ water" values for the NWVP pluto$n$ ium oxide ranged from 0.30 to 0.61 , thus leading NWWP personnel to conclude that the material was well within the run plan specification.

This discrepancy was discovered after the accident at 303-C Building. Following the accident, the LOI was determined at $200^{\circ} \mathrm{C}$ for 2 hours on the original sample of the $6 \mathrm{~B}$ blend and was found to be $1 \%$. The sample of can $6 \mathrm{~B}$ material was, therefore, within the $1.5 \%$ limit specified in the run plan. It is, therefore, probable that the other plutonium oxide blends are also within 
the 1.5\% LOI 1 imit. It is concluded that although the HEDL error in the analysis procedure had a potential for serious consequences, it did not contribute to the accident at the 303-C Building.

Another deficiency that also could have had serious consequences, but did not cause this accident, was the packaging and transfer of the plutonium oxide to the 303-C facility before receipt of HEDL's analysis on the material. By transferring the material before receiving HEDL's analysis results, NWVP personnel demonstrated that they did not recognize the importance of the LOI specifications to the safe packaging and storage of the material. However, the safe operating procedure did not require waiting for the HEDL results. Nonuniform Heating in the Caiciner

As stated in Section 3.2, "Chronology of Events," a ceramic coating had been observed in the calciner, between the controlling thermocouple and the plutonium powder. This observation leads to the conclusion that the plutonium was not uniformly heated to $450^{\circ} \mathrm{C}$ or over, as specified in the run plan . (Exhibit 3). Supporting evidence for this conclusion includes:

- Lumps were observed in the material; the lumps were probably not heated through to the center.

- The loss on ignition at $200^{\circ} \mathrm{C}$ was greater than the moisture content.

- The average residence time in the calciner is unknown and was not specified in the SOPs. Therefore, the residence time of all of the material was not necessarily the same.

- The controlling thermocouple showed fluctuations in temperature.

The presence of lumps in the powder is significant because it is probable that, inside the lumps, the material was not heated to $450^{\circ} \mathrm{C}$. This nonuniform heating would have allowed more water and nitrates to stay in the material, available to evolve gases when heated inside the transfer container and to cause overpressurization.

Sample selection for HEDL analysis of the plutonium by-product tended to eliminate lumps from the samples. If the lumps were not analyzed, results of the analysis were not representative of the material as a whole. It is 
likely that there were more water and other impurities inside the lumps than in the fine powder material that was more uniformly heated.

The fact that the loss on ignition (LOI) at $200^{\circ} \mathrm{C}$ was greater than the water content is significant because it supports the theory that there were nitrates as well as water present in the material. As discussed previously and detailed in Exhibit 7, this material was probabiy $\mathrm{NO}_{2}$ and $\mathrm{O}_{2}$. In combination with vaporization of water, these compounds could have evolved enough gas to rupture the container.

The average residence time in the calciner is important because, if some of the material was in the calciner for a short time, that material would not have been jroperly heated to $450^{\circ} \mathrm{C}$. Again, if the material was not heated to at least $450^{\circ} \mathrm{C}$, it probably contained too much water, $\mathrm{NO}_{2}$, and $\mathrm{O}_{2}$.

The fact that the controlling thermocouple showed fluctuations in temperature is another indication that the material may have been improperly. heated. Improper heating, for any or all of the above reasons, could have left enough volatile material in the calcined plutonium oxide to cause container overpressurization.

\subsection{PACKAGING AND TRANSFER METHODS}

Analysis revealed that several factors associated with packaging and transfer could have contributed to causing the occurrence. These factors include design of the container, placement of cans inside the container, the change to high-exposure material, lack of heat transfer analysis, and length of time the material was stored in the transfer container.

Design of Container

The design of the plutonium oxide storage container is depicted in Figure 6. As the illustration shows, the inner can is taped shut; bagged in heavy plastic, which is then tightly taped around the can; covered with aluminum foil; and placed in a larger can, which is mechanically sealed. The inner can with its slip-fit lid is always bagged out of the glove box to prevent any escape of contamination. 
The aluminum foil was wrapped around the can and plastic for the purpose of conducting heat away from the can. However, it now appears that the foil may have served to reflect heat back into the can. This heat reflection may have contributed to the postulated buildup of excessive heat, and the resulting vaporization of impurities and water in the plutonium oxide.

Placement of Cans Inside the Container

Another packaging condition that may have contributed to the severity of the material dispersion was the orientation of the inner can in relation to the outer can. Upon examination, investigators found that both $c$ ans $6 \mathrm{~A}$ and $6 \mathrm{~B}$ were assembled with the inner can upside-down in the outer can (see Figure 6 ). While this orientation probably did not affect the pressure buildup, it could have resulted in the dispersion of more powder when the rupture did occur. This is postulated based on the premise that the buildup of pressure in the inner can had to be relieved through the powder to escape to the outer can and, consequently, to the room environment. Pressure relief through the powder would tend to entrain powder in the escaping gas stream, which compounded the release. It is significant that there were no procedures specifying the orientation of the inner can.

Packaging of High-Exposure Material

Between the handing of blends 2-5 and the blending of blend 6 , a significant change occurred; i.e., blend 6 contained higher exposure material than the previous blends $(29,500 \mathrm{MWd} / \mathrm{tU}$ versus $20,500 \mathrm{MWd} / \mathrm{tU})$. Blend 6 fuel received more irradiation (exposure) in the reactor; therefore, the ${ }^{238} \mathrm{Pu}$ content of the higher exposure fuel was about twice that in the lower exposure material. The larger fraction of ${ }^{238} \mathrm{Pu}$ increased the heat-generation rate of the calcined powder in blend 6 by about $50 \%$ compared with the heat-generation rates of blends $2-5$.

Heat Transfer Analysis

Before the transfer of any plutonium oxide by-product, a heat transfer analysis was performed for the mechanically sealed can, but no analysis was requested or performed for the fully loaded and insulated 5791 transfer drum. The lower exposure by-product material that was transferred previously may not 

strength to the can to prevent its rupture. There is also the slight possibility that the metal can had already been ruptured but the interior plastic bag had not. In this situation, the bag would have protruded out of the rupture opening and may have been "nicked" by the foil during unwrapping of the can.

The personnel involved in the unpackaging immediately evacuated the 303-C facility when the rupture occurred. Their quick response to the situation prevented any detectable internal deposition of plutonium. Involvement of less well-trained and prepared personnel might have resulted in more serious consequences.

\subsection{EVENTS AFTER THE OCCURRENCE}

Events after the occurrence are shown in Figures 13,14 and 15. In the following discussion, personnel protection, environmental protection and evidence recovery and protection are analyzed.

Personnel Protection

No detectable internal deposition of plutonium occurred to any of the individuals immediately involved in the incident. The prompt evacuation of these people, taking the path that would most likely keep them out of the plutonium contamination cloud, undoubtedly prevented any significant intake of plutonium aerosol. The action of these individuals was commendable.

The immediate action of the radiation.monitor minimized contamination spreads. Finding the protective clothing supplies that were supposed to be available in the event of a problem unusable could have been serious. However, in this incident, no serious problems resulted.

Environmental Protection

There was apparentiy no measurable internal deposition of plutonium to employees working in the vicinity of the 303-C facility or to the public. Calculations using the assumptions shown in Exhibit 14 show that potential lung radiation exposures could have been as high as 0.64 rem to employees and 0.0084 rem to transient members of the public. The highest air concentration 
averaged over an hour measured in the nearest building downwind from the release ( 3708 Building) was $1.4 \times 10^{-10}$ microcuries per milliliter of alpha-emitting material (Exhibit 15). If an individual was in this location where the high air concentration persisted, the calculated lung dose could be as high as 0.14 rem (Exhibit 14). This can be compared with the allowable annual lung dose for radiation workers, which is 15 rem.

There is no evidence that any significant release occurred after the first HEPA filter was placed over the exhaust port.

Contamination Status of the 303-C Building and Vicinity

Preliminary survey information indicated that on the order of 1 gram of plutonium oxide was dispersed throughout the 303-C Building. Horizontal surfaces were highly contaminated. Vertical surfaces and ceiling were contaminated to a much lower degree or were not contaminated.

The few low-level contaminated spots outside the building were removed on the day of the incident. Following these decontamination efforts, no detectable contamination existed outside of the facility.

Evidence Recovery and Protection

The preparation, procedure review and performance during picture taking and recovery of the blend 6 cans was satisfactory. No contamination occurred beyond radiation zones. The cans were removed and transported to a glove box in the 325 Building, where their contents were examined and appropriate pictures were taken according to procedure and without incident. 
$$
\text { . }
$$ 

$$
\text { . }
$$ 



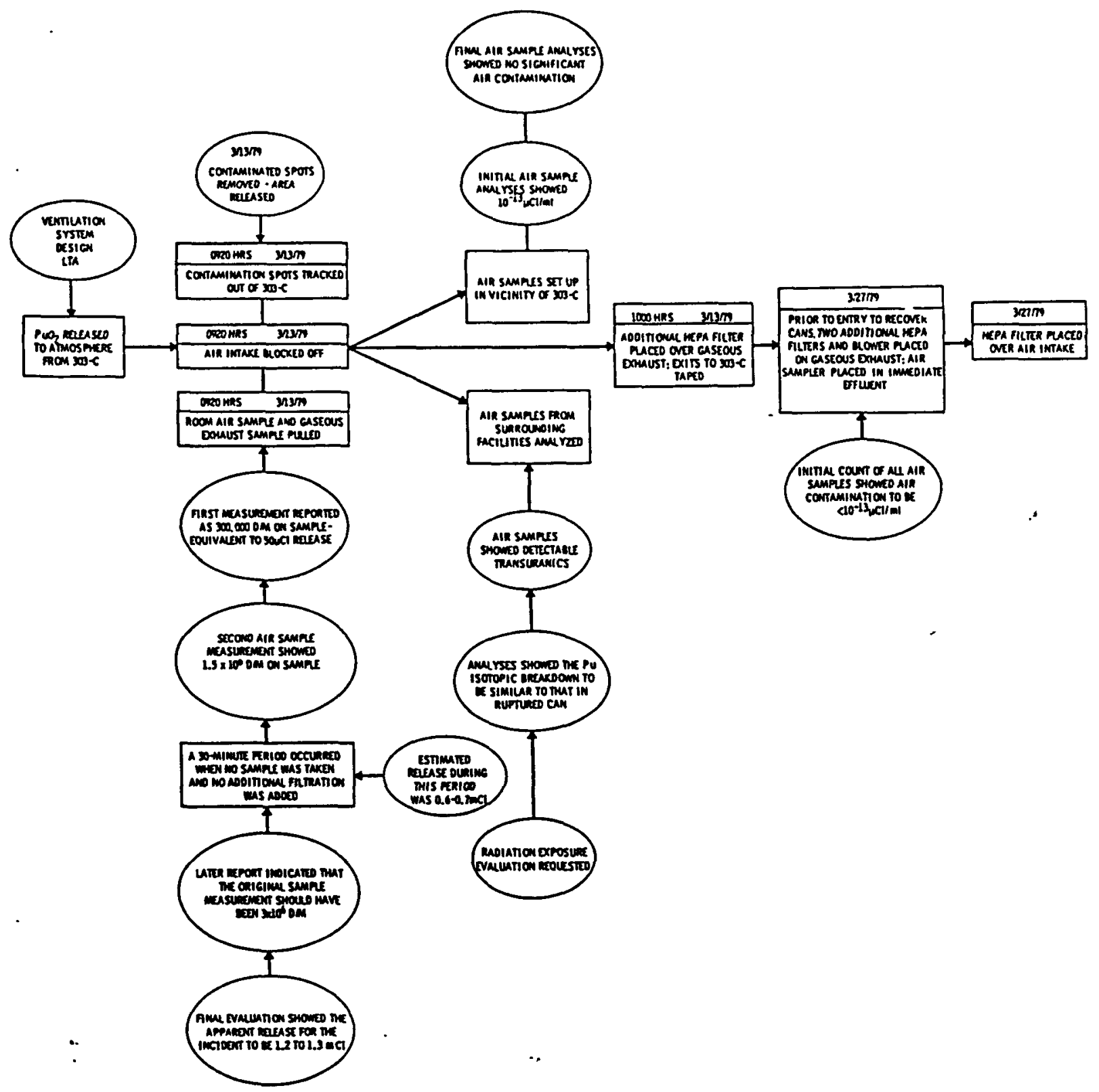

FIGURE 14. Environmental Protection Events and Conditions 


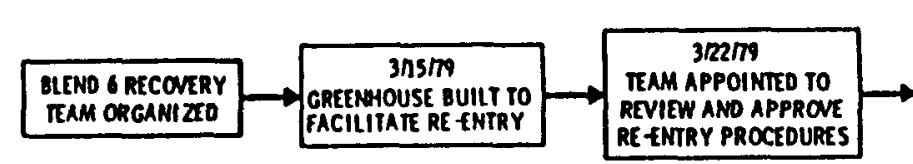

3RIIT9
TWO EMPLOYES ENTTRED
3OJ-C AND REMONED 2R
CONAINERS WITN BOTH
BLEND G CANS INSIDE

\begin{tabular}{|c|}
\hline 3RT79 \\
CONTAINER TAKEN IO \\
33: BIEND 6 CANS \\
SEALED IN GLOVEBOX \\
\hline
\end{tabular}

328/79
BLEND CANS OL AND 6B
OPENED FOR INS PECTIONN

IMVESTIGATING COMMITIEE REQLESTEO STUDIES TO

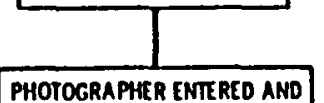

XS: BIEND 6 CANS

OPENCD FOR INSPECTION

AID IN DEITRMIMATIOO

PHOTOGRAPHER ENTE RED AND

TOOK PICTURES BEFORE AND

6 CONTAINERS

PHOTOGRAPIER TOO

PICTURES DURING

OPENING AND INSPECTION

OF THE CANS

FIGURE 15. Evidence Recovery and Protection Events and Conditions 
$$
\text { . }
$$ 


\subsection{CONCLUSIONS}

This section includes findings, probable causes and contributing factors, and judgements of needs.

\subsection{FINDINGS}

1. No technical requirements were formally established to meet either the ASTM or ROT specifications for plutonium products. A by-product specification relating only to temperature of calcining, moisture content and volatility content was established. There is insufficient technical information on the handling and packaging of plutonium oxide derived from high-exposure LWR fuel to conclude that meeting those specifications would have prevented the occurrence. Had the re-reviews prior to startup (see Item F, Exhibit 11) disclosed unmanageable handling and storage problems, more stringent criteria and specifications may have been developed, which might have precluded the accident.

2. The Pacific Northwest Laboratory's criteria for the safe transfer and storage of the by-product were based on less-than-adequate technical information. Many of the identified problems related to the plutonium by-product stream were not fully evaluated, and resolution of the problems was therefore not incorporated in technical guidance, operating procedures and controls.

3. The 303-C Building has inadequate contamination control features for managing failed packages releasing aerosols.

- The exhaust ventilation system is not adequate to prevent leaks of contamination to the environment.

- Contamination control systems are not adequate, e.g., no air locks exist, no compartmentalization either by air flow or by physical barriers is provided, etc. 
4. Nuclear Waste Vitrification Project by-product blends 1-5 are currently stored in the 303-C Building. Two of these cans are known to be bulged. Blends 2-5 consist of high-exposure material but of a lower level than blend $6(20,500 \mathrm{MWd} / \mathrm{tU}$ versus $29,500 \mathrm{MWd} / \mathrm{tU})$. It is possible that some of the cans currently in storage may have ruptured or may rupture in the future.

5. Product calcination may not have been complete, since the residence time in the calciner was unknown, the buildup of plutonium oxide on the trough floor inhibited heat transfer, and the product temperature was unknown. The length of time the product was at a specific temperature or higher was also unknown.

6. Analytical techniques specified by PNL were not used by HEDL; instead they used a technique that had been devised for other work. Pacific Northwest Laboratory did not verify that prescribed techniques :yere used by HEDL.

7. The technical input to the product sampling procedure was inadequate and, since sampling methods were poorly specified, representative samples may not have been collected. Consequently, the analyses for moisture content and other impurities may have been in error and misleading.

8. The procedure did not require sample analys is for moisture content to be received and evaluated before the plutonium oxide was transferred to the storage facility. Consequently, there was no assurance that specifications were met.

9. The plutonium isotopic composition communicated to the engineer performing the safety analysis for transfer and storage did not reflect the actual isotopic composition of the NWVP by-product.

10. The expected equilibrium temperature of the plutonium oxide packaged in the container, was not determined. Therefore, the consequences of internal heating were not evaluated.

11. Some observations of unusual conditions were not acted upon. 
12. The heat generated by blend 6 material during a 12-hour period in the insulated transfer container caused a high enough temperature to pressurize and rupture the $6 \mathrm{~A}$ storage container. The pressure resulted from vaporization of the moisture content and/or $\mathrm{NO}_{2}$ and $\mathrm{O}_{2}$ formation from the residual $\mathrm{PuO}_{2}\left(\mathrm{NO}_{3}\right)_{2}$. The storage container rupture occurred even though the moisture and other impurity specifications had been met.

13. The protective equipment supplies stored in the vicinity of $303-C$ Building were not usable.

14. The action taken by the people in the 303-C Building after the can rupture occurred was proper and prevented any of the three from incurring measurable internal deposition.

15. No violations of approved safe operating procedures were found.

16. The maximum potential radiation exposure to employees or members of the public did not exceed applicable radiation exposure limits.

17. Recovery of the blend 6 cans and examination of the contents were performed without incident.

\subsection{PROBABLE CAUSES ANO CONTRIBUTING FACTORS}

Heat buildup in an insulated transfer container, generated from radioactive decay and chemical reaction, led to pressurization of sealed cans containing plutonium oxide. The pressurization was due to 1) release of gaseous products from thermal decomposition of the plutonium oxide and 2) steam pressure from liberated moisture content of the plutonium oxide. The rupture of the sealed can resulted in severe contamination of the 303-C Building and minor contamination of personnel.

Contributing factors were:

1) less-than-adequate knowledge of the material temperature profile in the loaded transfer container 
2) lack of technical information concerning the packaging, transfer and storage of plutonium oxide

Factors that contributed to the severity of the incident were:

1) lack of a controlled environment enclosure in the 303-C faciijty for unpacking materials received into the facility in case of a breached package

2) poor design of the ventilation system at the 303-C facility, which permitted escape of material around the filter system.

\subsection{JUDGEMENTS OF NEEDS}

1. An appropriate technical data base should be established, from which technical specifications should be written for handling, shipping and storing of plutonium oxides.

2. It should be reaffirmed that, when problems are identified that might . cause incidents with serious consequences, the risks must be evaluated and appropriate action taken. The understanding that cost and schedule pressure must not be allowed to downgrade this requirement should be promoted.

3. The 303-C Building should be upgraded or replaced to assure adequate contamination control capability.

4. By-product blends now stored in the 303-C facility should be removed as soon as practicable for examination and further treatment as necessary to assure the material has adequate storage characteristics.

5. Any future calcination work should proceed only after the development of good technical specifications and the establishment of adequate analytical techniques to verify that the product meets the specifications.

6. Use of specified, proper analytical techniques should be verified. 
7. Procedures should be upgraded to include proper instruction for obtaining representative by-product samples.

8. Transfer of by-product material should not proceed until analytical results have been evaluated to confirm product specifications have been met.

9. When actual isotopic compositions are known, the safety analyses should be reviewed to verify that their bases are conservative.

10. Complete safety analyses should be conducted for all aspects of transfer and storage of self-heating materials. The results of these analyses should be used to establish limits to preclude overheating and overpressurization accidents.

11. Protective equipment supplies should be stored in locations or containers that protect the equipment. Routine inspections should be conducted to determine that the material is in usable condition.

12. Requirements to report observations of unusual conditions should be included in training programs and operating instructions. 
$$
\text { . }
$$ 
6.0 SIGNATURES
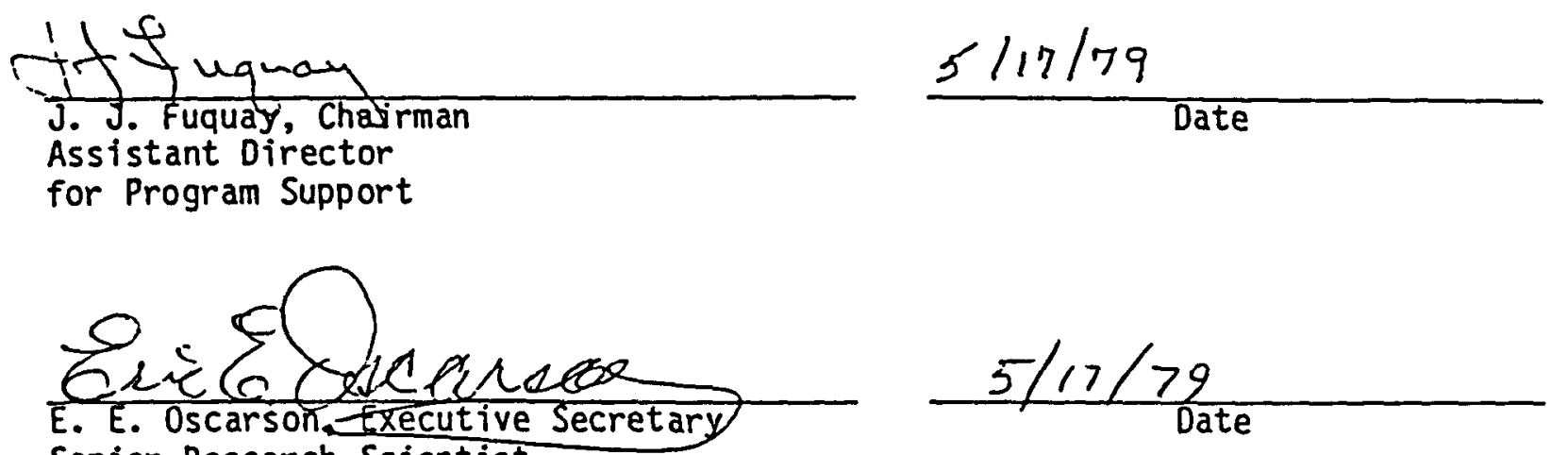
Senior Research Scientist Occupational and Environmental Safety
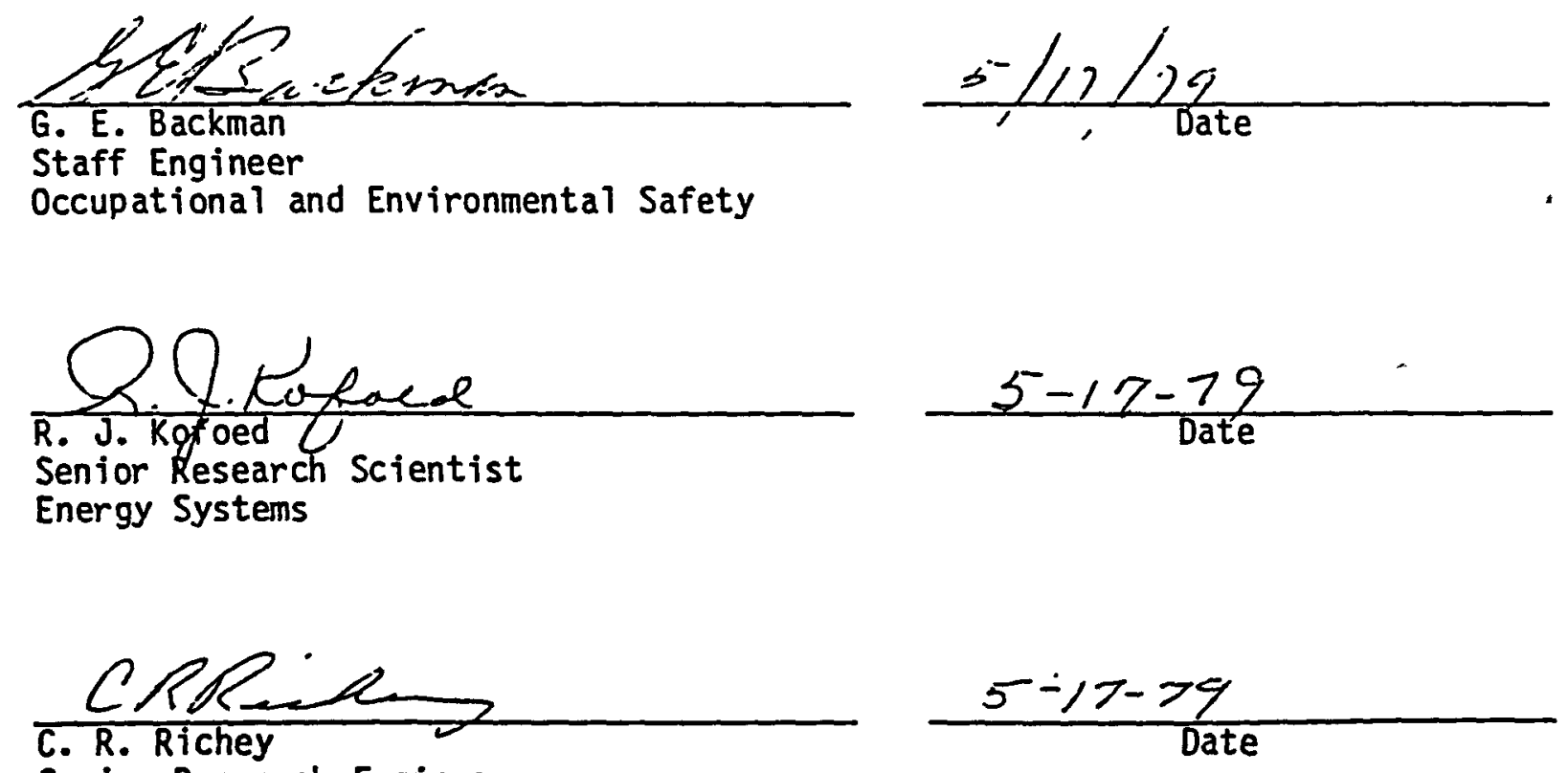
Senior Research Engineer Occupational and Environmental Safety 
$$
\text { . }
$$ 


\subsection{BOARD AUTHORITY}

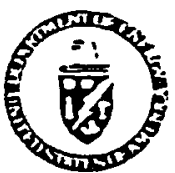

Department of Energy

Richland Operations Office

P.O. Box 550

Richland, Washington 99352

APR $\& 1979$

Dr. T. W. Ambrose, Director

Battelle Memorial Institute

Pacific Northwest Laboratory

Richland, Washington

Dear Dr. Ambrose:

303-C BUILDING OCCURRENCE, MARCH 13, 1979

In accordance with Manual Chapter 0502, I am appointing an accident investigation board to investigate for this office the subject occurrence. The following employees of Pacific Northwest Laboratory are to serve on this board.
J. J. Fuquay, Chairman
E. E. Oscarson, Executive Secretary
G. E. Backman
R. J. Kofoed
C. R. Richey

I am also appointing Mr. G. R. Yesberger, RL, to provide liaison between $R L$ and the investigation board; he is to officially represent RL in maintaining cognizance of the progress of the investigation, but' he is not a member of the board.

The investigation is to be conducted in accordance with Manual Chapter 0502, and the report of the investigation board is to be submitted to me within 30 days of receipt of this letter. The report should fully explain the technical elements of the causal sequence and describe the management systems which should have, or could have, prevented the occurrence. 
The Accident/Incident Investigation Manual (ERDA 76-20) is to be used for guidance in the conduct of the investigation and preparation of the report. Appropriate recomendations for improvement of the management systens will be required.

SAF :MFM

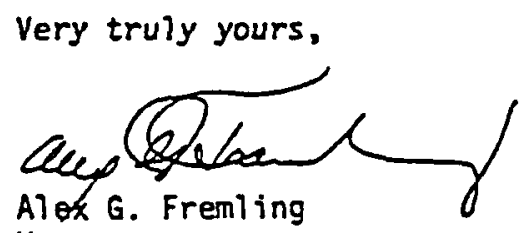

CC: J. J. Fuquay

E: E. Oscarson

G. E. Backman

R. J. Kofoed -

C. R. Richey

Manager 


\section{ACKNOWLEDGEMENTS}

The Investigation Committee wishes to express its appreciation for the fine cooperative spirit and responsiveness of all persons touched by this investigation. The full freedom extended the Comittee to conduct the investigation in its own style is gratefully acknowledged.

Consultive participation by individuals at Rockwell Hanford Company, Hanford Engineering Development Laboratory, Savannah River Plant, Rocky Flats, Mound Laboratory and the Department of Energy was particularly valuable, providing needed technical and experiential information.

Particular appreciation is expressed for the excellent technical resource support provided by Harold Van Tuyl and editorial publishing support provided by Linda Jaech, her colleagues, and other Communications Department staff. 
$$
\text { . }
$$ 
;

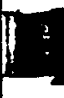


$$
\text { . }
$$ 
EXHIBIT 1. Memo Appointing PNL's Class C Investigation Committee

* Battelle

Pacific Northwest Laboratories

Dale March 14, 1979

To Harold Van Tuyl

From SoTominy Ambrose

Subject INVESTIGATION OF OCCURRENCE IN 303-C ON MARCH 12,1979

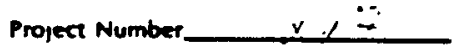

Internal Distribulion

Committee Members Directors' Council

HL Henry

JE Minor

CM Unruh

You are hereby appointed as Chairman of a committee to investigate an occurrence in 303-C Building. The following additional staff members are appointed as members of your comittee:

Eric Oscarson, Executive Secretary

George Backman

Ray Kofoed

Cliff Richey

Jim Fuquay

The investigation should attempt to establish the cause of the occurrence and the report should contain specific recommendations relative to the occurrence and any generic judgment of needs. Close coordination with the recovery team should be maintained to preserve or acquire data needed for your analysis.

In view of the fact that the incident may become classified as a Class $B$ incident, your investigation approach and report should lend themseives to the needs for that type of incident.

Please let me know when your final report can be expected. 

EXHIBIT 2. Letter Approving the 303-C Building as a

Plutonium Storage Facility

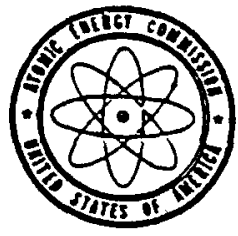

\author{
UNITED STATES \\ ATOMIC ENERGY COMMISSION \\ MICHLAND OPERATIONS OFFICE \\ P. $0.80 \times 530$ \\ RICHLAND, WASHINGTON 99332
}

atsin - WSR

FEB 131974

Battelle Memorial Institute

Pacific Northwest Laboratory

ATTN: Dr. E. L. Alpen, Director

Richland, Washington

Gentlemen:

BNWL-B-321 - SAFETY ANALYSIS REPORT - 303-C BUILDING

RL has reviewed the subject report and approves operation within the envelope of the SAR, subject to the following restrictions:

1. The 303-C Building should now be classified as a permanent storage facility, and this designation should be reflected in the title of the report.

2. A specific description of the "severe tornado" and the "most severe tornado" should be included.

3. The analysis conducted to establish location of the criticality detectors and alarm system needs to be referenced or included in the report.

4. The report should include statements which will justify that protection of the exhaust filters against a possible fire is not necessary.

5. The SAR should establish minimum packaging standards for all plutonium (other than clad fuel elements) of no less than a plastic bag inside either two tape-sealed metal cans or a single mechanically sealed can (or equivalent protection).

6. The SAR should include a discussion of potential dose rates and exposures to building occupants, including the method whereby BNW will keep exposures to as low as practicable. 


\section{EXHIBIT 2. Cont'd}

Pacific Northwest Laboratory

ATTN: Dr. E. L. Alpen

You are hereby authorized to receive material in the 303-C Building providing the condition of item 5 above is met. Unrestricted approval of the SAR will be granted pending satisfactory completion of the above-mentioned six items.

SQA :DWT

Very truly yours,

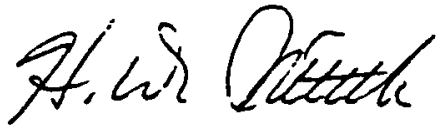

H. D. Smith, Director Contracts and Procurement Division 


\subsection{BY-PRODUCT PUO 2}

\subsection{INTRODUCTION}

Plutonium from the Waste Preparation Task is a by-product; the directcalcined plutonium oxide resulting from the operations will be eventually transferred to HEDL for use in the ROD Fuel Development Program. $(7,2)$ The flowsheet provides for plutonium purification and solidification so that it can be packaged, handled, transported and stored safely; although it is expected to be quite pure, there are no purity requirements for the plutonium oxide, per se. The following safety requirements are the only requirements placed on the Pu produced.

- Criticality Safety Specifications 325-1.3 and 325-1.4 and Criticality Safety Procedures (BNWL-MA-25) deal with the criticality safety aspects.

- Radiation Work Procedures for 325-A Building and Radiation Protection Manuals (BNLL-MA-3 and 6) deal with the personnel radiation protection aspects.

- Storage requirements, including safeguards and contamination barriers, are defined in ERDA-RL Manual Chapters 0529, 2405 and 7401 .

- Shipping requirements are defined in ERDA-RL Manual Chapter 0529 for onsite shipments and in the Code of Federal Regulations, Title 49, for offsite shipments. The Radioactive Materials Shipping Manual (BNWL-MA-81) covers both onsite and offsite requirements for shipping plutonium, including safeguards requirements.

This section sumarizes the various safety-related aspects about $\mathrm{PuO}_{2}$ by-product handling for the Waste Preparation Task. Section 7.3 deals with the SNM Accountability and Safeguards aspects.

(1) Letter, R. P. Saget to J. W. Finnigan, "CNWV Project - Disposition of Plutonium Oxide," July 1, 1977.

(2) Letter, J. W. Finnigan to R. P. Saget, "CiWW Project - Disposition of Plutonium Oxide," July 13, 1977. 


\section{EXHIBIT 3. Cont'd}

\section{$5.2 \mathrm{PUO}_{2}$ CHARACTERISTICS}

For purposes of conservatism in radiological safety matters, the highest exposure $\mathrm{Pu}$ which might be processed in the Waste Preparation Task factlities was selected for calculation of the $\mathrm{PuO}_{2}$ characteristics. (3) The following isotopic composition was assumed for the $\mathrm{PuO}_{2}$ :

\begin{tabular}{cr} 
Pu Isotode & : \\
\hline 238 & 1 \\
239 & 55 \\
240 & 26 \\
241 & 13 \\
242 & 5
\end{tabular}

The radiological and thermal implications are addressed in the next section on packaging and handling.

The physical properties of the direct-calcined $\mathrm{PuO}_{2}$ are dependent on time-at-temperature conditions. Development work ${ }^{(4)}$ on the screw calciner operating at a maximum temperature of $400^{\circ} \mathrm{C}$ yielded $\mathrm{PuO}_{2}$ with the following compositions:

$$
\begin{array}{ll}
\text { Density (Bulk) } \mathrm{g} / \mathrm{cm}^{3} & 2.2-3.7 \\
\text { Chenical Analysis } & \\
: \mathrm{Pu} & 78-87 \\
: \mathrm{NO}_{3}^{-} & 2-5 \\
: \text { Volatiles } & 3-10
\end{array}
$$

Particle Size

Tyler

$\begin{array}{ccc}\begin{array}{c}\text { Equivalent } \\ \text { Designation } \\ \text { Mesh }\end{array} & & \begin{array}{c}\text { Ntt: } \\ \text { Retained }\end{array} \\ 20 & & 5.8 \\ 35 & & -. \\ 65 & & 6.4 \\ 150 & & 36.4 \\ 270 & & 27.0 \\ 400 & & 19.1 \\ >400 & & 5.3\end{array}$

(3) Letter, J. M. Taylor to E. R. Irish, "Storage and Shipping of $\mathrm{PuO}_{2}$ Produced from the CNWVP," June 22, 1977 (and May 25, 1978 revision).

(4) Felt, R. E., Eouioment for the Oirect Calcination of Plutonium Nitrate, RL-SE?-6i4, Haniord Atomic Producis Operation, Richland, Wasnington, December, 1965, p. 31 . 


\section{EXHIBIT 3. Cont'd}

The aim of this work was to obtain a reactive $\mathrm{PuO}_{2}$ for fluorination, not a stable product. For our purposes, the aim is to obtain a calcined $\mathrm{PuO}_{2}$ low enough in nitrate and water for safe storage; thus, a higher calctnation temperature (i.e., $450-500^{\circ} \mathrm{C}$ ) will be used.

If the $\mathrm{PuO}_{2}$ were to be packaged in weided, unvented cans, the nitrate and moisture contents of the oxide would need to be reduced to $<1.5$ wt: loss of weight in two hours at $800^{\circ} \mathrm{C}(5)$ to prevent rupture of the can due to pressure buildup from themal and radiolytic processes. However, with the packaging system described in the next section, these volatile components need only be reduced to a nominal $I$ to 1.5 wt: loss of weight in two hours at $200^{\circ} \mathrm{C}$ ( ${ }^{(6)}$ This condition should be reached with operation of the calciner outlet control temperature in the range of $450-500^{\circ} \mathrm{C}$. If the $\mathrm{PuO}_{2}$ volatile components exceed 1.5 wts, the oxide should be recycled through the calciner again. If the volatile content of the oxide is found to be a result of absorption of moisture from the glove-box, the atmosphere in the glove-box may have to be controlled at a lower humidity. These factors will need to be determined during startup operations, with operating conditions adjusted appropriately thereafter.

\section{$5.3 \mathrm{PUO}_{2}$ PACXAGING AND HANOLING}

The $\mathrm{PuO}_{2}$ will be stored initially in the 303-C Building nuclear materiais storage facility; this facility meets safeguards requirenents specified by DOE. The facility contains horizontal tubes, 8-in. I0 and 83-in. long, into which storage cans are placed. Adequate space is presently available for several years of operation. The current Criticality Safety Specifications limit the amount of $\mathrm{PuO}_{2}$ to $5.2 \mathrm{~kg}$ per storage tube. The $\mathrm{PuO}_{2}$ must be stored in four batches not exceeding $1.3 \mathrm{~kg}$ per batch. Each batch must be separated by at least a foot within the tubes.

(5) Byrne, J. T., et.al., Measurements Involved in Shipping Plutonium Oxide, RFP-502, The Dow Chemical Company, Rocky flats Division, 10 August 1965, p. 13.

(6) Personal communication, R. E. Felt, Rockwell Hanford Operations, March 10, 1978. 


\section{EXHIBIT 3. Cont'd}

Storage safety requirements require the $\mathrm{PuO}_{2}$ to be confined at least within two barriers. $\mathrm{PuO}_{2}$ has been stored in metal cans for long periods of time without deleterious effects. The cans are made from tin-coated steel plate, usually 0.011-in. to 0.014-in. thick.* A convenient size container for packaging $1.3 \mathrm{~kg}$ of oxide is a 3-1/2-in. dta $\times 3-1 / 2-\mathrm{in}$. high metal can. Filled with $1.3 \mathrm{~kg}$ of oxide, the can will be about $80 \%$ full. This size can can be handied easily within tre calciner hood where the $\mathrm{PuO}_{2}$ will be produced.

Based on the isotopic composition listed previously, the maximum heat output for a $1.3 \mathrm{~kg}$ batch of $\mathrm{PuO}_{2}$ would be about 13 watts ( $\mathrm{yr}$ old). A 13 watt heat output would heat the surface of a 3-1/2-in. dia $\times 3-1 / 2-i n$. high metal can standing in atr under equilibrium conditions to about $135^{\circ} \mathrm{F}$. This probabiy would require gloves for thermal protection when handling the can after it reached the equilibrium temperature. The estimated dose rate on the surface of the can containing fresh made $\mathrm{PuO}_{2}$ would be about $0.85 \mathrm{rem} / \mathrm{hr}$; one-year-old $\mathrm{PuO}_{2}$ would give a dose rate of $2.3 \mathrm{rem} / \mathrm{hr}$ at the surface of the can. This increased dose rate would be principally from the ${ }^{241}$ Am that will grow in. Handling the cans for initial packaging might require special (remote) handing in the interest of ALATEP. Actual conditions will be significantly lower than indicatad above because the Pu being processed has a higher ${ }^{239} \mathrm{Pu}$ content and comparably lower anounts of the higher isotopes of Pu. Nevertheless, the precautions indicated are appropriate.

For containment of the $\mathrm{PuO}_{2}$. inside the can, it would be preferabie to mechanically seai the lid to the can; however, pressurization due to radiolysis will occur uniess the can is vented. Thus, tape (pressure sensitive piastic variety) sealing the lid to the can is acceptable providing the tape retains its adhesive quality during handling operations. Bagging the 3-1/2-in. dia $\times 3-1 / 2-i n$. high can out of the calciner glove-box using the nomal polyethylene bag, will be acceptable. The heat generated by the oxide will not cause the plastic to melt or decompose; the plastic is quite heat resistant as it is usually cured at temoeratures in the range of $200-300^{\circ} \mathrm{C}$. Once the can is bagged out of the hood it should be put into a 4-1/4-in. dia $x$ 5-9/16-in. hign metal can. Aluminum foil should be packed around the 3-1/2-in. dia can for heat transfer. The lid of the 4-1/4-in. dia can should be mechanically sealed to the can.

- The metal cans described herein are all ayailable from Rockwell stores. 
EXHIBIT 3. Cont'd

For storage, the 4-1/2-in. dia cans will be placed inside the horizontal tubes 8-in. I0 $\times 83-i n$. long in the 303-C Building. These tubes are encased in a reinforced concrete vault which acts as an infinite heat sink. The highest temperature that the inside can $(3-1 / 2-i n$. dia) is expected to reach inside the tube is $178^{\circ} \mathrm{F}$. This temperature should not cause unmanageable pressure buildup or cause deterioration of the packaging components.

Shipment of the oxide will likely involve both onsite and offsite movement; however, at present, it is not certain where or when the oxide will be shipped offsite. Shipping requirements for onsite transport of the oxide are considerably more flexible than for shipment offsite. For the initial operations, the two shipping containers now available to PNL and identified as USA/ $5791 /$ BLF $^{(7)}$ may be used for onsite shipment. These containers have been subjected to criticality safety analysis and are approved to transport up to $5.0 \mathrm{~kg}$ of Pu. No new Criticality Safety Specification is needed to cover transporting this amount of $\mathrm{Pu}$ in the container onsite. It is estimated that the dose rate at the surface of the available USA/5791/BLF containers will be a maximum of $22 \mathrm{mrem} / \mathrm{hr}$.

New safeguard regulations ${ }^{(8)}$ require that transport of large quantities $(>2000 \mathrm{~g})$ of $\mathrm{Pu}$ onsite from one building to another building within the 300 Area be done with a dedicated Rockwell truck driven by a "Q"-cleared driver and escorted by Rockwell Patrol. It is necessary for all other personnel accompanying the shipment to have a " $Q$ " clearance. Shipping requirements (see BNWL-MA-8T, p. IV -10 ) indicate that the sender must notify the receiver when the shipment is to be made.

Shipment of the oxide offsite will require Department of Transportation (DOT)approved containers. The USA/5791/BLF containers mentioned earlier are not now DOT-approved containers and would require modification or replacement to meet current dose rate criteria; in order to make offsite shipment practical, more than two containers would be desirable. Rockwell Hanford Operations has new USA/5791/BLF containers on order, which should be usable for potential future

(7) Radioactive Materials Shipping Manual, BNWL-MA-8], V.5.6, January 1, 1977.

(8) Addition to Radioactive Materials Shipping Manual, BNWL-MA-81, October 11, 1978. 


\section{EXHIBIT 3. Cont ${ }^{2} d$}

needs; if these containers become available in time for onsite shipment during processing operations, they could be used. Shipment of more than $2 \mathrm{~kg}$ Pu offsite requires special safeguards provision. The most practical means of shipping large quantities of oxide would be to use the Safe Secure Trailer (SST). The SST can accommodate up to 60 drums equivalent to the size and weight of the USA/5791/BLF. 


\section{EXHIBIT 4. Memo, "Tests Related to Rupture of $\mathrm{PuO}_{2}$}

Storage Can"

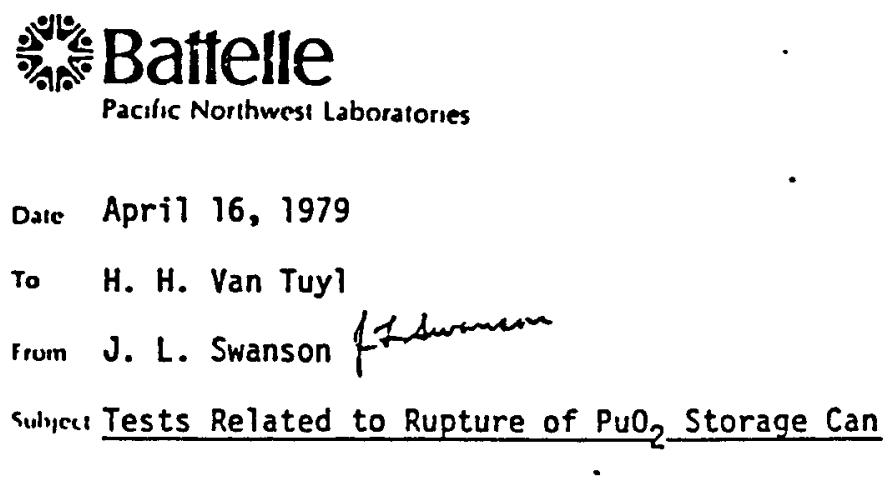

\author{
Project Number \\ Internal Distintulion \\ GE Backman \\ GH Bryan \\ JJ Fuquay \\ HL Henry \\ DE Knowlton \\ ED MCFall \\ RE Nightingale \\ EE Oscarson \\ CR Richey \\ EJ Wheelwright \\ JL Swanson-LB/File
}

Several tests have been conducted in the last week or so in an effort to. gain understanding of what caused the storage can to rupture in 303-C Building. This letter summarizes the results of those tests.

The simple early tests merely. involved heating specimens of plastic bag-out bags and various tapes in an oven. The first test involved exposure for 16 hours at about $160^{\circ} \mathrm{C}$; severe darkening of the plastic was obtained, and the "green tape" backing split away to a considerable extent. The second test involved exposure for 54 hours at about $135^{\circ} \mathrm{C}$; gradual deterioration occurred but never reached the extent of that in the first test.

In another test a small piece of the plastic underwent a $9 \%$ weight loss in 3 days in the oven at about $140^{\circ} \mathrm{C}$ when fully exposed to the (air) atmosphere. Another piece of plastic was heated at the same time in a lidded (but not sealed) can; this piece underwent only a $0.3 \%$ weight loss and was obviously more flexible and sticky-feeling than the one fully exposed to air. This latter piece was given to E. C. Martin for IR examination.

Tests with tape-sealed cans of the type used to contain the $\mathrm{PuO}_{2}$ (3.5" diameter + 3.5" tall) indicate that these cans do not hold a pressure. The first such test involved sealing an empty can and putting it into the $140^{\circ} \mathrm{C}$ oven (a pressure of 5-6 psig should have resulted); no sign of pressurization was noted. Other tests involved sealing cans containing water; in all these tests the water disappeared within 1.5 hours, demonstrating that the cans were leaking. One of the cans thus tested was the one that had been involved in the rupture incident.

Tests were also performed with simulated storage packages prepared by the 325-A Building technicians. These packages reportedly consisted of (1) a tape-sealed (white tape) inner can with a security seal down the side of the can, (2) a sealed bag-out bag containing the inner can, with green tape over the sealed edges, (3) a wrapping of aluminum foil, and (4) a mechanically-sealed outer can (4.25" diameter $\times 4.75$ " tall).

The first such test involved an empty inner can and a temperature of about $140^{\circ} \mathrm{C}$. Bulging of the ends of the can was observed within 3 hours but little or no change occurred in 3 days. When the package was cooled, the bulges disappeared. When the outer can was opened, corrosion was observed on its inner surface. The plastic was badly darkened. 


\section{EXHIBIT 4. Cont'd}

H. H. Van Tuyl April 16, 1979

Page 2

The second test with a simulated storage package involved placing $5 \mathrm{ml}$ $\mathrm{H}_{2} \mathrm{O}$ and $50 \mathrm{~g}$ sand (so the water wouldn't run out) within the inner can; other conditions were the same. This test was terminated after 45 minutes as both ends of the can were badly bulged and buckled. This package was saved for exhibition.

JLS: Im

I

I

I

I

1

$I$

1

1

$\zeta$

I

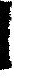

, 
EXHIBIT 5. Memo, "Background Information on Studies Related to Storing and Shipping $\mathrm{PuO}_{2}$ Associated with the NWVP"

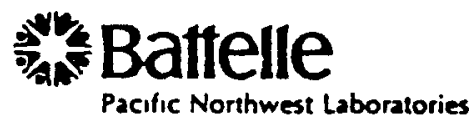

Date April 25, 1979

To J. J. Fuquay

From J. M. Taylor O.m.T.

SUbjed BACKGROUND INFORMATION ON STUDIES RELATED TO STORING AND SHIPPING PUD 2 ASSOCIATED WITH THE NWVP
Project Number

Iniernal Disinbution

GE Backman

HL Henry

LR Jaech

RJ Kofoed

EE Oscarson

CR Richey

CM Unruh

HH VanTuyl

File/LB

As per a request from $\mathrm{Cliff}$ Richey, I am providing some coments concerning studies made prior to the shipping and storing of the $\mathrm{PuO}_{2}$ generated from the NWV Project.

In Aprit of 1977, Ev Irish requested a study be made, by us, of the storage capability for $\mathrm{PuO}_{2}$ in the 300 Area; the packaging requirements for storage, and shipping methods and requirements. A study was made, addressing the above points and the results of the study were included in a letter to Irish dated June 22, 1977.

A thermal analysis of the oxide inside the shipping container was not included in the letter to Irish because preliminary calculations, using a two-dimensional model, gave a wide range of temperatures, depending on what conductivities (some of which had to be guessed at) were used and according to how the cans containing the oxide were positioned inside the shipping container. Temperature versus heat level (watts) curves, determined at Mound Laboratory for the 5791 container, were also consulted in an attempt to ascertain temperatures of the cans. However, the experimental setup used at Mound to obtain the curves was different than the way the cans of oxide would be packaged in the container. Consequently, the temperatures determined by calculation and from the curves, didn't appear to be meaningful. However, using some guesstimates for the temperatures of the inner can, it was conjectured that there would probably be no pressure buildup to cause problems. This was based on decomposition of the plastic only. Our main concern was with degradation of the plastic bag used as a contamination barrier for the can containing the oxide. This concern for degradation of the plastic bag led us to conduct'some thermal tests inside the storage tubes at $303-C$. The thermal tests were made, using four - 15 watt light bulbs, spaced about $1-1 / 2 \mathrm{ft}$. apart, inside a storage tube. The bulbs were surrounded with a plastic bag; the same as those used to bag out material from a glovebox. The light bulb plus plastic bag were placed inside metal cans similar to those used to package the Pu oxide. Thermocouples were attached directly to the surface of the bulbs. Tests were made using different amounts of plastic wrapped around each bulb. In one test, a large plastic bag was placed around each bulb and then stuffed into a metal can; the surface temperature of the bulbs ranged from $280^{\circ} \mathrm{F}\left(138^{\circ} \mathrm{C}\right)$ to $336^{\circ} \mathrm{F}\left(169^{\circ} \mathrm{C}\right)$. Holding the bulbs at that temperature for over two hours caused the plastic, where it was several layers thick and in close contact with the bulbs, to inelt, and in some cases to change color from a light yellow-brown to a dark brown. This was the case with all four bulbs. Repeating the test, using a close-fitting sleeve of plastic over each bulb, and foil packed around each bulb, the surface temperature of the bulbs ranged from $265^{\circ} \mathrm{F}\left(129^{\circ} \mathrm{C}\right)$ to $291^{\circ} \mathrm{F}\left(144^{\circ} \mathrm{C}\right)$. Holding the bulbs for several hours at these temperatures caused no apparent change to the plastic. These tests showed (with cverlapping temperatures) that based on the 


\section{EXHIBIT 5. Cont'd}

J. J. Fuquay

April 25, 1979

Page - 2

heat transfer through the plastic, the plastic would either remain undamaged or degrade and melt, depending on whether the plastic was in a single layer around the bulb, allowing good heat flow or bunched up around the bulb, creating a hot spot.

In the letter to Irish, it was recomended that good heat transfer between the inner and outer can be provided. It was suggested that aluminum foil be packaged around the 3-1/2" diameter can. Because of the concern with plastic degradation, contact was made with R. F. Gimpel, Rockwell Hanford. Gimpel was associated with the Plutonium Process Engineering Unit and was studying methods for storing Pu metal and oxide in the 234-5 storage vaults. Gimpel stated that their method of storing oxide was the same as we proposed to use. Namely, an inner can with a taped lid inside a plastic bag inside a food pack can that had a mechanically sealed lid. He indicated that they had stored oxide containing up to 2 Wt.\% Pu-238 in this manner without any problems with plastic degradation. If there were problems with gas generation from other sources, he didn't mention it to me at the time. Based on conversations with Gimpel and my own experience with storage of Pu oxide at the 231-Z Facility, it was concluded that with good heat transfer the plastic bag would not degrade or be a source for gas decomposition products.

The factor that was overlooked was the Pu oxide. It was assumed that the calcination process would convert the Pu nitrate to stoichiometric Pu oxide and there would be no volitiles or gaseous products that would be released at the storage temperature determined. Most of the oxide stored at the 234-5 Facility or at the 23i-Z Facility, was made from either Pu oxalate or Pu metal. Studies should have been made on the characteristics of oxide made from Pu nitrate. This factor probably would have been caught if a change analysis had been done before the fact rather than after the fact. 


\section{EXHIBIT 6. Memo, "Laboratory Studies Related to 303-C Incident"}

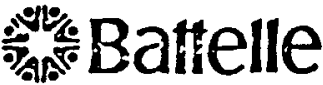

Pacilic Norlimest Labnratories

\author{
Date Aprit 16, 1979 \\ To J. J. Fuquay \\ Prom \\ H. H. Van Tuyl $)$ thl
}

Sulyeet
Laboratory Studies Related to 303-C Incident
Propect Number

Internal Dislabution

GE Backman

GH Bryan

HL. Henry

DE Knowlton

RJ Kofoed

ED McFall

RE Nightingale

EE Oscarson

CR Richey

JL Swanson

EJ Wheelwright

HH Van Tuyl-LB/File

The two cans retrieved from 303-C were examined as described in my memo to R. E. Nightingale, dated March 29, 1979, the first can was opened and examined as described in a memo from J. L. Swanson to me, dated March 30, 1979, and the second can was opened and examined as described in my memo to you, dated March 30, 1979. These observations showed appreciable damage to the plastic bag and tape which could be from heat or radiation or both. Laboratory studies were conducted to determine the effect of heat on materials and mockup systems, as described in a memo from J. L. Swanson to me, dated April 16, 1979. These laboratory tests indicate a maximum plastic temperature of about 150 to $160^{\circ} \mathrm{C}$ in the $6 \mathrm{~A}$ container and about $140^{\circ} \mathrm{C}$ in the $6 \mathrm{~B}$ container. Minimum plastic temperatures were probably somewhat lower, perhaps 120 to $130^{\circ} \mathrm{C}$ in each can.

According to E. J. Wheelwright, the isotopic composition of the plutgnium in cans $6 \mathrm{~A}$ and $6 \mathrm{~B}$ was $1.49 \% 238 \mathrm{Pu}, 59.50 \% 239 \mathrm{Pu}, 23.98 \% 240 \mathrm{Pu}, 10.33 \% 249_{\mathrm{Pu}}$, and $4.70 \% 242 \mathrm{Pu}$. This was translated to decay heat using half-lifeyalues of 87.74 $y$ for $238 \mathrm{Pu}, 24,110 \mathrm{y}$ for $239 \mathrm{Pu}, 6,537 \mathrm{y}$ for $240 \mathrm{Pu}, 14.4 \mathrm{y}$ for $24 \mathrm{Pu}_{\mathrm{Pu}}$ and 3.763 $\times 10^{5}$ y for $242^{\prime} \mathrm{Pu}$. Decay energy values were $5.59327,5.2435,5.25596,5.1393$, and 4.9831 MeV for the respective aipha decays, and 0.02081 for $241 \mathrm{Pu}$ beta decay. Abundance of $241 \mathrm{Pu}$ alpha decay was taken to be $2.45 \times 10-3 \%$. This results in a total heat load of 13.52 watts for 1150 grams of plutonium shortly after purification. from americium. After a year, an additional heat load.of about 0.60 watts will result from $24 i \mathrm{Am}$ decay. For earlier batches of $\mathrm{Pu}$, the isotopic composition of Pu was taken from the summary sheet prepared by E. R. Irish on 3/20/79. This earlier material will produce 8.74 watts per 1150 grams $P u$ when freshly purified, and 9.28 watts per 1150 grams when aged 1 year.

H. T. Fullam calculated equilibrium temperatures of the material in a shipping container as a function of thermal conductivity values, $K$, for the insulation surrounding the $2-R$ container. Temperature values for a heat generation rate of 14 watts per can are shown in the following table. A value of $K=0.05$ BTU $\mathrm{hr}^{-1} \mathrm{ft}^{-2}{ }^{\circ} \mathrm{F} \mathrm{ft}^{-1}$ was selected as most likely based on insulating properties of cellular gypsum and observed plastic degradation in the ruptured contisiner. 


\section{EXHIBIT 6. Cont'd}

J. J. Fuquay

April 16, 1979

Page 2

\begin{tabular}{|c|c|c|c|c|c|}
\hline \multirow[b]{2}{*}{$\begin{array}{l}\text { Thermal } \\
\text { Conductivity, } K \\
\end{array}$} & \multicolumn{5}{|c|}{ Temperature, ${ }^{\circ} \mathrm{C}$} \\
\hline & $\begin{array}{l}\text { Outside } \\
\text { Drum } \\
\end{array}$ & $\begin{array}{c}\text { 2-R } \\
\text { Container } \\
\end{array}$ & $\begin{array}{l}\text { Outer } \\
\text { Can } \\
\end{array}$ & $\begin{array}{l}\text { Surface of } \\
\text { Inner Can } \\
\end{array}$ & $\begin{array}{c}\mathrm{PuO}_{2} \\
\text { Centerline }\end{array}$ \\
\hline $\begin{array}{l}0.025 \\
0.05 \\
0.1 \\
0.2 \\
0.3\end{array}$ & $\begin{array}{l}22 \\
22 \\
22 \\
22 \\
22\end{array}$ & $\begin{array}{r}167 \\
108 \\
86 \\
75 \\
71\end{array}$ & $\begin{array}{l}197 \\
139 \\
117 \\
109 \\
102\end{array}$ & $\begin{array}{l}219 \\
156 \\
133 \\
128 \\
124\end{array}$ & $\begin{array}{l}264 \\
200 \\
178 \\
172 \\
168\end{array}$ \\
\hline
\end{tabular}

E. C. Martin examined the thermally degraded plastic, and compared it with fresh plastic. The infrared spectrum showed principally dioctyl phthalate with either polyethylene or polyvinyl chloride (PVC). A chemical test confirmed the presence of PVC. The degraded material showed a greater amount of unsaturation and an increase in $\mathrm{OH}$ bonds as compared to fresh plastic. Martin conducted a brief literature study to determine the products on thermal decomposition of PVC.

The maximum service temperature is reported to be $85^{\circ} \mathrm{C}$. Evolution of $\mathrm{HCl}$ occurs when PVC is heated above $100^{\circ} \mathrm{C}$. Normally the evolution of $\mathrm{HCl}$ is not detected because it is neutralized by the stabilizer incorporated into the polymer. However, $\mathrm{HCl}$ will be detected when the stabilizer is exhausted. The color of the PVC darkens as $\mathrm{HCl}$ is evolved because of the formation of polyenes. Gas chromatographic analysis verified that $\mathrm{HCl}$ is the main volatile product of thermal degradation processes below $2300-400^{\circ} \mathrm{C}$. However, traces of other volatiles can be detected, notably benzene. (See Stromberg, et al., J. Polymer Sci., 35, 335 (1959)). Benzene has been detected at temperatures as low as $180^{\circ} \mathrm{C}$.

Color can be detected at extremely low degrees of degradation, corresponding to the earliest detection of $\mathrm{HCl}$ being liberated from the polymer. There is an auto retarding temperature range for $\mathrm{HCl}$ below $170^{\circ} \mathrm{C}$, but above $200^{\circ} \mathrm{C}$ is an auto accelerating region. Only 5\% loss of $\mathrm{HCl}$ occurs at $170^{\circ} \mathrm{C}$. See Guyot, et al., J. Appi. Polymer Sci., 6, 103 (1962).

The $\mathrm{HCl}$ formed will act as a catalyst for additional dehydrochlorination and for discoloration and cross-linking.

No further work with plastic decomposition products was performed since the experiments by Swanson showed that the plastic and tape alone did not generate enough pressure to cause permanent deformation of the can at about 130 to $140^{\circ} \mathrm{C}$.

G. H. Bryan, et al., had studied solid plutonium nitrate, including a thermogravimetric analysis of the decomposition of plutonium nitrate (BNML-1941, p. 20). An intermediate compound, believed to be $\mathrm{PuO}_{2}\left(\mathrm{NO}_{3}\right)_{2}$, was observed at about $200^{\circ} \mathrm{C}$. This should decompose thermally at 190 to $280^{\circ} \mathrm{C}$ according to the equation 


\section{EXHIBIT 6. Cont'd}

J. J. Fuquay

April 16, 1979

Page 3

$$
\mathrm{PuO}_{2}\left(\mathrm{NO}_{3}\right)_{2}+\mathrm{PuO}_{2}+2 \mathrm{NO}_{2}+\mathrm{O}_{2} \text {. }
$$

Assuming a free volume in the outer can of $900 \mathrm{ml}$, and a pressure of $60 \mathrm{psig}$ at $140^{\circ} \mathrm{C}$ to rupture the can, the gas content of the can would be 0.11 moles. The can contains about $1280 \mathrm{~g}$ PuO 2 with $0.43 \%$ water and about $3 \%$ loss on ignition (LOI) at $950^{\circ} \mathrm{C}$. This represents 0.31 moles of water, and if the other $L 01$ is $\mathrm{PuO}_{2}\left(\mathrm{NO}_{3}\right)_{2}$, it would represent 0.53 moles of nitrate that would decompose to. 0.80 moles of gas. Thus, the pressure will be great enough to rupture the can if about one-third of the water vaporizes or if one-seventh of the nitrate decomposes.

According to Bryan, et al.. (BNWL-1947, p. 15), radiolytic decomposition of $\mathrm{Pu}\left(\mathrm{NO}_{3}\right)_{4} \cdot \mathrm{xH}_{2} \mathrm{O}$ liberates about $0.1 \mathrm{~mole}$ of gas per kilogram of $\mathrm{Pu}$ at an accumulated dose of about $1020 \mathrm{MeV}$ per kilogram Pu. This should be much greater than the gas generation from material that is principally $\mathrm{PuO}_{2}$. However, even if the same rate of gas generation is assumed, it would require about 15 days to liberate 0.1 mole of gas from can $6 A$ or $6 B$. If the rate is proportional to the weight of nitrate, the time required to liberate 0.1 mole of gas will be well over one year. At any rate, radiolytic decomposition of solid plutonium nitrate would not generate appreciable pressure in the 12 hours required to rupture can $6 \mathrm{~A}$.

Although it is highly likely that thermal decomposition of the Pu product caused the pressure, there are only limited data to provide guidance in packaging future materials. Additional research is needed to characterize the Pu product from direct denitration, to evaluate the thermal stability and decomposition products of $\mathrm{PuO}_{2}\left(\mathrm{NO}_{3}\right)_{2}$ or other intermediates, to elucidate the hydration and dehydration behavior of $\mathrm{PuO}_{2}$, to measure radiolysis rates and products, to determine thermal and radiation stability of packaging materials such as plastic and tape, to determine temperatures at various locations in the packaged material, and to determine pressures required to bulge, buckle, and rupture the package.

HHVT: Im

Enclosure 
$$
\text { . }
$$ 


\section{EXHIBIT 7. Memo, "Nitrogen Content of 6B Sample"}

Baftelle

Pacific Northwest Laboratones

Date April 30, 1979

To J. J. Fuquay

From

G. H. Bryan

Subject Nitrogen Content of 6B Samole
Project Number

Internal Distribution

-

GE Backman

HL Henry

DE Knowlton

RJ Kofoed

ED McFall

RE Nightingale

EE Oscarson

eR Richey

JL Swanson

HH Van Tuy?

EJ theelwright

GH Bryan-LB/File

HEDL analytical results for nitrogen on Batch $6 B$ ( +40 mesh screen size) indicate that it contained an average of $3335 \mathrm{ppm}$ (duplicate samples, 3390 and $3280 \mathrm{ppm})$. If the nitrogen is in the form of $\mathrm{PuO}_{2}\left(\mathrm{NO}_{3}\right)_{2}$, an intermediate compound believed to be formed during the thermal decomposition of plutonium nitrate at $190-280^{\circ} \mathrm{C}$ as reported by $\mathbf{G}$. H. Bryan, et al., in BNWL-1941, P. 20, the reaction for decomposition to $\mathrm{PuO}_{2}$ follows the equation

$$
\mathrm{PuO}_{2}\left(\mathrm{NO}_{3}\right)_{2} \triangleq \mathrm{PuO}_{2}+2 \mathrm{NO}_{2}+\mathrm{O}_{2} \text {. }
$$

The amount of gaseous products produced by heating the contents of $6 \mathrm{~B}$ to convert it all to $\mathrm{PuO}_{2}$ would exert a pressure of about 206 psia using the following assumptions and calculations:

Assumptions:

1. The sample is representative of the entire contents of $6 \mathrm{~B}$ (1280 gms).

2. The ideal gas law $(p v=n R T)$ is valid for the calculation of pressure.

3. The equation for the decomposition of the $\mathrm{PuO}_{2}\left(\mathrm{NO}_{3}\right)_{2}$ is correct and each mole of nitrogen produces 1.0 mole of $\mathrm{NO}_{2}$ and 0.5 mole of $0_{2}$.

4. The volume of the sealed can is about one liter.

5. Temperature of the gas product is about $100^{\circ} \mathrm{C}$.

Calculations:

1. Total amount of nitrogen in the $6 \mathrm{~B}$ can $=1280 \times 0.00335=4.27 \mathrm{gms} N$

2. Moles of nitrogen $=4.27 / 14=0.305$

3. Moles of gas product $=0.305 \times 1.5=0.458$

4. $p=\frac{n R T}{v}=\frac{0.458 \times 1.206 \times 1273+100}{l}=206$ psia

It is not likely all of the nitrogen found by the analysis is in the form of $\mathrm{PuO}_{2}\left(\mathrm{NO}_{3}\right)_{2}$. Other nitrogen containing species are undoubtedly present such as $\mathrm{NO}_{2}$, $\mathrm{HNO}_{3}$, etc.; however, the above calculations indicated a significant 


\section{EXHIBIT 7. Cont'd}

J. J. Fuquay

Apri门 30, 1979

Page 2.

pressure buildup in a sealed can could be expected if any undecomposed $\mathrm{PuO}_{2}\left(\mathrm{NO}_{3}\right)_{2}$ remained after calcination. These calculations do not include the pressure contribution from any water that may be present which may be expected to add a significant pressure depending on the amount and temperature.

GHB: Im 
EXHIBIT 8. Contamination of Personnel as a Result of Occurrence

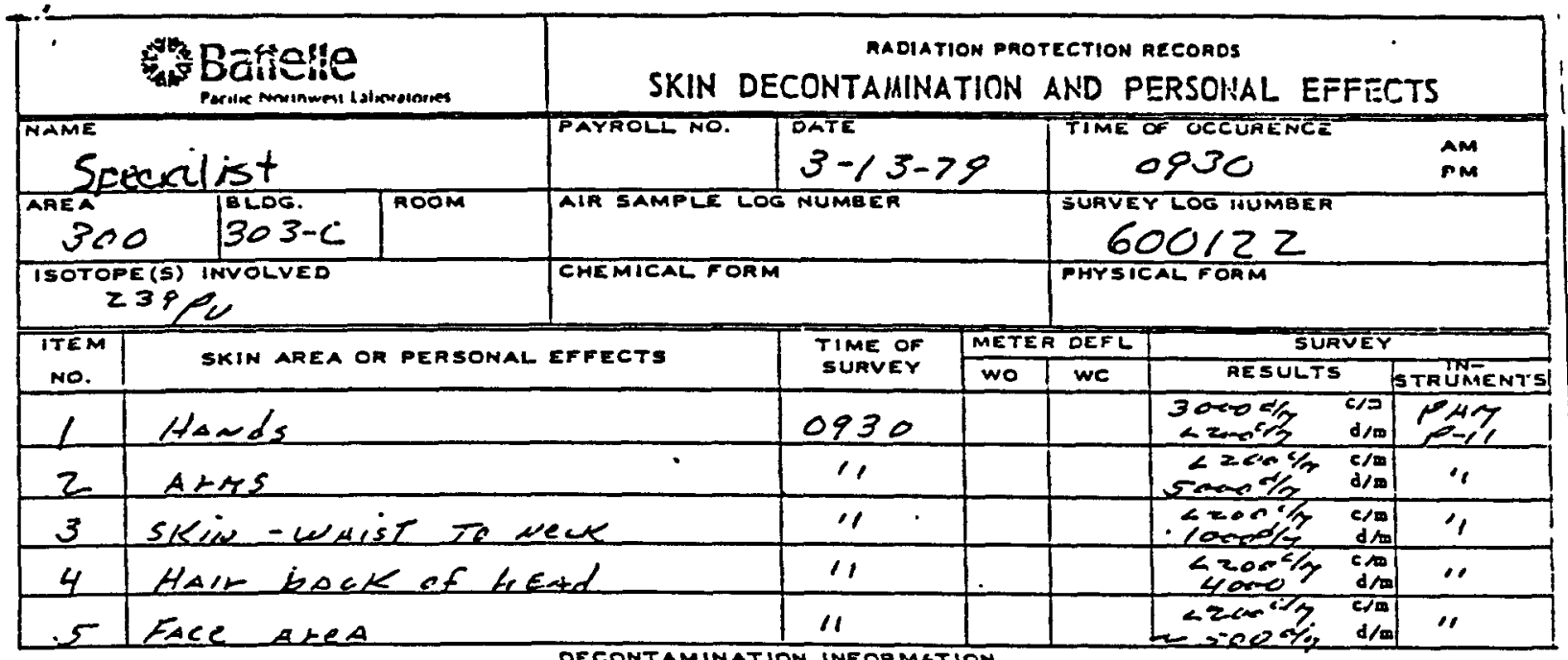

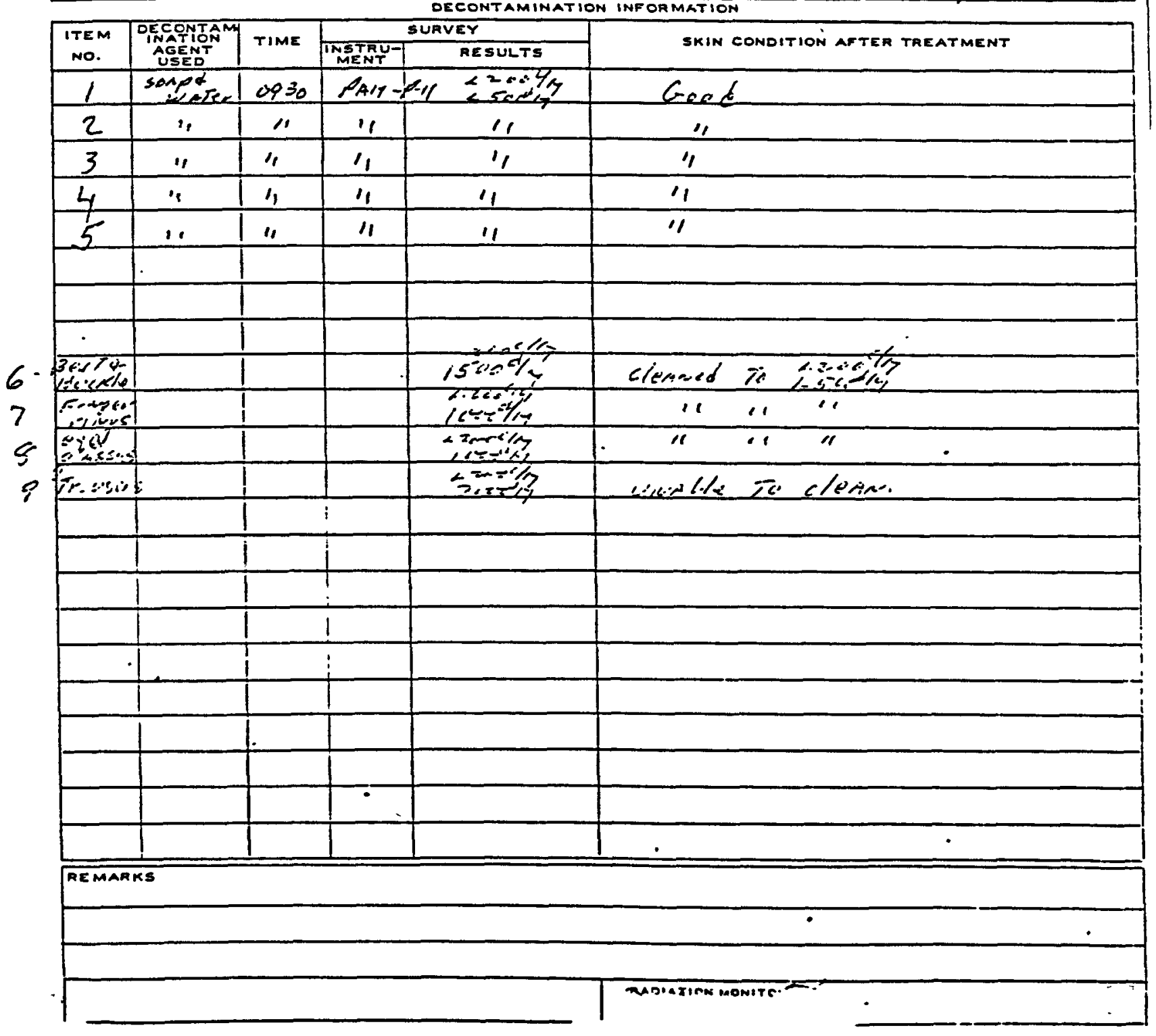


EXHIBIT 8. Cont'd

INDICATE AFFECTED SITES

$\triangle$ SKIN $\triangle$ PERSONAL EFFECTS $\square$ PROTECTIVE CLOTHING
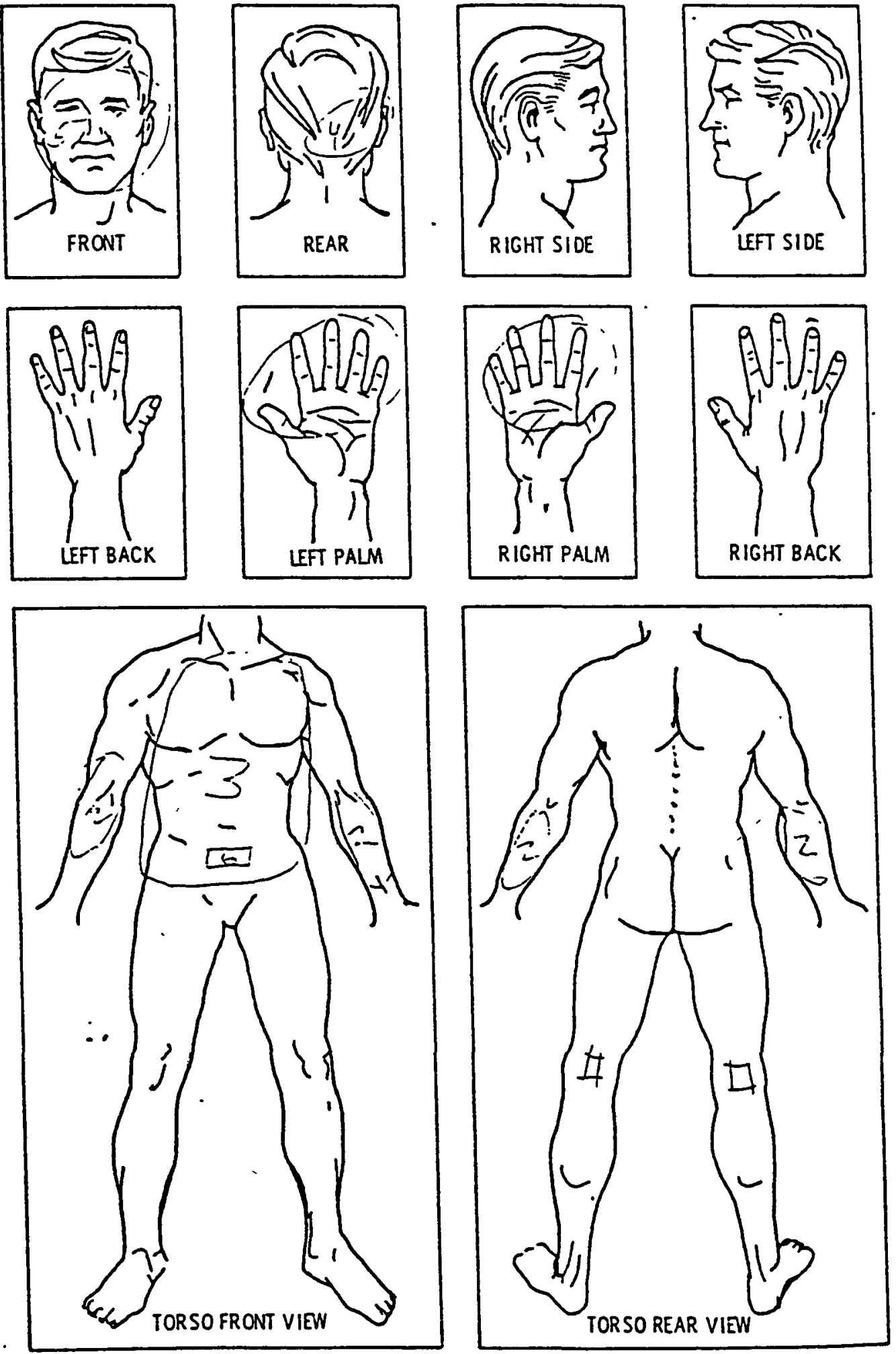
EXHIBIT 8. Cont'd

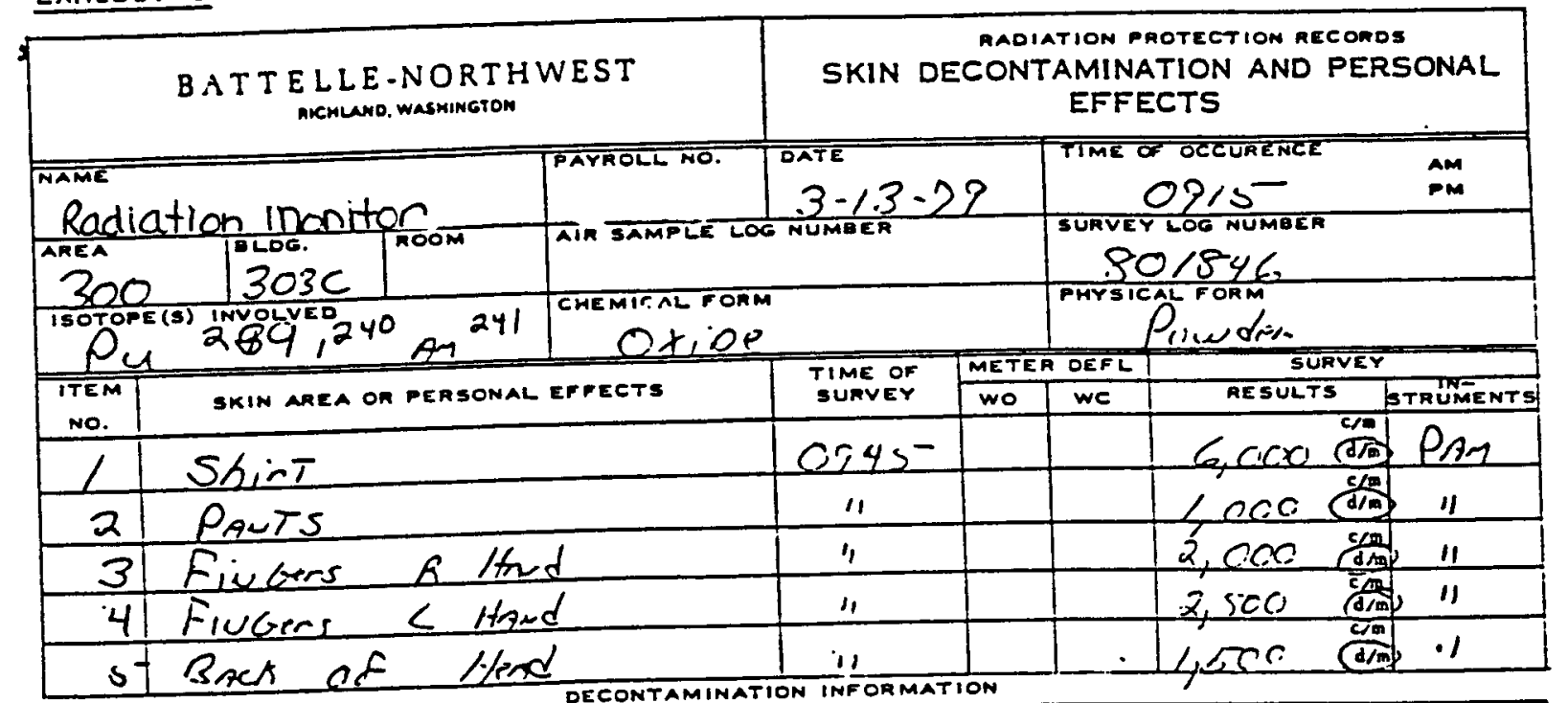

STEEY SKIN CONDITION AFTER TREATMENT

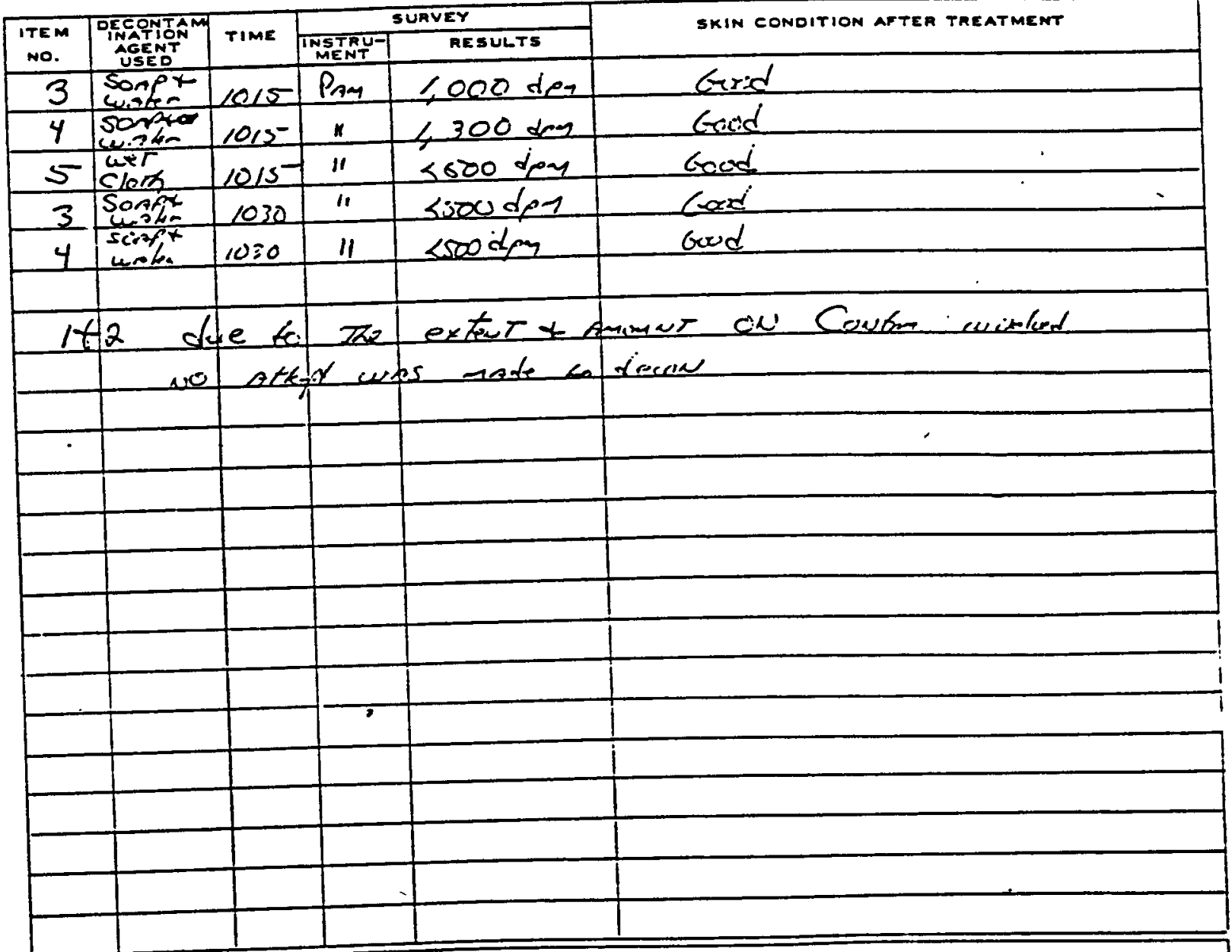


EXHIBIT 8. Cont'd

INDICATE AFFECTED SITES

$\triangle$ SKIN \ PERSONAL EFFECTS $\square$ PROTECTIVE CLOTHING
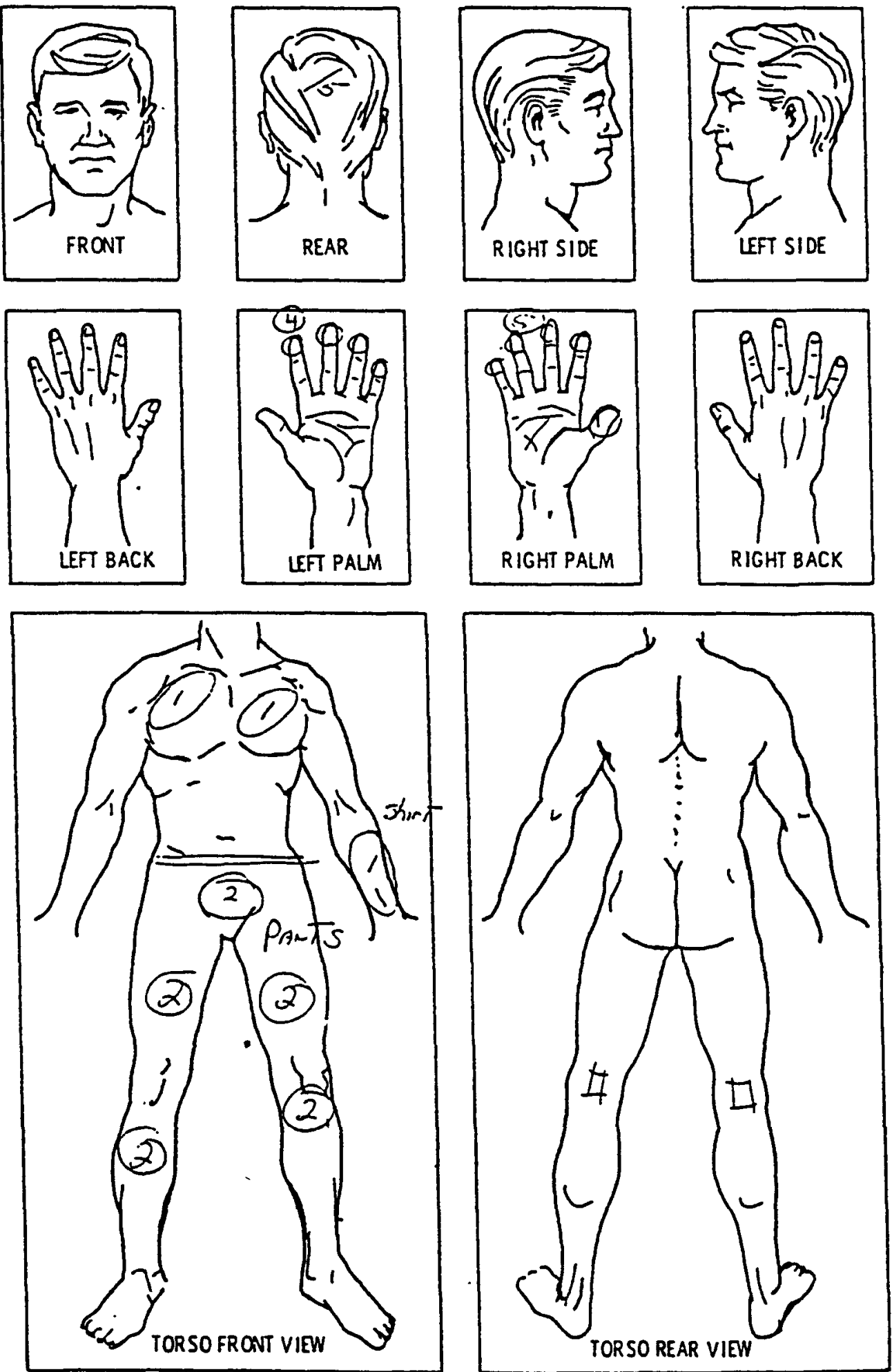


\section{EXHIBIT 8. Cont'd}

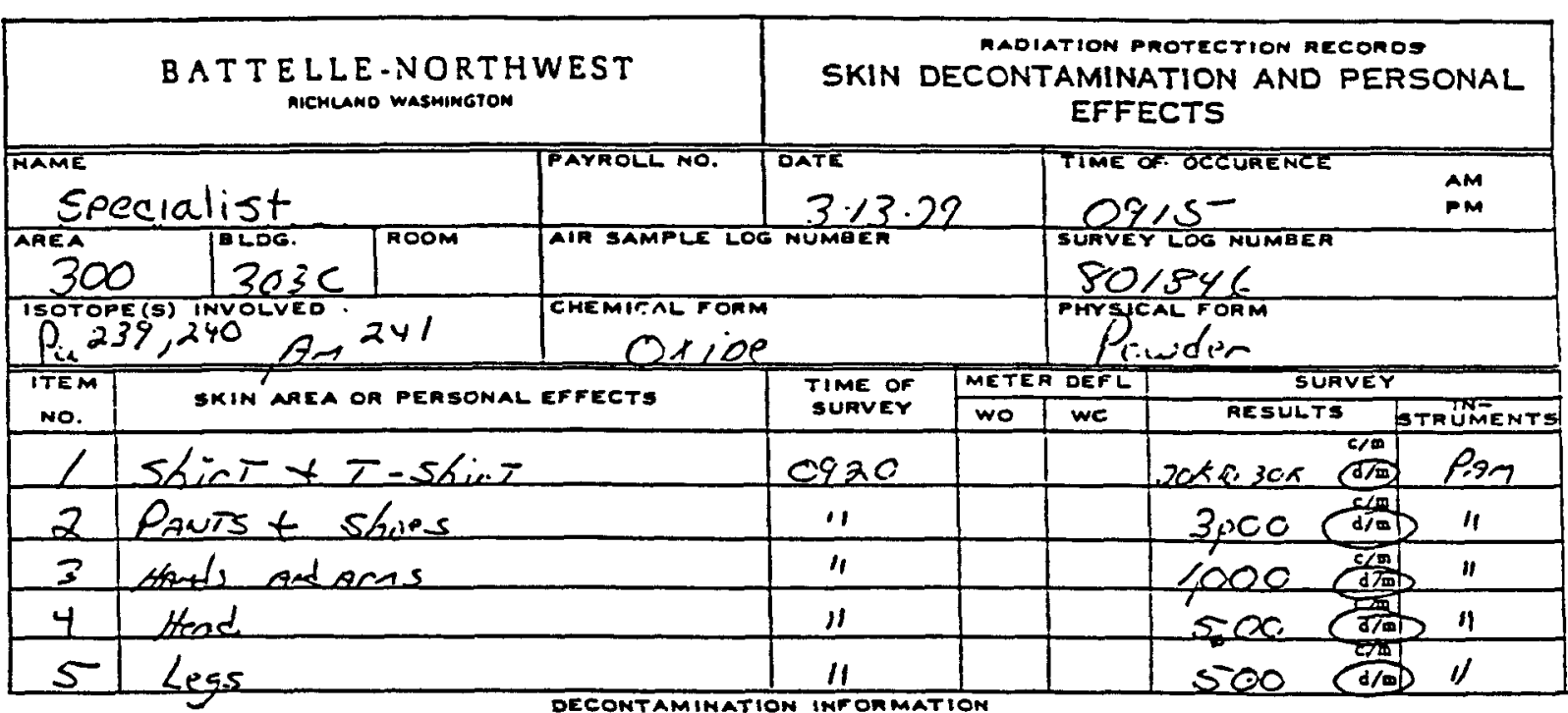

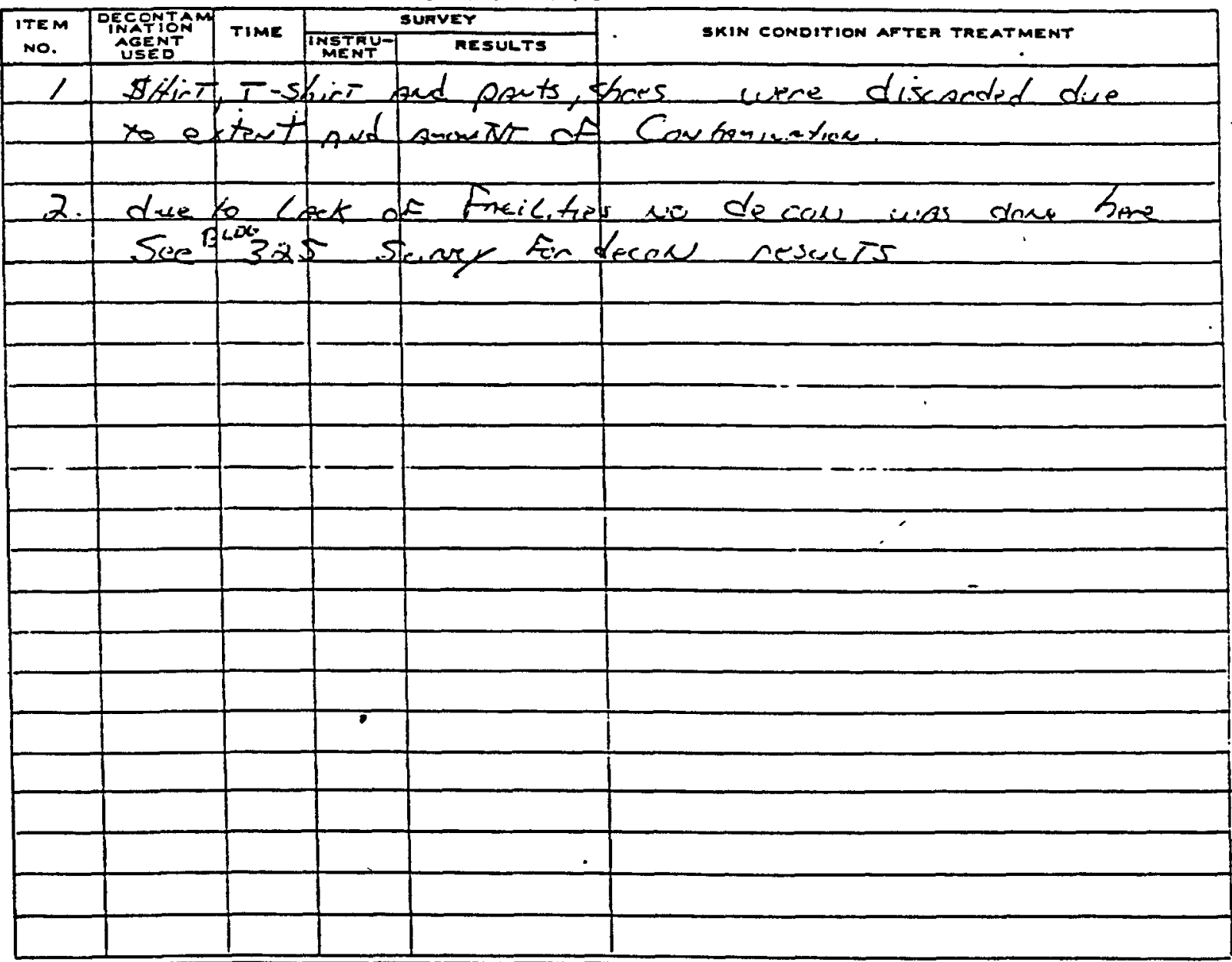

nemaAks! 
EXHIBIT 8. Cont'd

INDICATE AFFECTED SITES

$\triangle$ SKIN $\triangle$ PERSONALEFFECTS $\square$ PROTECTIVE CLOTHING
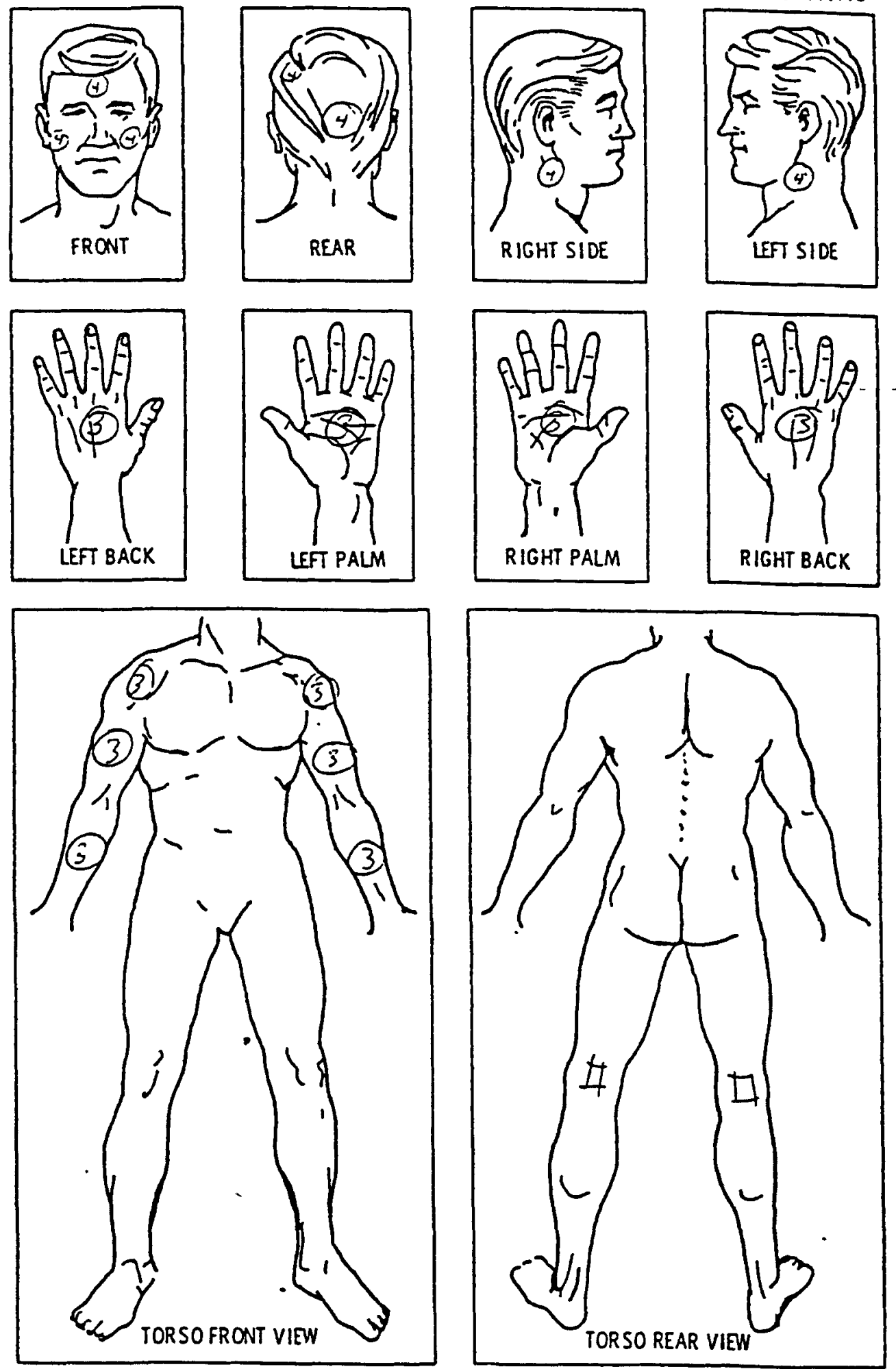
EXHIBIT 8. Cont'd

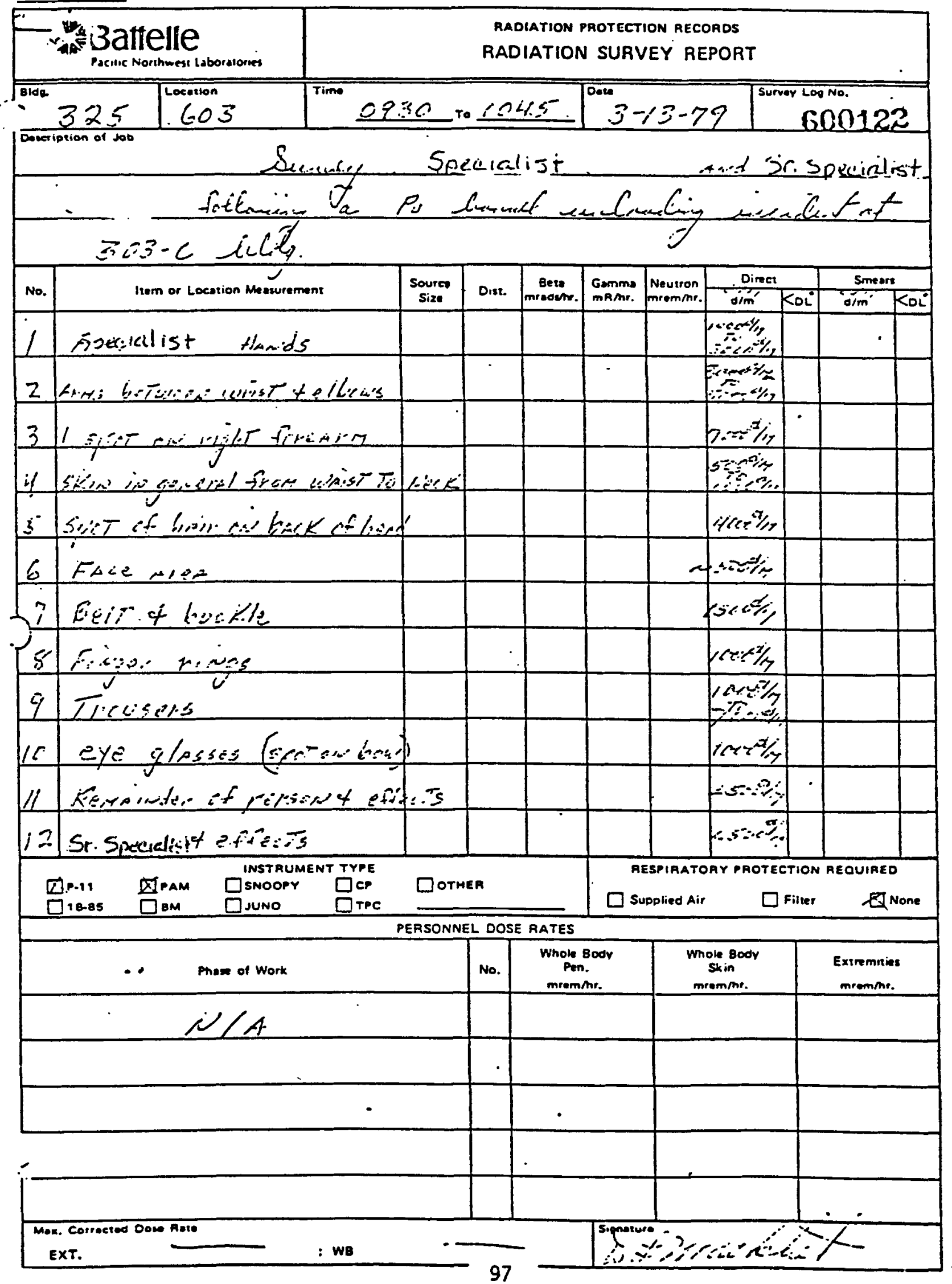


EXHIBIT 8. Cont'd

is.

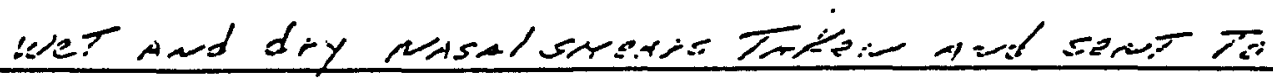

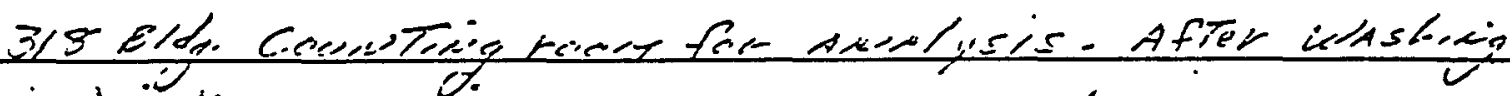

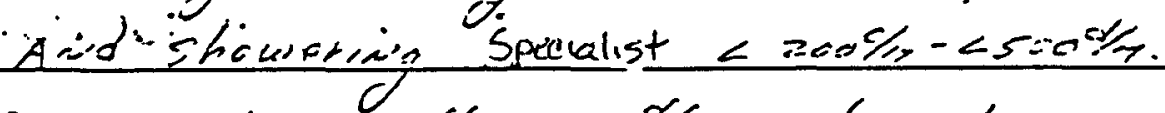

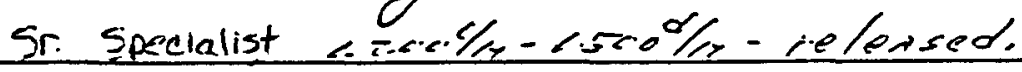

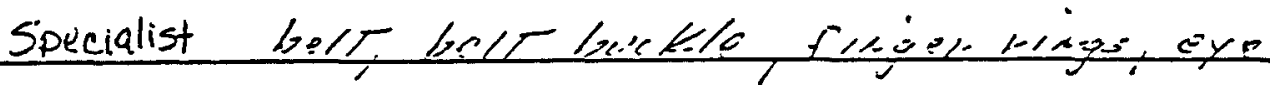

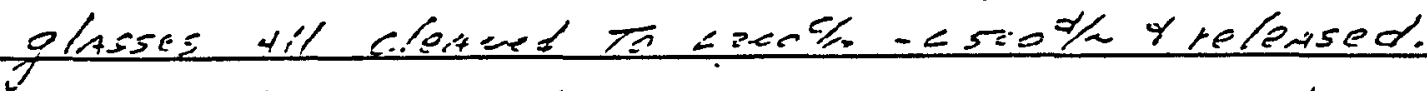

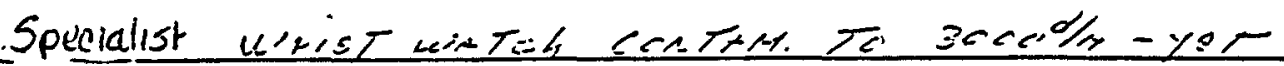

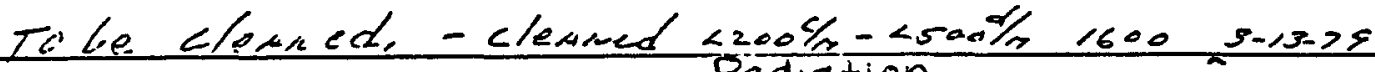

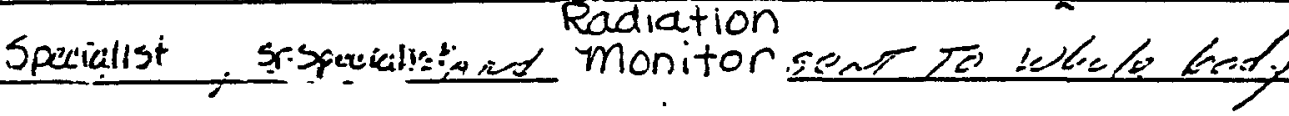
Cocontret.

SKETCH

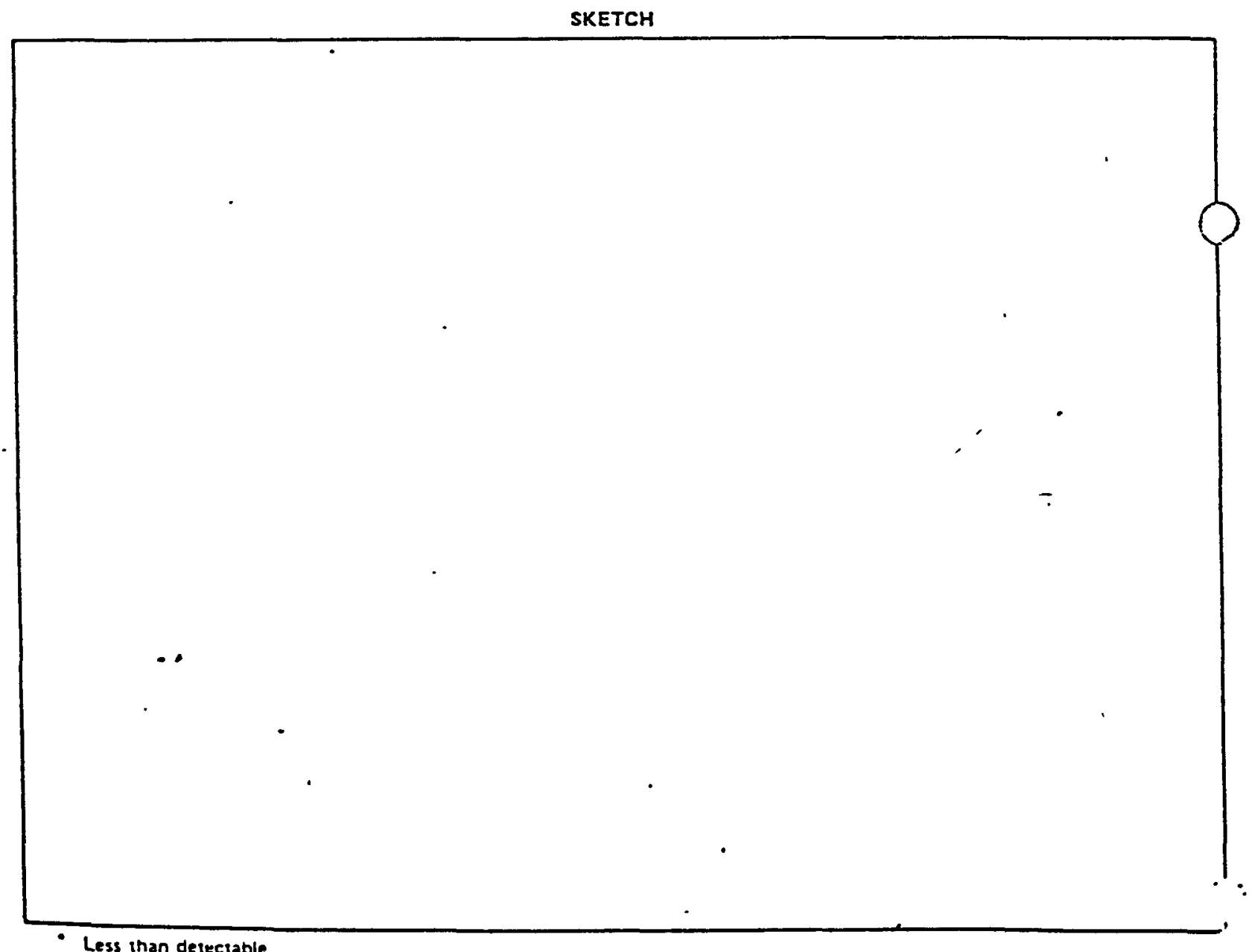

- The PAM is calibrated to give $28 \mathrm{cpm}$ from $100 \mathrm{pCi} / 100 \mathrm{~cm}^{2}$ at $0.5 \mathrm{~cm}$ distance.

- The P.11 is calibrated to give $\geq 100 \mathrm{cpm}$ from $1 \mathrm{nCi} /$ probe area using $5 \%$ efficiency for unknown energy betas.

98 
EXHIBIT 9. Release to the Environment as A Result of Occurrence

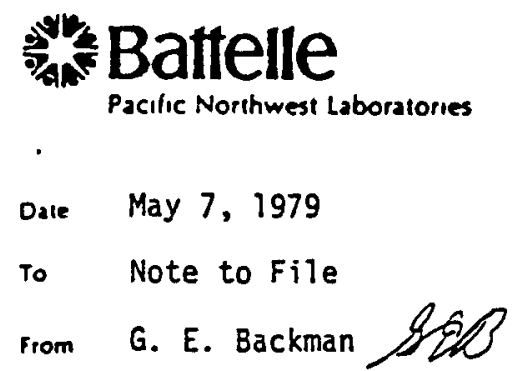

Projecl Number.

Internal Distribution

Subject ESTIMATE OF QUANTITY OF PLUTONIUM RELEASED DURING 303-C FACILITY INCIDENT

The original estimate of the quantity of transuranic alpha emitters released on March 13, 1979, was based on the eariy information that the air sample filter was contaminated to $300,000 \mathrm{~d} / \mathrm{m}$. Since the ventilation exhaust was $600 \mathrm{cfm}$ and the air sample flow rate was $2 \mathrm{cfm}$, and the number of $\mathrm{d} / \mathrm{m}$ per $\mu \mathrm{Ci}$ is $2.22 \times 10^{6}$, the quantity released was calculated as follows:

$$
\frac{3 \times 10^{5} \mathrm{~d} / \mathrm{m}}{2.22 \times 10^{6} \mathrm{~d} / \mathrm{m} / \mu \mathrm{Ci}} \times \frac{600 \mathrm{cfm}}{2 \mathrm{cfm}}=40.54 \mu \mathrm{Ci}
$$

This was reported as approximately $50 \mu \mathrm{Ci}$.

Later it was learned that the first sample taken after the incident collected $3 \times 10^{6} \mathrm{~d} / \mathrm{m}$ and a ten minute sample taken immediately following was $1.5 \times 106$ $\mathrm{d} / \mathrm{m}$.

For thirty minutes between the ten-minute sample and the time that an additional filter was placed over the exhaust, there was no sample. It was assumed that the quantity release rate would be approximately the same as during the previous ten minutes. This would result in an estimated $4.5 \times 10^{6}$ $. d / m$. The total release is calculated below:

$$
\begin{gathered}
3 . \times 10^{6} \mathrm{~d} / \mathrm{m} \\
1.5 \times 10^{6} \mathrm{~d} / \mathrm{m} \\
\frac{4.5 \times 10^{6} \mathrm{~d} / \mathrm{m}}{9 \times 10^{6} \mathrm{~d} / \mathrm{m}} \\
\frac{9 \times 10^{6} \mathrm{~d} / \mathrm{m}}{2.22 \times 10^{6} \mathrm{~d} / \mathrm{m} / \mu \mathrm{Ci}} \times \frac{600 \mathrm{cfm}}{2 \mathrm{cfm}}=1216.22 \mu \mathrm{Ci}
\end{gathered}
$$

This was reported as 1.2 to $1.3 \mathrm{mCj}$ released.

GEB:SC 
$$
\text { . }
$$ 


\section{EXHIBIT 10. Report on Property Damage or Loss}

FORM ERDA-283

(6-75)

EADAM OSO2
US. ENERGY RESEARCH AND UEVELOPMEUT ADMINISTRATIO\%: REPORT OF PROPERTY DAKAGE OR LOSS

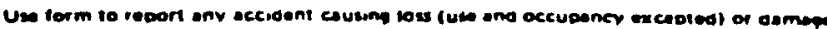

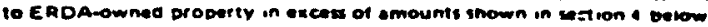

\begin{tabular}{|c|c|c|c|c|}
\hline \multicolumn{5}{|c|}{ 1. GENERAL } \\
\hline $\begin{array}{l}\text { - TIELD ORgANizATION } \\
\text { Richland Operations }\end{array}$ & \multicolumn{4}{|c|}{ 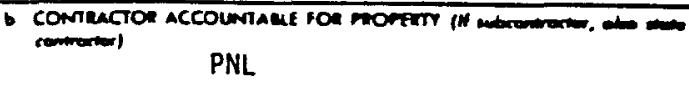 } \\
\hline $\begin{array}{l}\text { C LOCAnON OF ACCIDEN } \\
\text { 303-C Building, } 300 \text { Area }\end{array}$ & \multicolumn{2}{|l|}{$\begin{array}{c}\text { d OAIE OF ACCLOEMT } \\
3-13-79\end{array}$} & \multicolumn{2}{|c|}{$\begin{array}{l}\text { - nut of acooent } \\
9: 30 \text { a.m. }\end{array}$} \\
\hline 2 Mre of ACTVITY & \multicolumn{4}{|c|}{ 3. PERSONNE GFECTS } \\
\hline \multirow{4}{*}{ 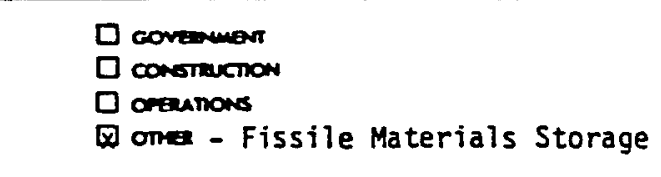 } & \multirow{2}{*}{\multicolumn{2}{|c|}{ - ratant }} & asc & anc \\
\hline & & & - & - \\
\hline & \multicolumn{2}{|c|}{ - occupational injuar } & - & - \\
\hline & . OCCUPATIONAL & VESS & - & - \\
\hline
\end{tabular}

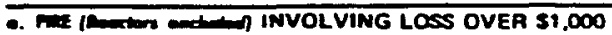

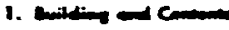

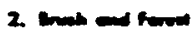
뭄
口

3. Ober (f, oty

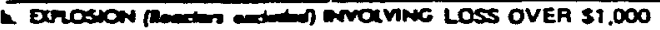

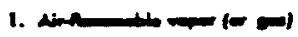

2 Ongied

1. Compand

4. Mistim

5. Do

$\square$

$\square$

$\square$

- NATUAAL CAUSES INVOLVIMG LOSS OVEA $\$ 1,000^{\circ}$

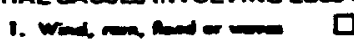

2. 1.

3.

믄

OVEA \$1,000:

OSS OVER \$1.000 Q

- transportation loss ovea si,000/Cargo only, all everest - Mechanically Caused daMage loss over $\$ 10000$

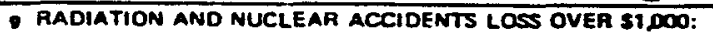

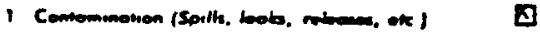

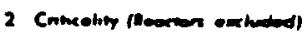

$\square$

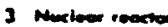

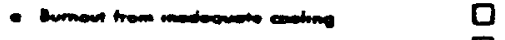

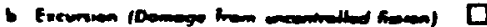

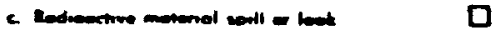

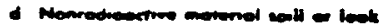

- Fre

1 Ormer (Somplit

in onven (somenty)

\section{ELECTAICAL FAULT OR FALURE LOSS OVER $\$ 1.000$ D}

3. MONGTARY DAMACE OR loss QY ACCJDENT TYP

\begin{tabular}{|c|c|c|c|c|c|c|c|}
\hline \multirow{3}{*}{ min } & \multicolumn{6}{|c|}{ TO AfC Ommes moritr } & \multirow{3}{*}{ 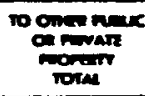 } \\
\hline & \multicolumn{2}{|c|}{$\operatorname{loc}^{\circ}$} & \multirow{2}{*}{$\operatorname{mos}$} & \multirow{2}{*}{. } & \multirow{2}{*}{ m } & \multirow{2}{*}{ FRDA Total } & \\
\hline & 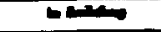 & ando & & & & & \\
\hline $4-g-1$ & $\$ 238,000^{*}$ & & & & & $\$ 238,000^{*}$ & \\
\hline & & & & & & & \\
\hline notans & $\$ 238,000^{*}$ & & & & & $5238,000^{*}$ & \\
\hline
\end{tabular}

Rupture of a plutonium oxide package occurred during unloading at the storage building, 303-C. resulting in contamination of the premises with plutonium oxide powder. Loss

includes desks, tables, chairs, and miscellaneous small items, plus cost of decontamination and restoration to pre-occurrence conditions.

\section{FFECT ON PROOUCTON OR OFERATION CAPABUTT}

Access to 303-C for storage of SNM is limited. No new material will be accepted for storage. Stored material is removed as needed for program continuation. Full access will not be restored for about five months.

* Estimated property loss and cleanup costs. 
EXHIBIT 10. Cont'd

Form ERDA-283 (Contumued)

8. CAUSE AND CONTRO

- canse

An investigation is in progress to determine cause anci corrective action.

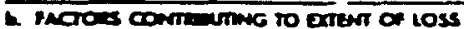

Loss was confined to inside 303-C Building by prompt action of personnel involved.

Personal contamination resulted in minor loss of personal clothing.

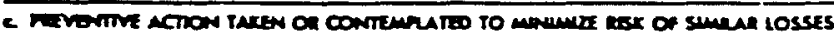

Not availabe at this writing.

See investigation report.

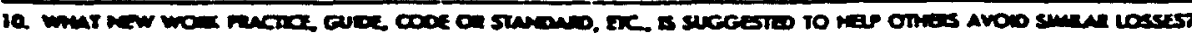

To be determined by the investigators.

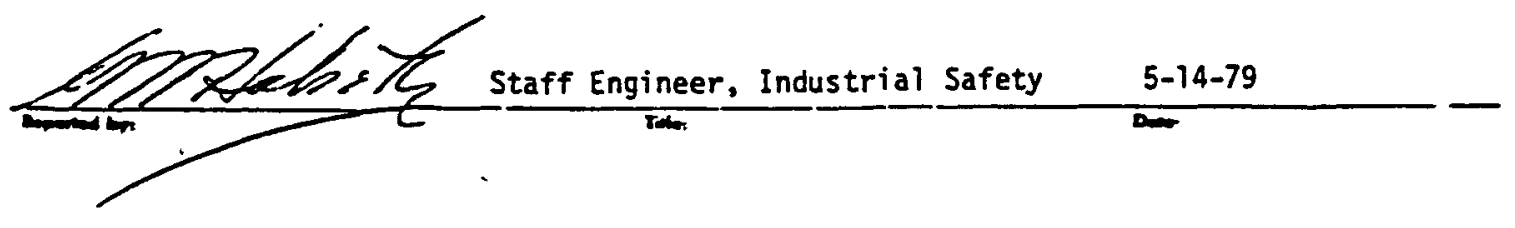

- U.

5 


\title{
EXHIBIT 11. Correspondence Regarding NWVP Items Identified for Corrective Action
}

\author{
Immediate Preparations Before Glovebox Operations
}

A.

November 4, 1978, "NWVP Assistance" identified 15 items for review and resolution. One of these items stated, "The likelihood of obtaining nonstoichiometric oxide product from the calciner is very real. What provisions have been made for handling, further treatment, etc., if this occurs?"

B. 1 --..", "Glovebox Startup Preparations" identified 17 items for correction or resolution. Nonstoichiometric oxide is not specifically addressed, but reference to item $A$ is made to include the items in that memo.

C. I.

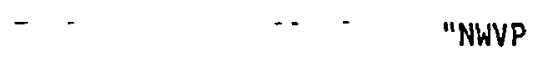
nonstoichiometric oxide. The memo states, "Other items identified in recent memos will be handled in other ways."

D. "Additional Agreements for NWVP Assistance" identifies 10 items for specific action. Again the list does not include nonstoichiometric oxide. It indicates the pressure of schedule by saying, "I understand that all items must be completed startup Monday, December 4."

E. "Status of NWVP Assistance" lists 6 items that have not been completed.

F. 1 325-A Building Readiness Review" lists 5 items to be completed. One item states, "Procedures for safe handling of nonstoichiometric oxide must be in place before calcining of Pu begins." It also refers to item $A$ above, and states, "Procedures to satisfactorily determine the presence of nonstoichiometric oxide in sealed containers must be in place before calciner operation with Pu feed." 
$$
\text { . }
$$ 
EXHIBIT 12. Safe Operating Procedure for NWVP Calcining Operation

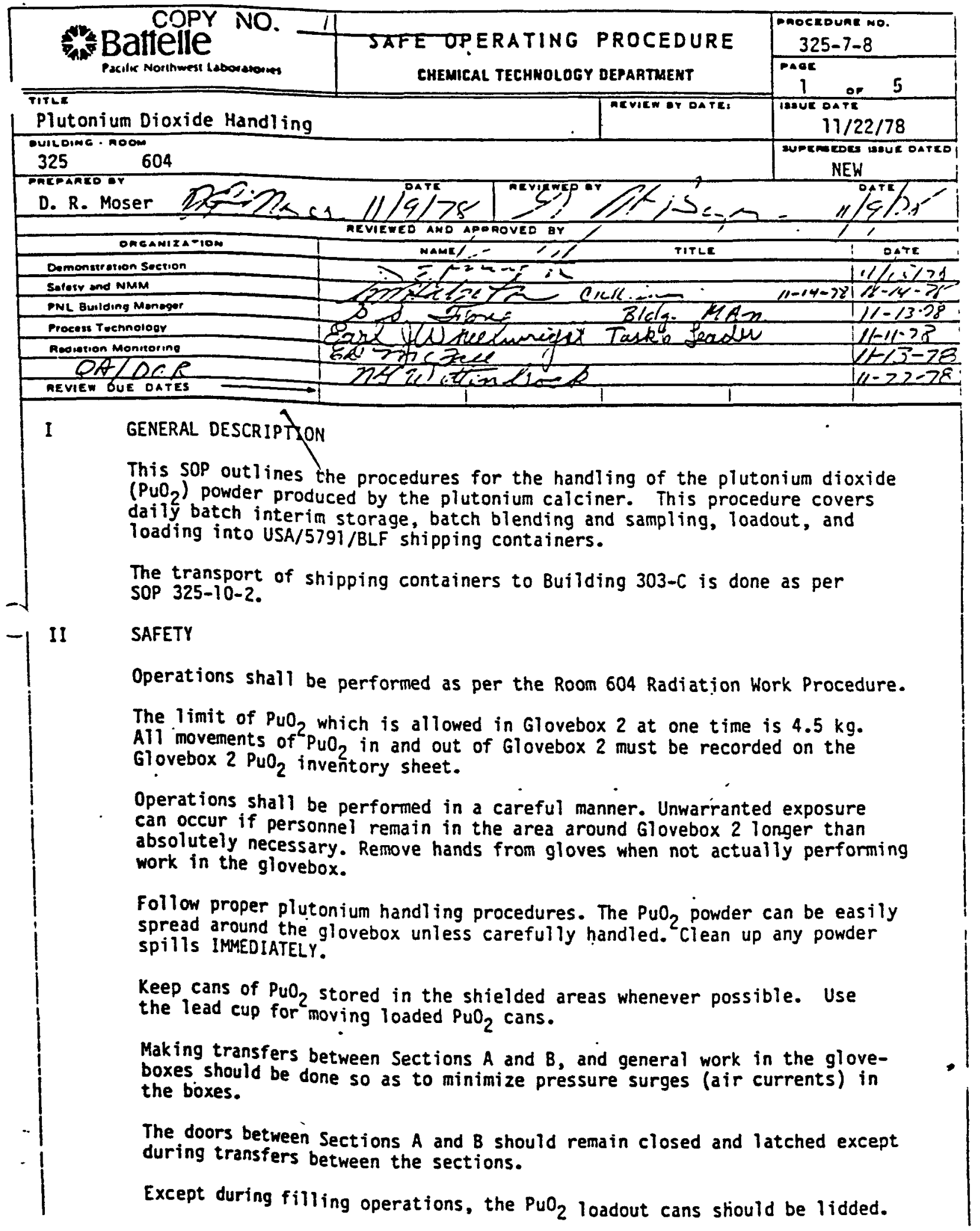




\section{EXHIBIT 12. Cont'd}

\section{SAFE OPERATING PROCEDURE}

\section{PROCEDURE}

NOTE: The same lid and can are to be used together and weighed together throughout the operation. $\mathrm{All} \mathrm{PuO}_{2}$ storage cans must be labeled for easy identication.

IMPORTANT: The power to the Scientech balance must be turned on at least 30 minutes prior to usage of the balance.

NOTE: If a Batch Blending and Loadout Worksheet was provided, carry out Steps 1 - 6, then 12 - 31, otherwise carry out Step 1 - 11.

1. Zero the balance. Record the $\mathrm{PuO}_{2}$ storage can number. Weigh the $\mathrm{PuO}_{2}$ storage can and lid. Record the weight on the plutonium dioxide handling worksheet (single batch) under " $\mathrm{PuO}_{2}$ Storage Can Tare Weight".

2. Move the stainless steel $\mathrm{PuO}_{2}$ receiver from Section $B$ to Section $A$ of the glovebox. Place the receiver in position under the calciner.

3. Proceed with SOP 325-7-7. This will place one batch (normally about 435 grams) of $\mathrm{PuO}_{2}$ in the receiver.

4. Place the cover on the $\mathrm{PuO}_{2}$ receiver. Move the receiver from Section $\mathrm{A}$ of the glovebox to Section $B$.

5. Using a spatula, carefully transfer the contents of the receiver into the storage can.

6. Zero the balance. Weigh the $\mathrm{PuO}_{2}$ storage can, lid and contents. Record the weight of the storage can, lid and contents on the $\mathrm{PuO}_{2}$ handling worksheet (single batch) under " $\mathrm{PuO}_{2}$ Storage Can Gross Weight".

7. Subtract the storage can tare weight from the gross weight and record the resulting weight under "Net $\mathrm{PuO}_{2}$ Weight".

8. Use white electricians' tape to tape seal the $\mathrm{PuO}_{2}$ storage can.

9. Obtain a security seal from the Operations Engineer. Place the seal on the $\mathrm{PuO}_{2}$ storage can. Record the security seal number on the worksheet.

10. Zero the balance. Weight the $\mathrm{PuO}_{2}$ storage $\mathrm{Can}, \mathrm{Iid}, \mathrm{PuO} 2$ and seals. Record the weight on the $\mathrm{PuO}_{2}$ Handling Worksheet (single batch) uncer "PuO 2 Sealed Storage Can Gross Weight".

11. Place the storage can in the shielded can storage area in the glovebox.

12. Sign, date, and record the time on the worksheet.

13. Place the worksheet in the completed worksheet basket.

NOTE: Proceed with Steps 14-31 only if a $\mathrm{PuO}_{2}$ handling worksheet (Batch Blending and Loadout) has been authorized for use by the Operations Engineer

$$
\text { TITLE Plutonium Dioxide Handling }
$$

$\int_{\text {nervisiom }}^{\frac{N E W}{11 / 22 / 78}}$ soe wo. $\frac{325-7-8}{2} \times \frac{5}{5}$




\section{EXHIBIT 12. Cont'd}

SAFE OPERATING PROCEDURE

\section{PROCEUURE (CONE d)}

14. Enter the $\mathrm{PuO}_{2}$ storage can number, sealed gross weight, gross weight, and tare weight, and $\mathrm{PuO}_{2}$ net weight on the Batch Blending and Loadout worksheet for the batch just processed.

NOTE: Blend all batches listed on the Batch Blending and Loadout Worksheet.

15. Remove a $\mathrm{PuO}_{2}$ receiver from the receiver storage area.

16. Zero the balance. Weight the storage can. Record the storage can number, security seal number, and sealed gross weight in the appropriate places on the Batch Blending and Loadout Worksheet.

17. Zero the balance. Break the security seal and destroy. Remove the white tape. Weigh the storage can and its contents and record the storage can gross weight in the appropriate place on the worksheet.

18. VERY CAREFULLY, use a spatula to transfer the $\mathrm{PuO}_{2}$ from the storage can to the $\mathrm{V}$-blender. The $\mathrm{PuO}_{2}$ weight in the $\mathrm{V}$-blender must not exceed $4.5 \mathrm{Kg}$.

19. Zero the balance. Weigh the now empty $\mathrm{PuO}_{2}$ storage can and record the storage can tare weight on the worksheet. Determine the net weight of $\mathrm{PuO}_{2}$ transferred.

20. Repeat Steps $15-19$ for the remaining $\mathrm{PuO}_{2}$ storage cans in the can storage area and for the last single batch processed.

21. Operate the V-blender for one hour.

22. Two 1 to 2 gram samples and one 0.1 to 0.2 gram $\mathrm{PuO}_{2}$ sample are to be taken. Zero the balance. Weigh each sample bottle and record each weight under "Sample Bottle Tare Weight". Also record the sample bottle numbers in the appropriate places.

23. Use a spatula to carefully transfer the needed amount of $\mathrm{PuO}_{2}$ to the sample bottles.

24. Reweigh each bottle and record each weight under "Sample Bottle Gross Weight". Determine the net weight of each sample and record on the data sheet.

25. Zero the balance. Determine the tare weight of each of the inner loadout cans. Important: Use enough inner loadout cans so that the amount of $\mathrm{PuO}_{2}$ in any one can does not exceed $1.3 \mathrm{~kg}$. Record the tare weights on the work sheet.

26. Using a spatula, carefully transfer the $\mathrm{PuO}_{2}$ from the $\mathrm{V}$-blender into the inner loadout cans.

27. Place the lids on the cans and weigh each can. Record the inner can gross weights on the data sheet.

28. Determine the $\mathrm{PuO}_{2}$ net weight in each can. $\mathrm{No}$ can is to exceed $1.3 \mathrm{~kg}$. of $\mathrm{PuO}_{2}$.

29. Tape seal the loadout cans with white tape.

TITL Rlutonium Dioxide Handing

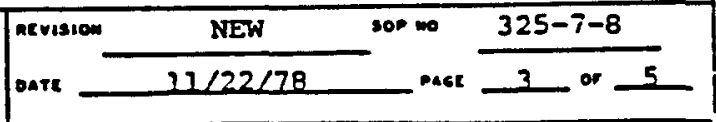


EXHIBIT 12. Cont'd

\section{SAFE OPERATING PROCEDURE}

III PROCEDURE (cont'd)
$\therefore \quad 30$. Weigh each sealed can and record the weight.
IMPORTANT: If Steps 31 and 32 cannot be carried out immediately, then obtain the necessary number of security seals from the Operations Engineer to seal the loaded Pu loadout cans in the glovebox. Security seal each of the loaded inner loadout cans and record the security seal numbers.
31. Bagout each can as per SOP 325-7-9. This should be done carefully to minimize exposure.
32. Place the can and surrounding bag in an aluminum foil "cradle" in an outer load out can. Mechanically seal the outer loadout can. Record the outer loadout can number in the appropriate place on the worksheet. Obtain a security seal from the Operations Engineer and seal the outer loadout can. Record the seal number on the worksheet.

33. Place a maximum of two loadout can assemblies (the inner/outer can combination) in the USA/579T/BLF shipping container.

a. Because of the high heat loads allowed, combustible packaging material is not allowed.

b. The primary container should provide adequate heat transfer. Encapsulating or placing the material in sealed metal containers is considered proper packaging. The surface of the primary container should be free of contamination.

c. Place the primary container inside the inner steel $2 R$ container. To prevent excessive movement, the primary container should be surrounded by aluminum foil or other suitable material.

d. Make certain the lid is bolted on the $2 R$ steel container.

e. Make certain the $2 R$ steel inner container is well seated in the cellulose wadding before replacing celotex cover.

f. Check gasket on the drum cover. The gasket should be soft and pliable, free from cracks and splits. If not in good condition, replace.

g. Place cover on drum and install lock ring. Make certain that the lock ring is installed with the lock ring tabs (lugs) in the down position. Insert bolt in lock ring tabs and wrench tighter. A lock nut must be used on bolt. A $3 / 8$ inch diameter bolt must be used on the 55 gallon drum and a $5 / 8$ inch, diameter bolt on drums larger than 55 gallon.

h. Attach a tamperproof seal to the bolt near the locking nut to prevent illicit entry.

1. Record the seal number on the worksheet. Important: If a seal was broken to load the USA/5791/BLF container, record the broken seal number and give the seal to the Operations Engineer.

\begin{tabular}{|c|c|c|c|}
\hline nevisian & NEW & Sor mo. & $325-7-8$ \\
\hline oare & $11 / 22 / 78$ & pace & 4 \\
\hline
\end{tabular}




\section{EXHIBIT 12. Cont'd}

SAFE OPERATING PROCEDURE

\section{PROCEDURE (Cont'd)}

34. Label the container as required by R.M.

35. The shipping containers also must be labeled with the following information:

Applicable Criticality Safety Specification (325-1.4)

Maximum $\mathrm{PuO}_{2}$ permitted $(5.6 \mathrm{Kg}$ per container).

Amount of $\mathrm{PuO}_{2}^{2}$ in the container.

36. Sign and date the worksheets. Place them in the Completed Worksheet basket.

acvision

NEW

200 $00 . \quad 325-7-8$ Dore

$11 / 22 / 78$
mex $5 \% 5$ 
$$
\text { . }
$$ 
EXHIBIT 13. SOP for Plutonium Oxide Transfer from the 324 Building to the 303-C Building

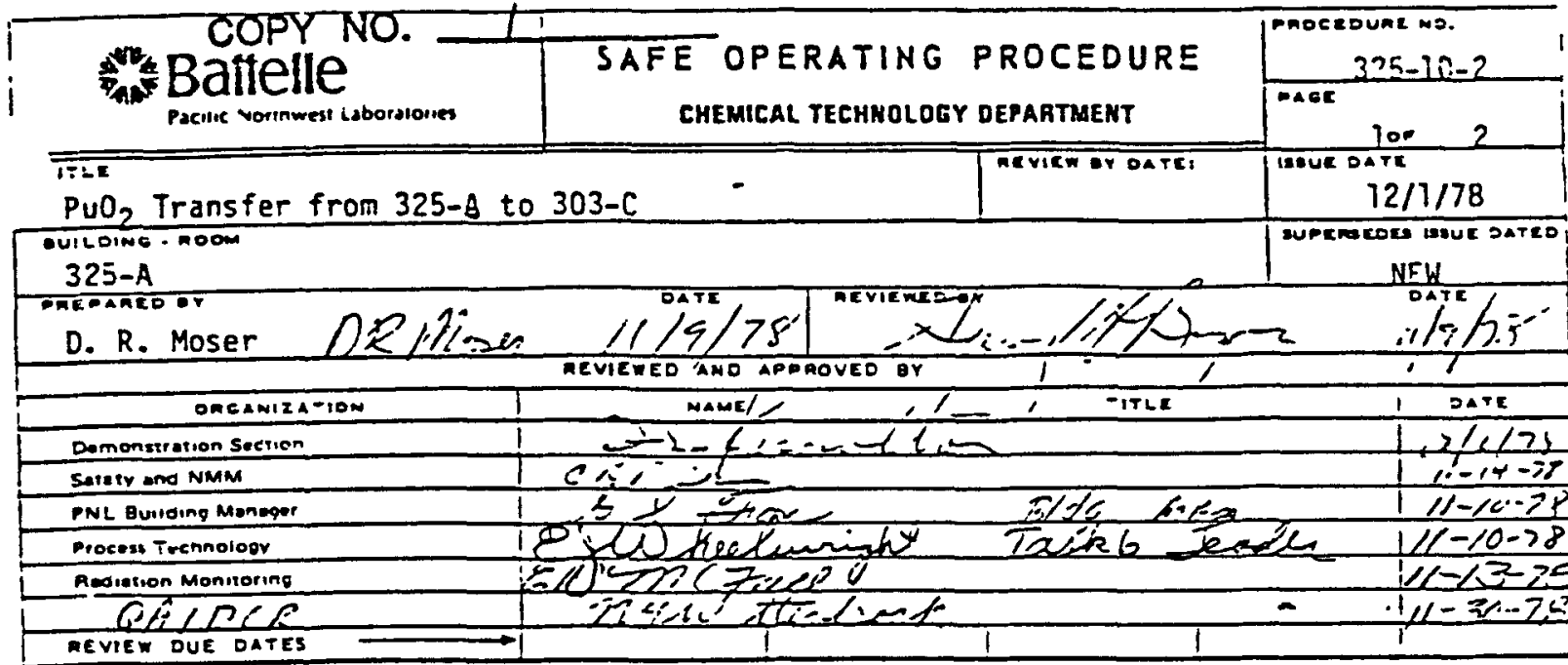

I GENERAL DESCRIPTION

The $\mathrm{PuO}_{2}$ powder is packaged and loaded into BLF/5791/USA shipping containers as per SOP 325-7-8. SOP 325-10-2 concerns the transfer of the shipping containers to $303-\mathrm{C}$ and return to $325-\mathrm{A}$.

The shipping container transfers are done by Rockwell transportation and must be accompanied by Patrol. An exempt Operations member also must accompany the shipment.

\section{SAFETY}

The shipping containers must not be loaded with more than $5.6 \mathrm{~kg}$ of $\mathrm{PuO}_{2}$. Other fissionable materials are to be kept at least 3 feet from the shipping containers.

The shipping containers must be labeled, giving the following information:

Applicable Criticality Safety Specifications (325-1.4)

Maximum $\mathrm{PuO}_{2}$ permitted $(5.6 \mathrm{Kg}$ per container)

Amount of $\mathrm{PuO}_{2}$ in the container.

The shipping containers weigh several hundred pounds each. Care must be exercised when moving these heavy barrels.

\section{PROCEDURE}

1. The following notifications must be made at least 24 hours prior to a shipment.

Patrol

Rockwell Transportation

F. Zelly or A. Pentella

J. L. Green

G. H. Bryan

E. D. McFall

2. A copy of the applicable Batch Blending and Loadout Worksheet of SOP 325-7-8 must accompany the container. 


\section{EXHIBIT 13. Cont'd}

\section{SAFE OPERATING PROCEDUAE}

\section{PROCEDURE (cont'd)}

- 3. Verify that the container is labeled with the following information:

Applicable Criticality Safety Specification (325-1.4)

Maximum $\mathrm{PuO}_{2}$ permitted $(5.6 \mathrm{~kg}$ per container)

Amount $\mathrm{PuO}_{2}$ in container

4. Fill out an Onsite Radioactive Shipment record.

5. Using a barrel lifter, move the container from Room 604 to the Truck Lock when the truck is in position.

6. Load the barrel on the transport vehicle.

7. Have the driver secure the barrel to the transport vehicle.

8. Have RM survey as necessary.

9. Have the driver, escorted by Patrol and accompanied by an Operations exempt, proceed to $303-\dot{C}$.

10. Have the driver unload the shipping container at a location outside the gate as specified by a $303-C$ representative.

11. Have the 303-C assigned people take the containers into 303-C, unload, and return the container to the truck. Obtain a receipt of transfer.

NOTE: Upon return to $325-\mathrm{A}$, give the transfer receipt to the SNM Custodian.

12. Have RM survey as necessary.

13. Have the driver place the now-empty container on the truck and secure.

14. Have the driver return to 325-A.

15. Unload the container.

16. Store the container in Room 604 .

17. Verify the container is properly labeled for storage.

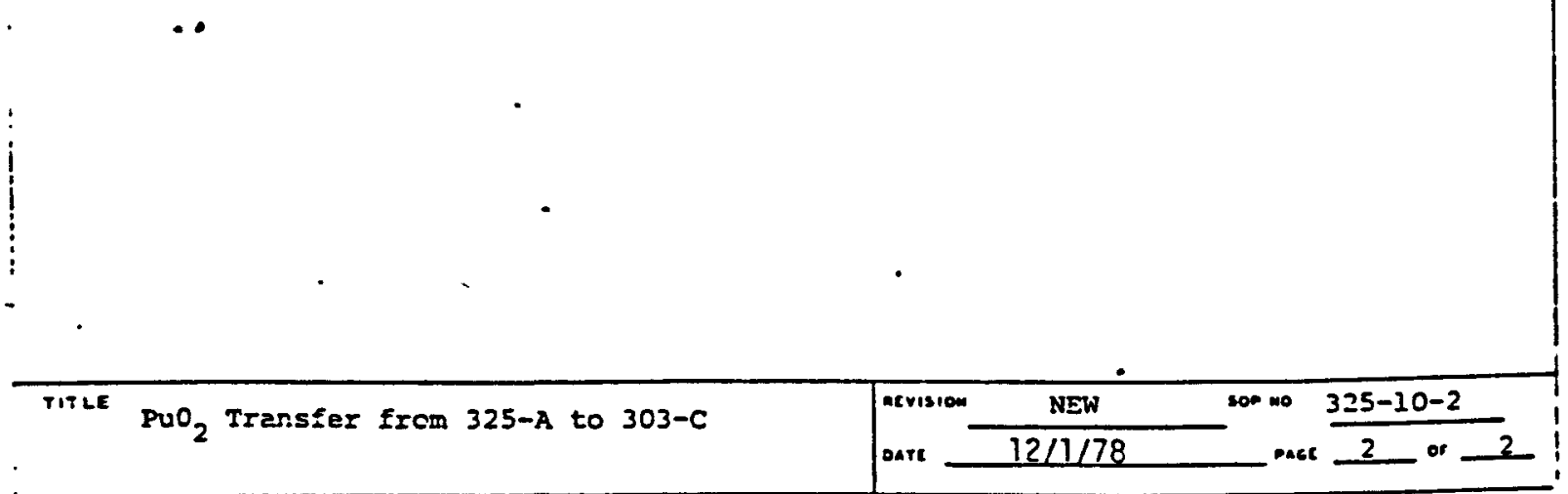




\title{
EXHIBIT 14. Memos, "303-C Dose Calculations"
}

\section{sats Battelle \\ Pacific Northwest Laboratories}

Project Number

Iniernal Distribution

File/LB

\author{
Dale May 2, 1979 \\ To George Backman \\ from Dave McCormack \\ Subjeat 303-C DOSE CALCULATIONS
}

Based on the measured air concentration in 3708 of $1.4 \times 10^{-10} \mu \mathrm{Ci} / \mathrm{Cc}$ a (memo Hickman to Backman $4 / 27 / 79$ ), the dose to an individual breathing this concentration for one hour is $35 \mathrm{mrem} / \mathrm{yr}$ to the lung and $135 \mathrm{mrem} / 50$ yrs to the bone. This calculation assumes the same isotopic plutonium breakdown described in my memo to you dated $4 / 27 / 79$. It is interesting to note that the calculated air concentration outside the 3708 building is $7.7 \times 10^{-10} \mu \mathrm{Ci} / \mathrm{Cc}$ a.

WOM:dp 
EXHIBIT 14. Cont'd

Table 1 First Year Dose - mrem - From 303-C

Plutonium Release

\begin{tabular}{|c|c|c|c|}
\hline Distance & $\begin{array}{l}\text { Total } \\
\text { Body }\end{array}$ & Bone & Lung \\
\hline $30 \mathrm{~m}$ & $2.7 \times 10^{-1}$ & $6.5 \times 10^{0}$ & $2.6 \times 10^{2}$ \\
\hline $350 \mathrm{~m}$ & $3.6 \times 10^{-3}$ & $8.6 \times 10^{-2}$ & $3.5 \times 10^{0}$ \\
\hline $4870 \mathrm{~m}$ & $3.2 \times 10^{-5}$ & $7.6 \times 10^{-4}$ & $3.0 \times 10^{-2}$ \\
\hline
\end{tabular}

Table 250 Year Dose Commitment - mrem From 303-C Plutonium Release

\begin{tabular}{rccc} 
Distance & $\begin{array}{c}\text { Total } \\
\text { Body }\end{array}$ & Bone & Lung \\
\hline $30 \mathrm{~m}$ & $4.5 \times 10^{1}$ & $1.0 \times 10^{3}$ & $6.4 \times 10^{2}$ \\
$350 \mathrm{~m}$ & $5.9 \times 10^{-1}$ & $1.3 \times 10^{1}$ & $8.4 \times 10^{0}$ \\
$4870 \mathrm{~m}$ & $5.3 \times 10^{-3}$ & $1.1 \times 10^{-1}$ & $7.5 \times 10^{-2}$
\end{tabular}

Table 3 Documentation of Dose Calculation For 303-C Plutonium Release

Facility: $303-C$

Releases: $9.6 \times 10^{8} \mathrm{pCi} \mathrm{Pu}-238,1.4 \times 10^{8} \mathrm{pCi} \mathrm{Pu}-239,2.1 \times 10^{8} \mathrm{pCi}$ $\mathrm{Pu}-240,4.0 \times 10^{10} \mathrm{pCi} \mathrm{Pu}-241,6.9 \times 10^{5} \mathrm{pCi} \mathrm{Pu}-242$

Meteorological conditions: Unstable

Wind Speed: $5 \mathrm{~m} / \mathrm{s}$

Dispersion Model: Gaussan, Hanford Parameters

Release height: $2 \mathrm{~m}$

$x / Q: 2.8 \times 10^{-3} \mathrm{sec} / \mathrm{m}^{3}$ o $30 \mathrm{~m}$ south, $3.7 \times 10^{-5} \mathrm{sec} / \mathrm{m}^{3}$ e $350 \mathrm{~m} \mathrm{south}$, and $3.3 \times 10^{-7} \mathrm{sec} / \mathrm{m}^{3}$ o $4870 \mathrm{~m}$ south

Computer Code: DACRIN, Rev. 3-31-78

Calculated dose: Acute inhalation, maximum individual, first year dose and 50 year dose commitment

Files addressede : Organ data library, Rev. 10-24-78

THERMA library, Rev. 10-29-75 
Battelle

Pacific Northwest Laboratories
Project Number

Internal Distribution

File/LB

Dale April 27, 1979

To George Backman

From Dave McCormack

Subject 303-C DOSE CALCULATIONS

Calculated inhalation doses from the 303-C plutonium release are attached. These doses assume a steady north wind of $5 \mathrm{~m} / \mathrm{s}$ and a release height of $2 \mathrm{~m}$. The dose receptors are located $30 \mathrm{~m}$ downwind, $350 \mathrm{~m}$ downwind (Cypress Gate parking lot) and, $4870 \mathrm{~m}$ downwind (Sprout Rd), and are assumed to be present for the entirety of the release. The release is based on $1.3 \mathrm{mCi}$ of alpha activity with the following Pu breakdown.

$\begin{array}{rcc} & \frac{W T \%}{1 T} & \text { Act \% } \\ \text { Pu-238 } & 1.49 & 2.32 \\ 239 & 59.50 & .332 \\ 240 & 23.98 & .50 \\ 241 & 10.33 & 96.8 \\ 242 & 4.70 & .00167\end{array}$

As a result, a total of $41 \mathrm{mCi}$ (including the Pu-241 activity not included in the $1.3 \mathrm{mCi}$ ) was released. These doses are calculated conservatively and should be considered a maximum upper bound of potential dose.

WDM: dp 
$$
\text { . }
$$ 


\section{EXHIBIT 15. Sumnary of Air Sample Data}

\section{Battelle}

Pacific Northwest Laboratories
Dale
May 2, 1979
To George Backman
From
Suhpect

Project Number

Internal Distribution

JJ Jech

LB/File

When analyzing this data keep in mind that the detection limit (D.L.) may change from sample to sample. The D.L. is a function of sampling period, flow rate, counting period, and background count all of which are variable.

The data is segregated into two parts. The first part provides a summary of data during the sampling period up to 4-19-79 of all samples directly associated with the $303 \mathrm{C}$ Building. The second part is a summary of data during the sampling period covering 3-13-79 for various facilities. Joe Berry assisted in the selection of sample locations. A second value is calculated for data in the second part of this report which assumes a one hour release-sampling period. Please keep in mind that the assumption of a one-hour sampling period can improperly bias the results. In many cases we are showing results in 10-12 range (using the 1 hour assumption) which represent only a few alpha counts over a 200-second counting period.

A large portion of the data was hand calculated and not all of the calculations have been double checked, however most of the pertinent data is fairly close to what the air sample computer printout will provide. 
EXHIBIT 15. Cont'd

PART I

$303 C$ BUILDING SAMPLES 
EXHIBIT 15. Cont'd

$$
\text { 303C STACK - \& CONC.ONLY }
$$

\begin{tabular}{|c|c|c|c|c|c|}
\hline DATE & $\begin{array}{l}\text { TIME } \\
\text { ON } \\
\end{array}$ & $\begin{array}{l}\text { OFF } \\
\text { DATE }\end{array}$ & $\begin{array}{l}\text { TIME } \\
\text { OFF } \\
\end{array}$ & $\begin{array}{l}\text { MANUAL } \\
\text { UCi/CC }\end{array}$ & $\begin{array}{l}\text { 7-DAY DELAY COUNT } \\
\text { UC }\{/ C C\end{array}$ \\
\hline $3-8$ & 0900 & $3-13$ & 0920 & $3.3 \times 10^{-9 *}$ & \\
\hline $3-13$ & 0920 & $3-13$ & 0930 & $1.2 \times 10^{-6}+$ & \\
\hline $3-14$ & 0830 & $3-15$ & 1100 & $<1.0 \times 10^{-13}$ & $1.9 \times 10^{-15}$ \\
\hline $3-15$ & 1100 & $3-16$ & 1120 & $41.0 \times 10^{-13}$ & $4.1 \times 10^{-15}$ \\
\hline $3-16$ & 1120 & $3-19$ & 0920 & $<1.0 \times 10^{-13}$ & $2.4 \times 10^{-15}$ \\
\hline $3-19$ & 0900 & $3-20$ & 0900 & $<1.0 \times 10^{-13}$ & $4.9 \times 10^{-15}$ \\
\hline $3-20$ & 0900 & $3-21$ & 0900 & $<1.0 \times 10^{-13}$ & $2.1 \times 10^{-15}$ \\
\hline $3-21$ & 0900 & $3-22$ & 0900 & $<1.0 \times 10^{-13}$ & $4.9 \times 10^{-15}$ \\
\hline $3-22$ & 0900 & $3-23$ & 0900 & $<1.0 \times 10^{-13}$ & $2.1 \times 10^{-15}$ \\
\hline $3-23$ & 0900 & $3-26$ & 0900 & $<7.1 \times 10^{-13}$ & $6.9 \times 10^{-16}$ \\
\hline $3-26$ & 0900 & $3-27$ & 0900 & $21.0 \times 10^{-13}$ & $2.1 \times 10^{-15}$ \\
\hline $3-27$ & 0900 & $3-27$ & 1600 & $<1.0 \times 10^{-13}$ & $7.7 \times 10^{-15}$ \\
\hline $3-27$ & 1600 & $3-28$ & 0900 & $<1.0 \times 10^{-13}$ & $2.9 \times 10^{-15}$ \\
\hline $3-28$ & 0900 & $3-29$ & 0900 & $<1.0 \times 10^{-13}$ & $2.1 \times 10^{-15}$ \\
\hline $3-29$ & 0900 & $3-30$ & 0900 & $<1.0 \times 10^{-13}$ & $4.2 \times 10^{-15}$ \\
\hline $3-30$ & 0900 & $4-2$ & 0900 & $<1.0 \times 10^{-13}$ & $<9.3 \times 10^{-16}$ \\
\hline $4-2$ & 0900 & $4-3$ & 0900 & $<1.0 \times 10^{-13}$ & $<9.3 \times 10^{-16}$ \\
\hline $4-3$ & 0900 & $4-4$ & 0900 & $<1.0 \times 10^{-13}$ & $<9.3 \times 10^{-16}$ \\
\hline $4-4$ & 0900 & $4-5$ & 0900 & $<1.0 \times 10^{-13}$ & $2.8 \times 10^{-15}$ \\
\hline $4-5$ & 0900 & $4-9$ & 1400 & $<1.0 \times 10^{-13} \mathrm{o}$ & \multirow{7}{*}{$\begin{array}{l}\text { These samples will be } \\
\text { counted } 4 / 20 / 79 \text { (weekend) }\end{array}$} \\
\hline $4-9$ & 1400 & $4-10$ & 0900 & $3.7 \times 10^{-11}$ & \\
\hline $4-10$ & 0900 & $4-10$ & 1330 & $<1.0 \times 10^{-13}$ & \\
\hline $4-10$ & 1330 & $4-11$ & 0900 & $<1.0 \times 10^{-13}$ & \\
\hline $4-11$ & 0900 & $4-12$ & 0900 & $<1.0 \times 10^{-13}$ & \\
\hline $4-12$ & 0900 & $4-16$ & 0900 & $<1.0 \times 10^{-13}$ & \\
\hline $4-76$ & 0900 & $4-17$ & 0900 & $<1.0 \times 10^{-13}$ & \\
\hline $4-17$ & 0900 & $4-18$ & 0900 & $<1.0 \times 10^{-13}$ & \multirow[t]{2}{*}{$\begin{array}{l}\text { These samples will be } \\
\text { counted } 4 / 27 / 79 \text { (weekend) }\end{array}$} \\
\hline $4-18$ & 0900 & $4-19$ & 0900 & $<1.0 \times 10^{-13}$ & \\
\hline
\end{tabular}

- Cross Contaminated

+ Extrapolated from $1.5 \times 10^{6} \mathrm{dpm}$ (Bumble Bee C.P.)

- Extrapolated from $3 \times 10^{6} \mathrm{dpm}$ (Juno), based on total sample period. 
EXHIBIT 15. Cont'd

303 DUCT - a CONC. ONLY

\begin{tabular}{|c|c|c|c|c|c|}
\hline DATE & $\begin{array}{l}\text { TIME } \\
\text { ON } \\
\end{array}$ & $\begin{array}{r}\text { OFF } \\
\text { DATE } \\
\end{array}$ & $\begin{array}{l}\text { TIME } \\
\text { OFF } \\
\end{array}$ & $\begin{array}{l}\text { MANUAL } \\
\text { UCi/CC } \\
\end{array}$ & $\begin{array}{c}\text { 7-DAY DELAY COUNT } \\
\mathrm{UCi} / \mathrm{CC}\end{array}$ \\
\hline $3-13$ & 1600 & $3-13$ & 1655 & $9.7 \times 10^{-11}$ & $1.2 \times 10^{-10}$ \\
\hline $3-13$ & 1655 & $3-14$ & 0830 & $7.9 \times 10^{-11}$ & $6.3 \times 10^{-11}$ \\
\hline $3-14$ & $8: 30$ & $3-15$ & 11100 & $4.3 \times 10^{-11}$ & $6.9 \times 10^{-11}$ \\
\hline $3-75$ & 1100 & $3-15$ & 1120 & $1.0 \times 10^{-11}$ & $2.3 \times 10^{-14}$ \\
\hline $3-16$ & 1120 & $3-19$ & 0900 & $7.5 \times 10^{-12}$ & $1.2 \times 10^{-11}$ \\
\hline $3-19$ & 0900 & $3-20$ & 0900 & $6.6 \times 10^{-12}$ & $9.7 \times 10^{-12}$ \\
\hline $3-20$ & 0900 & $3-21$ & 0900 & $5.3 \times 10^{-12}$ & $7.8 \times 10^{-12}$ \\
\hline $3-21$ & 0900 & $3-22$ & 0900 & $5.2 \times 10^{-12}$ & $8.0 \times 10^{-12}$ \\
\hline $3-22$ & 0900 & $3-23$ & 1500 & $5.7 \times 10^{-12}$ & $1.1 \times 10^{-11}$ \\
\hline $3-23$ & 1500 & $3-26$ & 0900 & $6.7 \times 10^{-12}$ & $3.3 \times 10^{-11}$ \\
\hline $3-26$ & 0900 & $3-27$ & 0900 & $7.3 \times 10^{-12}$ & $1.2 \times 10^{-11}$ \\
\hline $3-27$ & 0900 & $3-27$ & 1600 & $1.3 \times 10^{-10}$ & $1.5 \times 10^{-10}$ \\
\hline $3-27$ & 1600 & $3-28$ & 0900 & $1.5 \times 10^{-12}$ & $2.2 \times 10^{-12}$ \\
\hline $3-28$ & 0900 & $3-29$ & 0900 & $1.6 \times 10^{-12}$ & $2.3 \times 10^{-12}$ \\
\hline $3-29$ & 0900 & $3-30$ & 0900 & $1.0 \times 10^{-12}$ & $1.7 \times 10^{-12}$ \\
\hline $3-30$ & 0900 & $4-2$ & 0900 & $1.2 \times 10^{-12}$ & $2.0 \times 10^{-12}$ \\
\hline $4-2$ & 0900 & $4-3$ & 0900 & $1.3 \times 10^{-12}$ & $1.8 \times 10^{-12}$ \\
\hline $4-3$ & 0900 & $4-4$ & ogn? & $1.2 \times 10^{-12}$ & $2.9 \times 10^{-12}$ \\
\hline 4-4 & 0900 & $4-5$ & 0900 & $1.6 \times 10^{-12}$ & $3.6 \times 10^{-12}$ \\
\hline $4-5$ & 0900 & $4-9$ & 1400 & $7.4 \times 10^{-12}$ & $1.5 \times 10^{-11}$ \\
\hline $4-9$ & 1400 & $4-10$ & 0900 & Missing & \\
\hline $4-10$ & 0900 & $4-10$ & 1330 & $3.5 \times 10^{-10}$ & $4.4 \times 10^{-10}$ \\
\hline $4-10$ & 1330 & $4-11$ & 0900 & $1.2 \times 10^{-11}$ & $8.8 \times 10^{-12}$ \\
\hline $4-11$ & 0900 & $4-12$ & 0900 & $2.4 \times 10^{-12}$ & $3.1 \times 10^{-12}$ \\
\hline $4-12$ & 0900 & $4-16$ & 0900 & $\left.3.7 \times 10^{-12}\right)$ & \\
\hline $4-16$ & 0900 & $4-17$ & $n 900$ & $1.1 \times 10^{-12}$ & not counted yet \\
\hline $4-17$ & 0900 & $4-18$ & 0900 & $4.4 \times 10^{-13}$ & \\
\hline $4-18$ & 0900 & $4-19$ & 0900 & $7.1 \times 10^{-13}$ & \\
\hline
\end{tabular}


EXHIBIT 15. Cont'd

OUTER AIRLOCX (OR AIRLOCK \#2)

\begin{tabular}{|c|c|c|c|c|c|}
\hline DATE & $\begin{array}{l}\text { TIME } \\
\text { ON } \\
\end{array}$ & $\begin{array}{r}\text { OFF } \\
\text { DATE }\end{array}$ & $\begin{array}{l}\text { TIME } \\
\text { OFF } \\
\end{array}$ & $\begin{array}{l}\text { MANUAL } \\
\text { UCi/CC } \\
\end{array}$ & $\begin{array}{c}\text { 7-DAY DELAY COUNT } \\
\text { UCi/CC }\end{array}$ \\
\hline $3-20$ & 1500 & $3-21$ & 0900 & $<1.0$ & $<2.8 \times 10^{-14}$ \\
\hline $3-21$ & 0900 & $3-22$ & 0900 & $<1.0$ & $<2.1 \times 10^{-14}$ \\
\hline $3-22$ & 0900 & $3-26$ & 0900 & no sample & \\
\hline $3-27$ & 0900 & $3-27$ & 1600 & $<1.0$ & $7.1 \times 10^{-14}$ \\
\hline $3-27$ & 1600 & $3-28$ & 0900 & $<1.0$ & $2.9 \times 10^{-14}$ \\
\hline $3-28$ & 0900 & $3-29$ & 0900 & $6.0 \times 10^{-13}$ & $<2.1 \times 10^{-14}$ \\
\hline $3-29$ & 0900 & $3-30$ & 0900 & $<1.0$ & $<2.1 \times 10^{-14}$ \\
\hline $3-30$ & 0900 & $4-2$ & 0900 & $<1.0$ & $<6.9 \times 10^{-15}$ \\
\hline $4-4$ & 0900 & $4-5$ & 0900 & $<1.0$ & $<2.1 \times 10^{-14}$ \\
\hline $4-5$ & 0900 & $4-6$ & 1100 & $2.2 \times 10^{-12}$ & \\
\hline $4-6$ & 1100 & $4-6$ & 1250 & $<1.0$ & $<2.7 \times 10^{-13}$ \\
\hline $4-6$ & 1250 & $4-9$ & 1325 & $<1.0$ & $<6.8 \times 10^{-15}$ \\
\hline $4-9$ & 1320 & $4-10$ & 0900 & $<1.0$ & $7.6 \times 10^{-14}$ \\
\hline $4-10$ & 0900 & $4-10$ & 1330 & $<1.0$ & $<1.1 \times 10^{-13}$ \\
\hline $4-10$ & 1330 & $4-11$ & 0900 & $<. .0$ & $<2.6 \times 10^{-14}$ \\
\hline $4-11$ & 0900 & $4-12$ & 0900 & $4.9 \times 10^{-13}$ & $<2.1 \times 10^{-14}$ \\
\hline $4-12$ & 0900 & $4-16$ & 0900 & $<1.0$ & \\
\hline $4-16$ & 0900 & $4-17$ & 0900 & $<1.0$ & not counted yet \\
\hline $4-17$ & 0900 & $4-18$ & 0900 & $<1.0$ & \\
\hline $4-18$ & 0900 & $4-19$ & 0900 & $1.9 \times 10^{-13}$ & \\
\hline $3-31$ & 0900 & $4-1$ & 0900 & -.. & $1.0 \times 10^{-14}$ \\
\hline $3-22$ & 0900 & $3-23$ & 0900 & -- & $4.2 \times 10^{-14}$ \\
\hline $3-23$ & 0900 & $3-26$ & 0900 & --- & $<2.1 \times 10^{-14}$ \\
\hline $3-26$ & 0900 & $3-27$ & 0900 & $\cdots$ & $4.2 \times 10^{-14}$ \\
\hline
\end{tabular}


EXHIBIT 15. Cont'd

INNER AIRLOCK (OR AIRLOCK \#1)

\begin{tabular}{|c|c|c|c|c|c|}
\hline DATE & $\begin{array}{l}\text { TIME } \\
\text { ON } \\
\end{array}$ & $\begin{array}{r}\text { OFF } \\
\text { DATE } \\
\end{array}$ & $\begin{array}{l}\text { TIME } \\
\text { OFF } \\
\end{array}$ & $\begin{array}{l}\text { MANUAL } \\
\text { UCi/CC }\end{array}$ & $\begin{array}{l}\text { 7-DAY DELAY COUNT } \\
\text { UCi/CE }\end{array}$ \\
\hline $3-20$ & 1500 & $3-21$ & 0900 & $6.1 \times 10^{-13}$ & $<2.8 \times 10^{-14}$ \\
\hline $3-21$ & 0900 & $3-22$ & 0900 & $<1.0$ & $<2.1 \times 10^{-14}$ \\
\hline $3-22$ & 0900 & $3-26$ & 0900 & $<1.0$ & $<6.9 \times 10^{-15}$ \\
\hline $3-27$ & 0930 & $3-27$ & 1600 & $2.8 \times 10^{-11}$ & $4.0 \times 10^{-11}$ \\
\hline $3-27$ & 1600 & $3-28$ & 0930 & $<1.0$ & $2.4 \times 10^{-15}$ \\
\hline $3-28$ & 0930 & $3-29$ & 0930 & $<1.0$ & $<2.0 \times 10^{-14}$ \\
\hline $3-29$ & 0930 & $3-30$ & 0930 & $1.4 \times 10^{-13}$ & $2.0 \times 10^{-14}$ \\
\hline $3-30$ & 0930 & $4-2$ & 0930 & $<7.0$ & $6.9 \times 10^{-15}$ \\
\hline $4-4$ & 0900 & $4-5$ & 0900 & $<1.0$ & \\
\hline $4-5$ & 0900 & $4-5$ & 0940 & $<1.0$ & $3.1 \times 10^{-11}$ \\
\hline $4-6$ & 0940 & $4-6$ & 1250 & $2.0 \times 10^{-13}$ & $3.2 \times 10^{-13}$ \\
\hline $4-6$ & 1250 & $4-9$ & 1320 & $<1.0$ & $6.9 \times 10^{-15}$ \\
\hline $4-9$ & 1320 & $4-10$ & 0900 & $6.0 \times 10^{-13}$ & $5.1 \times 10^{-14}$ \\
\hline $4-10$ & 0900 & $4-10$ & 1330 & $2.6 \times 10^{-11}$ & $6.4 \times 10^{-12}$ \\
\hline $4-10$ & 1330 & $4-11$ & 0900 & $8.4 \times 10^{-13}$ & $5.1 \times 10^{-14}$ \\
\hline $4-11$ & 0900 & $4-12$ & 0900 & $<1.0$ & $<2.1 \times 10^{-14}$ \\
\hline $4-12$ & 0900 & $4-16$ & 0900 & $<1.0$ & not counted yet \\
\hline $4-16$ & 0900 & $4-17$ & 0900 & $4.9 \times 10^{-13}$ & \\
\hline $4-17$ & 0900 & $4-18$ & 0900 & $<1.0$ & \\
\hline $4-18$ & 0900 & $4-19$ & 0900 & $<1.0$ & \\
\hline
\end{tabular}


EXHIBIT 15. Cont'd

MCI WEST - a CONC. ONLY

\begin{tabular}{|c|c|c|c|c|c|}
\hline DATE & $\begin{array}{l}\text { TIME } \\
\text { ON } \\
\end{array}$ & $\begin{array}{r}\text { OFF } \\
\text { DATE } \\
\end{array}$ & $\begin{array}{l}\text { TIME } \\
\text { OFF } \\
\end{array}$ & $\begin{array}{l}\text { MANUAL } \\
\text { UCi/CC } \\
\end{array}$ & $\begin{array}{l}\text { 7-DAY DELAY COUNT } \\
\mathrm{UCi} / \mathrm{CC}\end{array}$ \\
\hline $3-13$ & 1100 & $3-13$ & 1210 & $<1.0 \times 10^{-13}$ & $5.7 \times 10^{-13}$ \\
\hline $3-13$ & 1210 & $3-13$ & 1570 & $<1.0 \times 10^{-13}$ & $<2.2 \times 10^{-13}$ \\
\hline $3-13$ & 1510 & $3-14$ & 0830 & $2.5 \times 10^{-13}$ & $3.8 \times 10^{-14}$ \\
\hline $3-14$ & 0830 & $3-15$ & 1100 & $<1.0 \times 10^{-13}$ & $5.0 \times 10^{-14}$ \\
\hline $3-15$ & 1100 & $3-16$ & 1120 & $9.7 \times 10^{-13}$ & $1.5 \times 10^{-14}$ \\
\hline $3-16$ & 1120 & $3-19$ & 0900 & $<1.0 \times 10^{-13}$ & $3.8 \times 10^{-14}$ \\
\hline $3-19$ & 0900 & $3-20$ & 0900 & $<1.0 \times 10^{-13}$ & $<2.8 \times 10^{-14}$ \\
\hline $3-20$ & 0900 & $3-21$ & 0900 & $<1.0 \times 10^{-13}$ & $<2.8 \times 10^{-14}$ \\
\hline $3-21$ & 0900 & $3-22$ & 0900 & $<1.0 \times 10^{-13}$ & $2.8 \times 10^{-14}$ \\
\hline $3-22$ & 0900 & $3-23$ & 0900 & $<1.0 \times 10^{-13}$ & $<2.8 \times 10^{-14}$ \\
\hline $3-23$ & 0900 & $3-26$ & 0900 & $<1.0 \times 10^{-13}$ & $<9.3 \times 10^{-15}$ \\
\hline $3-26$ & 0900 & $3-27$ & 0900 & $<1.0 \times 10^{-13}$ & $<2.8 \times 10^{-14}$ \\
\hline $3-27$ & 0900 & $3-27$ & 1600 & $<1.0 \times 10^{-13}$ & $<9.5 \times 10^{-14}$ \\
\hline $3-27$ & 1600 & $3-28$ & 0900 & $<1.0 \times 10^{-13}$ & $3.9 \times 10^{-14}$ \\
\hline $3-28$ & 0900 & $3-29$ & 0900 & $<1.0 \times 10^{-13}$ & $<2.8 \times 10^{-14}$ \\
\hline $3-29$ & 0900 & $3-30$ & 0900 & $<1.0 \times 10^{-13}$ & $<2.8 \times 10^{-14}$ \\
\hline $3-30$ & 0900 & $4-2$ & 0900 & $1.0 \times 10^{-13}$ & $<9.3 \times 10^{-15}$ \\
\hline $4-2$ & 0900 & $4-3$ & 0900 & $<1.0 \times 10^{-13}$ & $<2.8 \times 10^{-14}$ \\
\hline $4-3$ & 0900 & $4-4$ & 0900 & $<1.0 \times 10^{-13}$ & $<2.8 \times 10^{-14}$ \\
\hline $4-4$ & 0900 & $4-5$ & 0900 & $<1.0 \times 10^{-13}$ & $<2.8 \times 10^{-14}$ \\
\hline $4-5$ & 0900 & $4-9$ & 1400 & $<1.0 \times 10^{-13}$ & $<8.7 \times 10^{-15}$ \\
\hline $4-9$ & 1400 & $4-10$ & 0900 & \multirow{4}{*}{\multicolumn{2}{|c|}{ 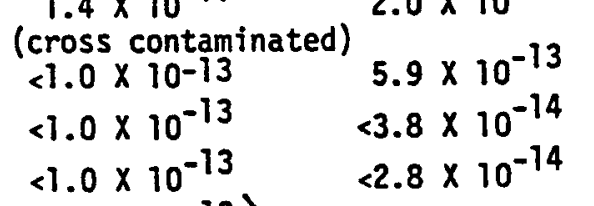 }} \\
\hline $4-10$ & 0900 & $4-10$ & 1330 & & \\
\hline $4-10$ & 1330 & $4-11$ & 0900 & & \\
\hline $4-11$ & 0900 & $4-12$ & 0900 & & \\
\hline $4-12$ & 0900 & $4-16$ & 0900 & $\left.<1.0 \times 10^{-13}\right)$ & \multirow{5}{*}{ not counted yet } \\
\hline $4-16$ & 0900 & $4-17$ & 0900 & $3.3 \times 10^{-13}$ & \\
\hline $4-17$ & 0900 & $4-18$ & 0900 & $<1.0 \times 10^{-13}$ & \\
\hline $4-18$ & 0900 & $4-19$ & 0900 & $<1.0 \times 10^{-13}$ & \\
\hline $4-19$ & 0900 & $4-20$ & 0900 & $<1.0 \times 10^{-13}$ & \\
\hline
\end{tabular}


EXHIBIT 15. Cont'd

MCI NORTH - a CONC. ONLY

\begin{tabular}{lllllll} 
DATE & $\begin{array}{l}\text { TIME } \\
\text { ON }\end{array}$ & $\begin{array}{l}\text { DATE } \\
\text { OFF }\end{array}$ & $\begin{array}{l}\text { TIME } \\
\text { OFF }\end{array}$ & $\begin{array}{l}\text { MANUAL } \\
\text { UCi } / C C\end{array}$ & $\begin{array}{l}\text { 7-DAY DELAY } \\
\text { UCi/CC }\end{array}$ \\
\cline { 2 - 3 } $3-13$ & 1100 & $3-13$ & 1210 & $1.7 \times 10^{-11}$ & $<5.7 \times 10^{-13}$ \\
$3-13$ & 1210 & $3-13$ & 1510 & $2.3 \times 10^{-12}$ & $<2.2 \times 10^{-13}$ \\
$3-13$ & 1510 & $3-14$ & 0830 & $<1.0 \times 10^{-13}$ & $<3.6 \times 10^{-14}$
\end{tabular}

Discontinued 
EXHIBIT 15. Cont'd

\begin{tabular}{|c|c|c|c|c|c|}
\hline \multirow[b]{2}{*}{ DATE } & \multicolumn{4}{|c|}{ STAPLEX } & \multirow[b]{2}{*}{$\begin{array}{l}\text { 7-DAY DELAY COUNT } \\
\text { UCI/CC }\end{array}$} \\
\hline & $\begin{array}{l}\text { TIME } \\
\text { ON }\end{array}$ & $\begin{array}{l}\text { DATE } \\
\text { OFF }\end{array}$ & $\begin{array}{l}\text { TIME } \\
\text { OFF }\end{array}$ & $\begin{array}{l}\text { MANUAL } \\
\text { UCi/CC }\end{array}$ & \\
\hline $3-13$ & 1625 & $3-13$ & 1655 & $<1.0 \times 10^{-13}$ & $2.7 \times 10^{-12}$ \\
\hline $3-13$ & 1655 & $3-14$ & 0830 & $1.6 \times 10^{-12}$ & $4.3 \times 10^{-14}$ \\
\hline $3-14$ & 0830 & $3-14$ & 0930 & $2.5 \times 10^{-11}$ & $<2.7 \times 10^{-14}$ \\
\hline
\end{tabular}


EXHIBIT 15. Cont'd

PART II

\section{SELECTEU BUILDING SAMPLES}




\section{EXHIBIT 15. Cont'd}

\section{BUILDING - a CONC. ONLY}

\begin{tabular}{l} 
LOCATION \\
\hline 501 \\
501 \\
$422 \mathrm{~W}$ \\
507 AM \\
$520 \mathrm{~W}$
\end{tabular}

$$
\text { DATE }
$$

$\underline{u C i / c c}$

$$
\begin{aligned}
& 3-12-3-13 \\
& 3-13-3-14 \\
& 3-7=3-14 \\
& \text { discontinued } \\
& 3-7-3-14
\end{aligned}
$$

$<2.8 \times 10^{-14}$

$<2.8 \times 10^{-14}$

$<4.0 \times 10^{-15}$

$<4.0 \times 10^{-15}$

3745A BUILDING - $\alpha$ CONC. ONLY

$3745 A$

$3-8-3-15$

$8.9 \times 10^{-15}$

$1.5 \times 10^{-12}$

3745 BUILDING - a CONC. ONLY

N - Well

S - Well

$$
\begin{aligned}
& 3-8-3-15 \\
& 3-8-3-15
\end{aligned}
$$

$6.0 \times 10^{-15}$

$<6.0 \times 10^{-15}$

3720 BUILDING - a CONC. ONLY

$150-1$

3-8 - 3-15

$1.8 \times 10^{-14}$

$105-1$

$3-8-3-15$

$<3.0 \times 10^{-15}$

306 BUILDING

120

FS-1

$$
\begin{aligned}
& \text { discontinued } \\
& 3-8=3-15
\end{aligned}
$$

$8.9 \times 10^{-15}$

320 BUILDING

113-1

113-2

114

$$
\begin{aligned}
& 3-8-3-15 \\
& 3-8-3-15 \\
& 3-8-3-15
\end{aligned}
$$

$$
\begin{array}{r}
8.9 \times 10^{-15} \\
3.0 \times 10^{-15} \\
<3.0 \times 10^{-15}
\end{array}
$$

$1.0 \times 10^{-12}$

$<5.0 \times 10^{-13}$
$3.0 \times 10^{-12}$

$<5.0 \times 10^{-13}$

$1.5 \times 10^{-12}$

$1.5 \times 10^{-12}$

$5.0 \times 10^{-13}$

$<5.0 \times 10^{-13}$
uCi/cc

(assuming $1 \mathrm{hr}$ release)

$<6.7 \times 10^{-13}$

$<6.7 \times 10^{-13}$

$.5 .7 \times 10^{-13}$

$<6.7 \times 10^{-13}$

( 3 counts over 2000) 
EXHIBIT 15. Cont'd

\section{BUILDING}

\begin{tabular}{|c|c|c|c|}
\hline LOCATION & DATE & $\underline{u C i} / \mathrm{cc}$ & uci/ce (1 Hour) \\
\hline ד-10 & $3-13-3-15$ & $1.3 \times 10^{-13}$ & $6.0 \times 10^{-12}$ \\
\hline $10-2$ & $3-13-3-15$ & $2.8 \times 10^{-14}$ & $1.3 \times 10^{-12}$ \\
\hline $10-3$ & $3-13-3-15$ & $2.8 \times 10^{-14}$ & $1.3 \times 10^{-12}$ \\
\hline $12-1$ & $3-13-3-15$ & $2.8 \times 10^{-14}$ & $1.3 \times 10^{-12}$ \\
\hline $12-2$ & $3-13-3-15$ & $5.6 \times 10^{-14}$ & $2.7 \times 10^{-12}$ \\
\hline Radeco & $\begin{array}{l}3-13-3-13 \\
(1130-1530)\end{array}$ & $5.0 \times 10^{-13}$ & $2.0 \times 10^{-12}$ \\
\hline Radeco & $\begin{array}{l}3-13-3-14 \\
(1530-1345)\end{array}$ & $2.9 \times 10^{-13}$ & $6.5 \times 10^{-12}$ \\
\hline Radeco & $3-14-3-15$ & $1.0 \times 10^{-13}$ & $2.0 \times 10^{-12}$ \\
\hline Radeco & $\begin{array}{l}3-8-3-13 \\
(0900-1130)\end{array}$ & $8.0 \times 10^{-13}$ & $9.8 \times 10^{-11}$ \\
\hline $10-1$ & $3-8-3-13$ & $1.1 \times 10^{-12}$ & $1.3 \times 10^{-10}$ \\
\hline $10-2$ & $3-8-3-13$ & $1.0 \times 10^{-12}$ & $1.2 \times 10^{-10}$ \\
\hline $10-3$ & $3-8-3-13$ & $1.0 \times 10^{-12}$ & $1.3 \times 10^{-10}$ \\
\hline $12-1$ & $3-8-3-13$ & $1.2 \times 10^{-12}$ & $1.4 \times 10^{-10}$ \\
\hline $12-2$ & $3-8-3-13$ & $8.6 \times 10^{-13}$ & $1.0 \times 10^{-10}$ \\
\hline \multicolumn{4}{|c|}{329 BUILDING } \\
\hline $9 \mathrm{AW}$ & $3-7-3-74$ & $6.0 \times 10^{-15}$ & $1.0 \times 10^{-12}$ \\
\hline $11 \mathrm{AW}$ & $3-7-3-14$ & $<3.0 \times 10^{-15}$ & $<5.0 \times 10^{-13}$ \\
\hline $12 \mathrm{AW}$ & $3-7-3-14$ & $8.9 \times 10^{-15}$ & $1.5 \times 10^{-12}$ \\
\hline 14 AW & $3-7-3-74$ & $8.9 \times 10^{-15}$ & $1.5 \times 10^{-12}$ \\
\hline
\end{tabular}

